\title{
OPTIMIZATION OF COMPOSITION AND HEAT TREATING OF DIE STEELS FOR EXTENDED LIFETIME
}

David Schwam

John F. Wallace

Quanyou Zhou

Case Western Reserve University

January 2002

Work Performed Under Contract DE-FC07-00ID13847

For

U.S. Department of Energy

Assistant Secretary for

Energy Efficiency and Renewable Energy

Washington D.C. 


\section{OPTIMIZATION OF COMPOSITION AND HEAT TREATING OF DIE STEELS FOR EXTENDED LIFETIME}

David Schwam

John F. Wallace

Quanyou Zhou

Case Western Reserve University

January 2002

Work Performed Under Contract DE-FC07-00ID13847

For

U.S. Department of Energy

Assistant Secretary for

Energy Efficiency and Renewable Energy

Washington D.C. 
ABSTRACT 2

PART 1: EFFECT OF COMPOSITION 2

1.0 INTRODUCTION 4

1.1 Background 4

1.2 Die Casting Die Materials

1.3 Die Casting Failure Modes 9

1.4 Thermal Stress and Mechanisms of Thermal Fatigue 11

1.5 Thermal Fatigue Resistance and Other Properties Required of Die Steels 13

2.0 MATERIALS AND PROCEDURES 15

$\begin{array}{ll}2.1 \text { Materials } & 15\end{array}$

$\begin{array}{ll}2.2 \text { Thermal Fatigue Test } & 17\end{array}$

$\begin{array}{ll}2.3 \text { Heat Treatment Procedure } & 20\end{array}$

$\begin{array}{ll}2.4 \text { Scanning Electron Microscopy } & 20\end{array}$

$\begin{array}{ll}\text { 3.0 RESULTS AND DISCUSSION } & 20\end{array}$

3.1 Thermal Fatigue Resistance of Five Steels 20

$\begin{array}{ll}3.2 \text { Cracking Pattern } & 23\end{array}$

3.3 Effect of Tempering on the Microstructure and Hardness of the
Five Steels

$\begin{array}{ll}\text { 4.0 CONCLUSIONS } & 30\end{array}$

$\begin{array}{ll}\text { 5.0 BIBLIOGRAPHY } & 32\end{array}$

PART 2: EFFECT OF HEAT TREATING 35

6.0 OIL QUENCHING OF DIES 35

$\begin{array}{ll}6.1 \text { Objectives } & 35 \\ 6.2 \text { Experimental }\end{array}$

$\begin{array}{ll}\text { 6.2 Experimental } & 36\end{array}$

$\begin{array}{ll}\text { 6.3 Results and Discussion } & 43\end{array}$

7.0 IN-PLANT EVALUATION OF DIES 46

$\begin{array}{ll}\text { FIGURES } & 50\end{array}$ 


\begin{abstract}
An "average" die casting die costs fifty thousand dollars. A die used in making die cast aluminum engine blocks can cost well over one million dollars. These costs provide a strong incentive for extension of die life. While vacuum quenched Premium Grade H13 dies have become the most widely used in the United States, tool makers and die casters are constantly searching for new steels and heat treating procedures to extend die life. This project was undertaken to investigate the effects of composition and heat treating on die life and optimize these parameters.
\end{abstract}

New steel compositions with lower silicon and vanadium, and higher molybdenum content than the standard premium grade $\mathrm{H}-13$ have been identified and evaluated. Four steels were included in the study: QRO 90, Dievar, TQ1 and RPU. These steels provide a significant improvement in thermal fatigue resistance compared to the conventional premium grade $\mathrm{H}-13$. The desirability of a low silicon content and controlled carbide content has been clearly demonstrated. These steels provide a better combination of the three carbide formers, chromium, molybdenum and vanadium. Each of these elements contributes in a different way to the performance of the die steel. Chromium provides high temperature strength, corrosion resistance, and matrix stability; molybdenum strengthens the matrix at high temperature better than any element; vanadium improves resistance to softening or tempering of the steel. However, vanadium in large amounts is known to produce fully stable vanadium carbides that reduce both toughness and thermal fatigue resistance. The best combination of these elements will provide the optimum die life. Other elements such as niobium, zirconium and titanium are important for grain size control and stability of the matrix at high temperatures. Additions of nickel and cobalt affect the matrix strength. Considerably more improvement in die life can be expected by exploring the individual effect of these elements and their best combination. All of the materials 
have to be produced to the high quality levels in terms of their nonmetallic inclusions and gas contents.

Significant improvement in the life of these die steels tested can be obtained by utilizing a rapid cooling rate from a somewhat higher austenitizing temperature during the hardening process. The heat treating industry is currently processing dies in vacuum furnaces utilizing nitrogen gas quenching. At present, the desirable very rapid fast cooling rates are not being attained because of limitations in the technical knowledge and available equipment. A faster cooling rate is attainable than with the present 10 bar gas quenching and this can be accomplished without objectionable distortion. In this study, an interrupted oil quenching procedure was utilized to heat treat $\mathrm{H} 13$ and $\mathrm{KDAl}$ dies. It is known that if the cooling rate from the austenitizing temperature to $1000^{\circ} \mathrm{F}$ is reached quickly enough, the precipitation of objectionable grain boundary carbides can be avoided. However, at this temperature, the metastable austenite has not transformed as yet. Distortion and potential cracking are associated with subsequent cooling of the die steel through the martensitic transformation range with high thermal gradients from the surface to the center of the dies. An interrupted cooling process was developed to control the transformation to martensite and low temperature bainite. This customized step cooling provides the best properties for the die at rates that balance transformation-cooling conditions throughout the die block. The step cooling process also minimizes the problems of distortion and eliminates cracking while obtaining the best properties in the die steel. 


\subsection{INTRODUCTION}

\subsection{Background}

Die casting is a vital process in many manufacturing industries - automotive, hardware, electrical and electronics, computers and many others. It efficiently provides components in aluminum, zinc and magnesium alloys with good mechanical properties. Die casting offers many features and advantages over traditional sand castings [1-4]:

(1) Complex shapes within closer tolerances than many other mass production processes; (2) Die castings are produced at high rates of production. Little or no machining is required; (3) Die casting provide parts which are durable, dimensionally stable, and have the feel and appearance of quality; (4) Die castings combine many functions in one, complex shaped part. Thus die casting technologies are finding more applications in the modern world than many other traditional casting methods.

Die casting is a sophisticated process [1-4]. It involves injecting molten metal under high pressure and velocity into water cooled metallic dies and imposes extreme demands on the die materials at the metal-die interface. During die casting cycle, the die surface is first exposed to molten aluminum which is at temperatures between $1200^{\circ} \mathrm{F}$ and $1400{ }^{\circ} \mathrm{F}$ when introduced into the die. The held in held in contact with the solidifying casting until the casting has cooled enough to be ejected. The die is then exposed to the air and sprayed with a liquid lubricant. This cycle is repeated with a period of a few seconds to a few minutes, depending on the size of the casting. 
A major concern in die casting technology is the die life [5-10]. Intermittent injection of hot aluminum and cooling of the die cause thermal fatigue and cracking. Dies are expensive to produce, particularly for large and complex parts. The number of casting that can be produced before the die is heat checked and has to be discarded can be a major economic consideration. Therefore, increasing the life of a die through die steel improvement and die failure prevention can make a major contribution towards the profitability of the die casting operations.

\subsection{Die Casting Die Materials}

Die steels for die casting must be able to withstand the thermal shock of extreme temperature swings, from the heat of the aluminum, magnesium, zinc, or brass, to the cooling effects of internal water lines, die lubricants, and die surface coolants. These environments require a combination of heat check (thermal fatigue) resistance, toughness, and high temperature strength (hot hardness, temper resistance).

Die steels should be chosen to accommodate the appropriate service temperatures [1-4]. Generally, molten aluminum and magnesium $\left(1100 / 1300^{\circ} \mathrm{F}\right)$ subject the die steel surfaces to maximum temperatures of about $900 / 1000^{\circ} \mathrm{F}$, but occasionally higher in the case of thin die sections, uncooled inserts, heavy castings, special alloys, etc. Molten zinc

presents a less severe thermal load, with casting temperatures of $800 / 900^{\circ} \mathrm{F}$, and thus zinc casting dies do not require as high properties as aluminum or magnesium casting dies. 
Copper and brass, with casting temperatures of over $1700^{\circ} \mathrm{F}$, may create special problems, because the molten metal temperature is high enough to cause severe softening of most die steels, sometimes to the point of severe damage to the original heat treatment at the surface of the die. Several commercially available die casting die steels and their characteristics are listed below [11].

\section{a. Modified H10}

Modified H10 die steels, with cobalt added to improve its high temperature properties are commercially available. These steels are considered an upgrade from H13 in applications requiring improved hot hardness or heat check resistance, at a slight decrease in toughness. They may be used at tool temperatures up to about $1100^{\circ} \mathrm{F}$, with brief exposures up to about $1200^{\circ} \mathrm{F}$.

Typical Chemistry: C 0.35, Cr 3.50, V 0.60, Mo 2.50, Co 2.00

b. H1 1

H11 is a general purpose hot work tool steel, combining good toughness with moderate high-temperature strength and heat check resistance. Because of its high toughness, it is particularly suited for applications where drastic coolants are used, or where gross cracking resistance is a concern.

Typical Chemistry: C 0.40, Cr 5.00, V 0.50, Mo 1.30 
H13 is the most popular die steel in the US, and perhaps most versatile, hot work tool steel, providing a good balance of toughness, heat check resistance, and high temperature strength, in addition to moderate wear resistance. It may be used for tool temperatures up to about $1000^{\circ} \mathrm{F}$, with brief exposures up to $1100^{\circ} \mathrm{F}$.

Typical Chemistry: C 0.40, Cr 5.20, V 1.00, Mo 1.30

\section{d. Premium Grade H13}

The premium version of H13, specially refined for enhanced internal homogeneity and cleanliness compared to conventional H13. It provides higher transverse toughness, for decreased risk of breakage or cracking failures related to material toughness. Improved internal cleanliness and structural uniformity allow polishing to a critical finish, and uniform texturing response. Because of its high attainable hardness and through-hardening characteristics, it is ideal for molds requiring high strength.

Typical Chemistry: C 0.40, Cr 5.20, V 0.95, Mo 1.30

e. Machinable H13

Modified H13 die and mold steel designed for easy machining as well as service as die casting dies and plastic injection molds are available from different suppliers. 
Some are supplied in the prehardened condition, and is easily machined using conventional chip-making methods.

Most are based upon the chemical composition as AISI H13 hot work steel to which sulfur has been added to provide machinability in the pre hardened condition. Typical Chemistry: C 0.36, Mn 0.35, Si 1.00, Cr 5.50, Mo 1.60, V 0.85, S 0.17

\section{f. H19}

H19 is designed for higher operating temperatures than H13, where wear resistance and heat check resistance are more critical than toughness. While H19 has excellent heat checking resistance, drastic cooling (flooding, dunking) should be avoided due to the risk of thermal shock. H19 may be used for tool temperatures up to about $1100^{\circ} \mathrm{F}$, with brief exposures up to about $1200 / 1250^{\circ} \mathrm{F}$.

Typical Chemistry: C 0.40, Cr 4.25, V 2.10, W 4.20, Co 4.20

g. H21

$\mathrm{H} 21$ is designed for tools which will run hot, at operating temperatures between about $600^{\circ} \mathrm{F}$ and $1100^{\circ} \mathrm{F}$. The tools should not be water cooled in service, due to a high risk of thermal shock. H21 offers wear resistance approaching H19, with slightly better toughness at high temperature (over about $600^{\circ} \mathrm{F}$ ). It may be used at tool temperatures up to $1100^{\circ} \mathrm{F}$, with brief exposures to $1200 / 1250^{\circ} \mathrm{F}$.

Typical Chemistry: C 0.30, Cr 3.30, V 0.25, W 9.00 
h. $\mathrm{P} 20$

P20 is often supplied as a prehardened, general purpose mold steel suitable for . production of machined or EDM'd plastic mold and zinc die casting die components. It is available from a number of suppliers as pre-hardened at two hardnesses: regular at about 300 Brinell and high hardness at about 340 Brinell.

Typical Chemistry: C $0.35, \operatorname{Cr} 1.70$, Mo 0.40

\subsection{Die Casting Die Failure Modes}

The dies used in aluminum die casting applications are subjected to a complex combination of stress and environment conditions during their operation. These conditions that can lead to die failures result from temperature fluctuations, molten aluminum-die interactions, and the mechanical loads applied during the die casting process [1-4]. Several failure modes have been identified for aluminum alloy die casting die material [1-4] including:
a. Thermal fatigue failure, also called heat checking
b. Gross or cleavage cracking
c. Erosion, mechanical erosion or washout
d. Chemical attack or corrosion 
Thermal fatigue failure or heat checking is the most frequently observed failure mode in die casting dies [12-15]. Thermal fatigue is caused by the cyclical temperature fluctuations present in the die casting process. It induces the stress and strain conditions that occur when the thermal expansion or contraction of a section is restrained by the surrounding materials. When such local stresses exceed the elastic limit or yield strength of the die materials, plastic deformation will occur, and with sufficient cycling, microcracks will nucleate. A repeated series of heating and cooling of the surface can produce a fine network of cracks in the die surface. This is thermal fatigue cracking, also called heat checking.

Gross cracking is not as generally prevalent as heat checking. It is usually catastrophic and may result in complete cracking through the die. Total fracture of die casting dies occurs when the die material is stressed beyond its fracture strength. This can occur even when the gross applied stress of the die is below the yield stress. It results from a combination of thermal and mechanical stresses [16]. This type of failure is related to the inherent resistance of the die material to brittle fracture termed "fracture toughness".

Mechanical erosion is caused by the high velocity of the molten die casting alloy as it enters the die. This entering stream may erode or "wash" the metal from the surface [17]. Erosion is most frequent at gating location where the maximum temperature and pressure occur. The characteristic appearance is that the steel appears to be washed away. 
Chemical attack or corrosion is involved in the initiation and propagation of heat checking. The thermal fatigue cracks start at corrosive pits and the fatigue cracks are filled.with metallic oxides that produce tensile stress components at the crack tip and contribute to crack propagation [18]. Chemical attack can occur through compositional change in the die surface, e.g. oxidation, or by chemical adhesion of the molten aluminum to the die surface i.e. soldering.

\subsection{Thermal Stress and Mechanism of Thermal Fatigue}

The thermal stresses that occur in the die develop from the thermal gradient across the die section $[8,9,19,20]$. Thermal gradient forms as a result of heating and cooling of the surface during injecting, ejection and lubricant spraying stages of the die casting cycle. When molten aluminum is injected into the die, the die surface heats up considerably compared to the cooler underlying mass of the die. This sets up an initially steep thermal gradient. As a result, the surface expends more than the interior. Because the interior is more massive, it prevents the surface from expanding. As a result of this restraint, the surface is placed under compression. As heat is conducted into the lower layers, the surface temperature decreases rapidly. When the casting is ejected, cooling to the surroundings from the surface and the spray of die lubricant further decrease the surface temperature [8]. If the surface cools more rapidly than the interior, high tensile streses may be created. 
The combination of the temperature gradient and the coefficient of the thermal expansion of the die materials determine the magnitude of the die surface stress. For a single case of a bar with fixed end supports, the thermal stress generated by a temperature range $\Delta \mathrm{T}$ is:

$$
\sigma=\alpha E \bullet \Delta T
$$

Where $\alpha$ is the linear thermal coefficient of expansion and $E$ is the elastic modulus [19]. For biaxial condition, the stress can be given by:

$$
\sigma=\alpha \mathrm{E} \bullet \Delta \mathrm{T} /(1-v)
$$

where $v$ is Poisson's ratio. The thermal stresses never fully develop to the maximum value because $\alpha, E, v$ and the thermal conductivity all change with temperature [20]. More detailed work by Graham who carried out a finite element analysis indicated that the maximum compressive stress may remain well below the yield strength of $\mathrm{H} 13$ steels for the aluminum die casting [21]. Initially, the surface strain is within the elastic capabilities of the die material.

Thermal fatigue mechanisms can be separated into crack initiation and propagation. Crack initiation usually occurs at stress concentration sites resulting from structure, geometry, machining irregularities or surface imperfections [21]. During the compression stage of the die surface, as the increase in temperature lowers the yield strength of material, the compressive strains caused by concentrated compressive stress may become plastic. If during the tension state, the concentrated thermal stress is larger than the yield strength of the material, reversed plastic deformation will occur. With a sufficient number of cycles, plastic deformation will cause the fatigue crack appearance. 
Once a crack is initiated, propagation occurs along planes perpendicular to the maximum cycling stresses. The fatigue cracks deviate noticeably from the expected plane of propagation only because of the presence of large prior austenite grain boundaries or when another crack is in close proximity [21]. The influence of other cracks on crack propagation is explained by the interaction of the highly stressed region at the tip of cracks. When the crack tips are close enough, this interaction occurs and changes the general state of stress. This provides an attraction of cracks to each other until the cracks are joined by crack branching or forking. When the side branches join each other, they produce the classical craze cracking pattern [22]. There are several opinions about the driving force for crack propagation. One opinion is that cracks widen and deepen by wedging action of the molten metal or iron oxide that is forced into them in each shot [23]. Another is that crack propagation occurs only by the thermal fatigue mechanism. In that event, propagation has to occur during the cooling cycle, since that provides the tensile stress necessary for crack propagation. Once a fatigue crack is formed, it grows under the effect of continued mechanical and thermal stresses because of the stress concentration effect even when the tensile stress is lower [24].

\subsection{Thermal Fatigue Resistance and Other Properties Required of Die Steels}

Thermal fatigue resistance of die materials is greatly influenced by a number of properties of material [25-28]. The most important of these are the coefficient of thermal 
expansion $\alpha$ and the thermal conductivity $\mathrm{k}$. A high conductivity can reduce the temperature gradients and hence the thermal strains $\varepsilon=\alpha \bullet \Delta \mathrm{T}$.

Depending on the prevailing operation conditions, the parameter $\mathrm{k} \varepsilon / \alpha$ can be used as an indication of thermal fatigue resistance $\mathrm{K}$.

$$
\mathrm{K}=\mathrm{k} \varepsilon / \alpha
$$

$\varepsilon$ can be given by the modulus $E$ and fatigue strength at the mean temperature $\sigma_{f}$.

$$
\varepsilon=\sigma_{f} / E
$$

The thermal fatigue resistance of die steel can be described by

$$
\mathrm{K}=\sigma_{\mathrm{f}} \mathrm{k} / \alpha \mathrm{E}
$$

A high value of $\mathrm{K}$ indicates good thermal fatigue resistance. The yield strength of superior die steels at elevated temperature should stay high. In reality, the yield strength tends to decrease with increasing temperatures due to tempering. High thermal conductivity will reduce thermal fatigue by lowering the thermal gradient between the surface and the underlying layers. Lower values of the coefficient of the thermal expansion are desirable since this will reduce the amount of relative expansion between the surface and the underlying layers. A lower modulus results in lower stresses at a given strain level as shown by equation (1-4).

To prevent other failure mode and process, good ductility and fracture toughness are needed to withstand severe mechanical and thermal shock or gross cracking. High hot hardness is also desirable because it retards softening of the surface and prevents erosion. 
However, too high a hardness will reduce the toughness and lead to gross cracking. Finding the right balance of properties is the key to extend the die life.

Research work on die materials has been conducted at Department of Materials Science and Engineering, Case Western Reserve University since early 1960's. The CWRU "Dunk" Test (immersion thermal fatigue test) is used to evaluate the thermal fatigue resistance. Significant work has been completed on thermal fatigue mechanisms in aluminum die casting die steels, effect of heat treatment on the thermal fatigue behavior and fracture toughness of H13 steel for aluminum die casting dies, effect of composition and processing on thermal fatigue resistance and toughness on die steels. In recent years die steel suppliers have offered a number of die steels that have advanced thermal fatigue properties in practice. Some of them are claimed to have advanced thermal fatigue properties but have not been systematically investigated and evaluated. The immersion thermal fatigue specimen developed at CWRU allows us to evaluate their resistance to heat checking. In this study, we evaluate and investigate the thermal fatigue behavior of these steels and compare them with premium Grade $\mathrm{H}-13$ die steel.

\subsection{MATERIALS AND PROCEDURES}

\subsection{Materials}

Five die steels were investigated in this study. They are premium grade $\mathrm{H}-13$, RPU, TQ1, Dievar and QRO90, all of which are commercially available. The composition of these steels is shown in Table 2.1. All five steels have similar carbon 
content and low sulfur and phosphorous contents. They were heat treated in a similar manner, that is, they were rapidly cooled from a high austenitizing temperature, with a double or triple temper. The CCT graphs of some of the steels are shown in Fig. 2.1.

H-13 is basically a hypo-eutectoid steel with high hardenability and a good combination of strength, hot hardness, toughness and ductility. It has good resistance to tempering. $\mathrm{H}-13$ is the most common used die steel in aluminum die casting industry. Compared with $\mathrm{H}-13$, the other four steels have a lower content of silicon, vanadium and higher content of molybdenum and manganese. QRO90 has a significantly lower chromium and less copper content compared with the other steels.

It is known that molybdenum is effective in improving the hardenability and high temperature strength. It retards the softening of martensite at all tempering temperatures and reduces susceptibility to tempering embrittlement. Above $1000^{\circ} \mathrm{F}$, the presence of molybdenum keeps the size of carbides small. Like molybdenum, chromium also retards the softening of martensite. By substituting chromium for some of the iron in cementite, the coalescence of carbides is retarded. Its effect on the hardenability is less than that of molybdenum.

Vanadium is a stronger carbide forming element than molybdenum and chromium. Vanadium containing carbides are stable at elevated temperature. Thus the steel has to be austenitized at a sufficiently high temperature and for a sufficient length of time to bring the carbides in solution and therefore vanadium is able to contribute to 
hardenability. When the content of vanadium is high, carbides will distribute at the grain boundaries, which lowers the steel toughness. A high content of vanadium also requires higher austenitizing temperature, which accelerates grain growth. Thus lower vanadium content is preferable in die steels.

Silicon tends to segregate at grain boundaries, martensite lath boundaries and/or martensite lath/carbide interfaces during tempering $[29,30]$, which enhances the embrittlement and lowers the toughness of die steels. A lower content of silicon presumably minimizes the interfacial segregation and results in higher toughness and thermal fatigue resistance [16].

\subsection{Thermal Fatigue Test}

\subsubsection{Specimens and Equipment}

The dimensions of specimens for thermal fatigue testing are shown in Fig. 2.2. The standard specimens are $2 " \times 2 " \times 7 "$ rectangular in shape with a $\phi 1.5 "$ diameter and 6.5" long hole in the center for internal water cooling. For QRO90 steel, 1"x1"x7" rectangular specimens were used because of its lower hoop stresses, thus lesser tendency to gross cracking (the dimension of the hole in the center is 0.5 " in diameter and 6.5 " in length). The four corners of the specimens are polished with 240,320 and 400 grit silicon carbide paper to a radius of 0.010 ". This dimension is important, therefore a special Vblock is used to ensure accuracy and reproducibility. 
The thermal fatigue test equipment is shown in Fig. 2.3. The specimens are alternately cycled between air and a molten aluminum alloy (380 grade) bath that is maintained at $1350^{\circ} \mathrm{F}$. An air cylinder is used to immerse and withdraw the specimens from the aluminum bath at a cycle of 12 seconds immersion and 24 seconds withdrawing. Water continually flows through the specimens at a rate of $1.0 \mathrm{gal} / \mathrm{min}$ through the internal cooling system shown in Fig. 2.2. In previous work, a diluted, water soluble lubricant was sprayed onto the surfaces of the specimens. After the water evaporates, a thin layer of die lubricant residue builds gradually on the surface of the specimen. This layer is thermally insulating, protecting the surface of the specimen from direct contact with molten aluminum. The TQ1, RPU, QRO90 and Dievar steels have better thermal fatigue resistance than $\mathrm{H}-13$ steels and require a more severe test to crack. Consequently, in the current study water was used instead of a die lubricant to make the experiment more severe. In the absence of the die lubricant, the surface of the specimen does not build an insulating layer. The variation in the specimen temperature when a water spray is used compared to a lubricant spray is shown in Fig. 2.4. The specimens were turned $90^{\circ}$ around their long axis every 1,500 cycles to insure the uniform application of the water spray.

\subsubsection{Cracks Measurement and the Evaluation of Thermal Fatigue Resistance}

Specimens were removed from the test system after 5,000,10,000 and 15,000

cycles and their cracks and thermal fatigue resistance were evaluated. Since the 
temperature fluctuations and geometrical constraints are the greatest at the corners, cracks form mainly at the corners.

For measuring the cracks, the surface of the specimens was polished with 240 , 320 and 400 grit silicon carbide paper. A V-shaped fixture with 400 grit silicon carbide paper was used to refinish the corners. Only cracks on the corner within 3" central length of the specimen were measured, to eliminate the "end" effect of the top and bottom areas.

Two concepts are used to evaluate the thermal fatigue resistance of the steels: average maximum crack length and total crack area. Average maximum crack length is the average length of the longest cracks on the four corners. The crack area of each crack is defined as the square of the crack length. The total crack area is the sum of the crack areas of all the cracks. The number and length of all cracks were measured under an optical microscope attached to a Leitz microhardness tester and a MSQ Image Analysis system. The process of crack measurement by the system is shown in Fig. 2.5.

\subsubsection{Hardness Measurement}

The hardness of the specimens was measured before and after thermal fatigue testing at 5,000,10,000, 15,000 cycles. A Buehler Micromet 2100 Microhardness Tester was used to derive a profile distribution of hardness from the specimen corner to the center. A Vicker's indenter was used, and the indentation load was 500 gram. The 
Vicker' hardness was converted to Rockwell C scale directly by a microprocessor in the tester.

\subsection{Heat Treatment Procedure}

To understand the effect of the microstructures of the five steels on their thermal fatigue resistance, a heat treatment experiment was conducted. One cubic inch sample of each steel was austenitized at $1875^{\circ} \mathrm{F}$ for 30 minutes, followed by quenching in oil. A sequence of tempering times at $1200^{\circ} \mathrm{F}$ was used to understand the microstructural evolution of these five steels. The temperature of $1200^{\circ} \mathrm{F}$ was selected for tempering because the maximum temperature at the thermal fatigue specimen corner during testing is about $1200^{\circ} \mathrm{F}$.

\subsection{Scanning Electron Microscopy}

A Hitachi S-4500 scanning electron microscope (SEM) was used to study the microstructure of the materials. The specimens were prepared by etching in $2 \%$ Nital solution

\subsection{RESULTS AND DISCUSSION}

\subsection{Thermal Fatigue Resistance of Five Steels}

\subsubsection{Average Maximum Crack Length and Total Crack Area}

The thermal fatigue cracking of Dievar, TQ1, RPU, QRO90 and H13 was measured after 15,000 thermal cycles. The thermal fatigue properties presented here are 
average value of two specimens for each kind of steel. The average maximum crack length and total crack area of the five steels are shown in Fig. 3.1 and 3.2, respectively.

The dimensions of the Dievar, TQ1 and RPU specimens are 2"x2"x7", while those of the QRO90 specimens are 1"x1"x7". H13 steel specimens are of both 1"x1"x7" and 2 "x2"x7" dimensions. The average maximum crack length and total crack area of Dievar, TQ1 and RPU specimens are compared with 2"x2"x7" H13 steel and are shown in Fig. 3.1a and Fig. 3.1b, respectively. The properties of QRO90 are compared with those of 1 "x1"x7" specimen of $\mathrm{H} 13$ and are shown in Fig. 3.2a and Fig. 3.2b, respectively.

It is shown that Dievar, RPU and QRO90 have shorter average maximum crack length than H13. TQ1 has similar average maximum crack length to H13. They all have smaller total crack areas than $\mathrm{H} 13$, thus have better thermal fatigue resistance. Among the

Of the three steels, Dievar, TQ1, RPU, Dievar has the least maximum crack length, followed by RPU and TQ1. The maximum crack length of Dievar is $\sim 55 \%$ shorter than that of $\mathrm{H} 13$, while that of RPU is $\sim 45 \%$ shorter. Comparison of total crack areas of Dievar, TQ1, RPU and H13 shows the same trend. That is, Dievar has the smallest total crack area, followed by RPU, TQ1 and H13. The total crack areas of Dievar, RPU and TQ1 are $\sim 70 \%, \sim 40 \%$ and $\sim 8 \%$ smaller that that of $\mathrm{H} 13$. 
Since the dimensions of QRO90 specimens are different from the Dievar,TQ1 and RPU, the thermal fatigue plots can not be compared directly. Fig.3.2a,b shows the total crack area and maximum crack length of QRO90 and H13. Both are much smaller for QRO90 than H13 when the same dimensions of the specimen are employed. QRO90 therefore has considerably better thermal fatigue resistance than $\mathrm{H} 13$.

\subsubsection{Softening during Thermal Cycling}

The temper resistance is a very important property that affects to a large extent the thermal fatigue resistance of die steels. Comparing the temper resistance of the five steels in the study promotes an understanding of why one steel has better thermal fatigue resistance than another. Temper resistance can be evaluated by the softening or the decrease in the hardness of the steel during use.

The microhardness of each steel was measured from the edge to the center of the specimen. As an example, the hardness distribution of H13 and Dievar after 5000 and 10000 cycles are shown in Figs. $3.3 \mathrm{a}$ and b, respectively. The trends in the two figures are the same; the hardness at the corners is lower than the hardness away from the corner. This is not surprising because the temperature at the corner of specimens is the highest. By comparing the two figures, it can be seen that the softening of Dievar is much less than for the H13 steel. 
Softening of the Dievar, TQ1, RPU, and H13 specimens for the 2"x2" 7 " standard test after 15,000 thermal cycles is shown in Fig. 3.4a. The softening of QRO90 and $\mathrm{H} 13$ for the 1 "x 1 "x7" specimen after 15,000 thermal cycles is shown in Fig. 3.4b. In these groups of steels, Dievar has the best temper resistance followed by TQ1 and RPU. H13 has the worst temper resistance. At the corner, the hardness loss after 15,000 cycles for Dievar is only $\sim 45 \%$ of that for H13, while the loss in hardness of TQ1 and RPU are about $\sim 58 \%$ of that for H13. The hardness loss of QRO90 steel at the corner is only $\sim 39 \%$ of $\mathrm{H} 13$.

Thus for 2"x2"x7" specimens, the tempering resistance of Dievar is the best, while that of $\mathrm{H} 13$ the worst, which is consistent with the thermal fatigue properties as measured by the immersion test. The tempering resistance and thermal fatigue properties for RPU and TQ1 are inconsistent, which is not unusual as crack initiation and propagation are complicated processes and microhardness is not the only parameter that controls the length and density of cracks in steels at elevated temperature.

\subsection{Cracking Pattern}

Fig. 3.5 illustrates the appearance the thermal fatigue crack patterns of RPU, Dievar, QRO90, TQ1 and H13 after 15,000 cycles. The crack pattern for H13 is characterized by cracks that generally reach the corners of the specimen. Most of the cracks are cut-through-corner cracks (these cracks are called corner cracks). The crack patterns of the other four steels are different. Some corner cracks coexist with shallow 
cracks distributed near the corner of the specimens at rather high density (such cracks are known as surface cracks). Surface cracks are numerous and shallow. Corner cracks of these four steels are shorter than those of H13.

As the corners of the specimens were under the highest stress condition, the corner cracks probably initiate from the corner and propagate towards the direction away from the specimen corner. The initiation source of surface cracks is not clear. It appears that their distribution is related to the location of corner cracks. The density of surface cracks is always low when the incidence that of corner cracks is high. For example, H13 has very little surface cracks, but a lot of corner cracks. Dievar steel has extensive surface cracks, but only a few corner cracks.

The distribution of corner cracks and surface cracks in the five steels is expressed as crack number per inch in Fig. 3.6. The results from RPU, Dievar, and TQ1 are compared with the 2"x2"x7" H13 steel specimen and are shown in Fig. 3.6a; that of QRO90 is compared with a 1"x1"x7" specimen of H13 and shown in Fig3.6b. Among RPU, Dievar, TQ1 and H13, the density of surface crack of Dievar is the highest, followed by TQ1, RPU and lastly H13. The density of corner cracks is in decreasing order: RPU ( $\sim 80 \%$ of that for H13), Dievar ( $\sim 60 \%$ of that for H13) and TQ1 $(\sim 55 \%$ of that for H13). In QRO90 the corner crack density is 74\% less than in a 1"Xl"x7" H13 specimen and a considerably higher surface crack density than that of H13. 
Since surface cracks are shallow, they have a lesser effect on the thermal fatigue resistance. Thus Figs. 3.1 and 3.2 only consider corner cracks. In fact, there is a close relationship between surface cracks and thermal fatigue resistance. When the density of surface cracks is high, the thermal fatigue resistance of the steel is also high.

It seems that if the steel has shorter and fewer corner cracks, there is more of a tendency for surface cracks to develop. This can be explained if initiation and propagation of the surface cracks relieve the thermal stresses around the corners, thus retarding the initiation of corner cracks. Steel with high thermal fatigue resistance develops shorter and fewer corner cracks, therefore more surface cracks initiate. If the steel has reduced hardness loss at the corner, then it has higher strength to withstand the thermal fatigue stresses present at the corner and the corner cracks are harder to initiate. The surface near the corner may experience somewhat higher thermal stresses than the corner. Since the thermal stresses in the corner region have to be relieved, surface cracks are initiated at stress concentration points caused by surface imperfection and corrosion pits. Dievar develops shorter and fewer corner crack than TQ1, RPU and H13, and simultaneously develops more surface cracks. The same is true for QRO90 when compared to $\mathrm{H} 13$ for the 1 "x1" $\times 7$ " specimens.

Even H13 develops some surface cracks, as show in Figure3.7. Surface cracks in this case exist mostly around corner crack's tip. But since the corner cracks of H13 samples propagate fast, this does not provide much chance for the surface cracks to 
develop. Surface cracks remain thin and shallow and usually are removed by the polishing for crack checking.

\subsection{Effect of Tempering on the Microstructures and Hardness of the Five Steels}

\subsubsection{Microstructure of the As-Quenched Condition}

The mechanical properties of materials are affected by their microstructure [3033]. To understand the contribution of the microstructures of the five steels to their thermal fatigue resistance, the microstructures of these five steels in as quenched condition were examined under scanning electron microscope. The results are shown in Figure 3.8.

Carbides are the most prominent feature in the microstructures. It is well known that carbides play an important role in determining the mechanical properties of steel. An example from literature showing the variation of the Charpy V-notch impact toughness of H13 with the volume percent of primary carbides was given in Fig. 3.9.

Since carbides have a significant effect on the strength and toughness of die steels, a quantitative comparison of the number and size of carbides in these five steels is very helpful in understanding their thermal fatigue resistance. The quantification was conducted on the SEM micrographs utilizing the MSQ image analysis system. 
Quantitative information on the carbides in the as quenched condition is shown in Fig. 3.10 and 3.11 .

H13 has the most carbides, and RPU has the largest carbides. The carbides in Dievar are fewest and smallest. There are over eight times more carbides in H13 as in Dievar, three times as many as in RPU and TQ1 and 1.5 times as many as in QRO90. The carbide diameter in H13 is very close to that of TQ1 and QRO90, and 1.5 times larger for Dievar. The average carbide diameter in RPU is almost 50\% larger than that of $\mathrm{H} 13$.

\subsubsection{Carbide Precipitation Patterns of Five Steels during Tempering}

Carbides precipitate from solid solution during tempering, and their precipitation rate and pattern affect the thermal fatigue properties of the steels. Fig. 3.12 is a group of SEM micrographs of these five steels after ten hours of tempering at $1200^{\circ} \mathrm{F}$.

The large carbides in these micrographs were formed during quenching, and the small carbides were precipitated during tempering. H13 has more precipitates than any other steel, while the microstructure of QRO90 did not appear to change. The carbides in RPU tend to precipitate around primary carbides formed by quenching, which makes the primary carbide distribution irregular. Dievar did not always have many precipitates, and sometimes the precipitates form stringers. The carbides in TQ1 tend to precipitate around the surface of former martensitic needles. Therefore, TQ1 has more of a tendency than 
the other four steels to form carbide stringers during tempering. This may provide an explanation for the inconsistency in the thermal fatigue resistance encountered for this steel.

Many cracks initiate from carbides, thus the thermal fatigue resistance of the steels has a close relationship with the size and distribution of carbides. H13 has more carbides than any other steels. The size of carbides in $\mathrm{H} 13$ is relatively large. Thus it has the lowest thermal fatigue resistance. The number and size of carbides in Dievar are the smallest, therefore its thermal fatigue resistance is the best. The carbide size of TQ1 is as large as that of H13. Even though RPU has a modest amount of carbides, which is a little more than that of TQ1, its carbide size is the biggest. Thus both TQ1 and RPU have lower thermal fatigue resistance than Dievar.

The carbide precipitation patterns in the five steels during tempering also relate to their thermal fatigue resistance. H13 has more precipitates than any other steels. The precipitate amounts in Dievar, RPU and TQ1 are similar, but TQ1 has more of a tendency to form carbide stringers. QRO90 precipitates much more slowly than other four steels.

Thermal fatigue resistance is determined by the combination of primary carbides found in the as quenched condition and carbides precipitated during tempering. Smaller and fewer carbides in Dievar in the as-quenched conditions makes crack initiation more difficult, and the well dispersed carbide precipitation pattern impedes crack propagation. The larger size of carbides in RPU and stringer-precipitation pattern of carbides in TQ1 
make their thermal fatigue resistance inferior to Dievar, but the better combination of carbide number and size still makes them superior in thermal fatigue resistance to H13. The easily dissolvable carbides in -QRO90 results in the excellent thermal fatigue resistance of QRO90.

\subsubsection{Effect of Tempering on the Hardness of Five Steels}

The hardness of the five steels in the study was measured after each step in the heat treatment experiment. Fig. 3.13 is a chart showing how the hardness decreases with increasing tempering time.

QRO90 has much better temper resistance than the other steels. Dievar and TQ1 are similar and have a higher temper resistance than RPU and H13. Considering the obvious differences in the hardness distribution of the thermal fatigue samples, stresstempering effects might have kicked in during thermal fatigue testing.

The hardness in the as-quenched condition is different among these five steels,

too. The large number of precipitated carbides during quenching in some steels make them harder than other steels with fewer carbides. 


\subsection{CONCLUSIONS}

The thermal fatigue resistance and tempering resistance of the four steels, Dievar, TQ1, QRO90, RPU is better than that of H13. Dievar has the best thermal fatigue resistance, followed by RPU and TQ1 and H13. The tempering resistance ranking of these steels follows the order of: Dievar, TQ1, RPU and H13. Both the thermal resistance and tempering resistance of QRO90 are considerably higher than $\mathrm{H} 13$.

Two kinds of crack patterns were observed: cutting-through corner cracks and shallow surface cracks. The crack pattern of $\mathrm{H} 13$ is dominated by corner cracks, while the others have both corner cracks and surface cracks. The steels with higher thermal fatigue resistance tend to have more surface cracks and less corner cracks.

Microstructure plays an important role in determining the mechanical properties of die casting steel. Carbides are unfavorable for the thermal fatigue resistance. They exist in two forms: carbides formed from quenching and secondary carbides precipitated during tempering. Results show that lower thermal fatigue resistant steels in this study i.e. H13 contains the highest concentration of carbides. The least number of carbides and smallest sizes were found in Dievar that exhibits the highest thermal resistance among the five steels. The number of carbides is in the order of H13, QRO90, RPU, TQ1 and Dievar. The carbide sizes in the other steels follow the order of RPU, H13, TQ1, QRO90 and Dievar. Steels with lower thermal fatigue resistance are characterized by more secondary carbide precipitation during tempering. 
In summary, Dievar is the best die steel in terms of both thermal fatigue resistance and tempering resistance among the five steels studied and thus is highly recommended for use in die casting industry. 


\subsection{BIBLIODRAPHY}

Benedyk, J.C.; Moracz, D.J.; Wallace, J.F. "Thermal Fatigue Behavior of die materials for Aluminum Die Casting", Paper No. 111, $11^{\text {th }}$ International Die Casting Exposition \& Congress Transactions, Cleveland, Ohio, 1970. 13.

Berger, C.M.; Finn, J "The Effect of Annealed Microstructure on the Impact Toughness of Premium H-13 Die Steel", Transactions of the $18^{\text {th }}$ International Die Casting Congress and Exposion, October, 1995, pp. 357-359. 31.

Bertolo, R.B. "Fracture Toughness of Aluminum Die Casting Die Steels," Ph. D Thesis, Case Western Reserve University, 1976. 16.

Birol, Y. "Reduction in Corrosion in Aluminum Die Casting Dies", Mater Thesis, Case Western Reserve University, 1984.18.

Das, S. K. "Effect of Heat treatment on the thermal fatigue behavior and fatigue toughness of $\mathrm{H} 13$ steel for aluminum die casting dies," Ph. D Thesis, Case Western Reserve University, 1981.22.

Dieter, G. Mechanical Metallurgy, McGraw-Hill Inc., New York etc., 1986. 19.

Donald J. Moracz, "Thermal Fatigue Behavior of Die Materials for Aluminum Die Casting", M.S. Thesis, Case Western Reserve University, 1969. 14.

Fuchs, K.D.; Haberling, E; Rasche, K. "Microstructure and Technological Properties of Hot-Work Tool Steels for Pressure Casting Dies," Thyssen Edelst. Techn. Ber., (1990) 16-24. 25.

Garrison, W.M., Jr. "Influence of Silicon on Strength and Toughness of 5 wt. \% Cr Secondary Hardening Steel," Materials Science and Technology, 3(1987)256-259. 29.

Gehricke, B; Klarenfjord, B.; Schindler, A.; Schruff, I. "Relation between Microstructure and Ductility of Hot-Work Tool Steels H-11 and H-13- Presentation of New Acceptance References fro Microstructures," Transactions of the $18^{\text {th }}$ International Die Casting Congress and Exposion, October, 1995, pp. 337-342. 33.

Graham, R.R. "Thermal Fatigue Mechanisms in Aluminum Die Casting Die Steel", $P h$. D Thesis, Case Western Reserve University, 1978. 11.

Hockanadel, P.W.; Edwards, G.R.; Maguire, M.C.; Baldwin, M.D. "The Effect of Microstructure on the Thermal Fatigue Resistance of Investment Cast and Wrought AISI H-13 Hot Work Die Steel," Transactions of the $18^{\text {th }}$ International Die Casting Congress and Exposion, October, 1995, pp. 343-355. 32. 
Johnson, B. "Die Steels and Improved Productivity", Foundry Trade J 163 [3370] (1988) 412-415. 10.

Kaye, A. Die Casting Metallurgy, Butterworth Scientific, London, Boston, 1978. 3.

Lewin, M. J. "H-13 Die Life-Finding the Missing Link"" Die Casting Engineer, 32[1] (1988) 24-26. 27.

Mukherjee, P.C. Fundamentals of Metal Casting Technology, Oxford \& IBH Pub. Co., New Delhi, 1988. 2.

Nagao, Y.; Knoerr, M.; Altan, T. "Improvement of tool life in cold forging of complex automotive parts," Journal of Materials Processing Technology. 46 [1-2] (1994) 73-85. 6.

Nichols, H.P. "Recent Improvements in H-13 Steels for Aluminum Die Casting Dies" Die Casting Engineer, 29[4] (1985) 64-65. 26.

Noesen, S.J.; Williams, H.A. "The Thermal Fatigue of Die-Casting Dies," Modern Casting, 51 (1967) 119-132. 9.

Norstrom, L.A.; Johansson, B.; Ohrberg, N."Thermal Fatigue and Thermal Shock Behavior of Martensitic Hot Work Steel," Paper G. T81.093, $11^{\text {th }}$ International Die Casting Exposition \& Congress Transactions, Cleveland, Ohio, 1981. 12.

Norstrom, L.; Johnson, L. "New Premium Die Steel for the 1990s", Die Casting Engineer, 32[1] (1988) 12-14. 11.

Pettersson, S.; Sandberg, O.; Johnson, B. "Designing the Hardening Practice for Premium H13 Die-Casting Dies," Heat Treatment of Metals, 20[2] (1993) 49-54. 28.

Roberts, G.A.; Grobe, A.H. "Service Failure of Aluminum Die Casting Dies," Metal Progress, 69 (1956) 58-61. 24.

Roland R. Graham, "Thermal Processing Structure and Thermal Fatigue Relations for Die Steel", M.S. Thesis, Case Western Reserve University, 1974. 15.

Schwam, D.; Wallace, J. F. "Improvement of die life in aluminum die casting," Die Casting Engineer. 39[2] (1995) 4-. 5.

Seth, B.B. “A Review of Die Casting Dies", Die Casting Engineer, 16 (1972) P12-21. 20.

Sharp, H.J. "Aluminum Pressure Die Casting Dies-Their Failure by Surface Carcking," Metal Industry, 51 (1953)164-166. 23. 
Stern, M. Die-Casting Practice, McGraw-Hill Book Company, Inc., New York etc., 1930. 1.

Street, A. The Diecasting Book, Portcullis Press, Redhill, 1977. 4.

Ule, B.; Vodopivec, F.; Pristavec, M; Gresovnok, F. "Temper Embrittlement of Hot Work Die Steel," Materials Science and Technology, 6(1990)1181-1185. 30.

Venkatesan, K.; Shivpuri, R. "Experimental and Numerical Investigation of the Effect of Process Parameters on the Erosive Wear of Die Casting Dies," Journal of Materials Engineering and Performance, 4 (1995) 166-174. 17.

Wallace, J.F. “Thermal Conditions in the Die," Foundry, 96(1968) 176-179. 8.

Young, W., "Die Casting Die Failure and Its Prevention," Precision Metal, 37 (1979) 2831. 33. 


\section{PART 2 - OPTIMIZATION OF HEAT TREATING}

\section{OIL QUENCHING OF DIES}

\subsection{OBJECTIVES}

The results of the thermal fatigue test clearly demonstrate a significant increase in resistance to heat checking with increased cooling rates during quenching. This improvement was accomplished for all the steels in the study, regardless of their specific chemistry.

The improvement in thermal fatigue resistance at fast cooling rates is known at least qualitatively to many in the die and tool making business, yet not pursued aggressively. The main reason is a justifiable concern for excessive distortion of the die or even cracking during the quench. The probability of cracking and/or excessive distortion does increase with the speed of quenching and is highest for the larger and more complex dies. Neither the tool maker nor the heat treater wish to assume the liability of damaging expensive dies. This situation may produce an overly conservative approach and slow quench speed for the die that sacrifices die life in order to avoid even the slightest chance of cracking or excessive distortion.

The objective of this part of the project was to investigate the feasibility of fast oil quenching for some typical $\mathrm{H} 13$ inserts. It also can provide information on the threshold 
values for the severity of cooling that can be tolerated without cracking. For those dies that survived a severe oil quench the resulting distortion was measured in detail.

\subsection{EXPERIMENTAL}

About fifteen used H13 die inserts were donated to CWRU by Thoro with the assistance of Badger Metalife. These die inserts were originally used to die cast a lawn mower part. Engineering drawings of these inserts are not available. The inserts range in weight from 150 to 800 pounds. The thickness of the inserts is in the $4-6$ inches range. The length and width vary from 10 to 60 inches.

The inserts were first carefully inspected for cracks. Inserts that had gross cracks were scrapped and all the other inserts were vacuum annealed. Some degree of heat checking was noticeable on most of these inserts. A few also had weld repairs.

The oil quenching experiments were conducted at Euclid Heat Treating in Euclid, Ohio. The heat treating process was identical for all the dies only the quenching procedure varied:

1. The die was placed on the heat treating fixture and instrumented with $1 / 16^{\prime \prime} \mathrm{MgO} /$ Inconel sheath thermocouples. 
2. The fixture was lowered into a gas pit furnace preheated to $1400^{\circ} \mathrm{F}$ as imposed by the furnace requirement to avoid thermal shock. The carbon equivalent of the atmosphere control was set at $0.4 \%$. After equalizing at $1400^{\circ} \mathrm{F}$, the furnace temperature was increased to $1875^{\circ} \mathrm{F}$. It was held at that temperature for 30 minutes after the measured core temperature of the die reached this $1875^{\circ} \mathrm{F}$ temperature.

3. After austenitizing, the fixture with the die was removed from the gas furnace and immersed in the agitated, medium speed oil quenchant in a tank with a diameter of 36 inches and a height of 96 inches. The temperature of the oil was $130^{\circ} \mathrm{F}$. The die was immersed in the oil until the surface thermocouple read between $550-750^{\circ} \mathrm{F}$ depending of the quench employed. The oil quench was then interrupted by raising the fixture from the tank. When the core and surface temperatures were within $100^{\circ} \mathrm{F}$ of each other, the die was either immersed back into the oil or not returned to the oil tank, but left to cool in still air. In all instances, the cooling was continued until the die cooled below $200^{\circ} \mathrm{F}$.

4. The fixture was transferred to a pit tempering furnace preheated to $200^{\circ} \mathrm{F}$ and then heated in the furnace to $1100^{\circ} \mathrm{F}$. Tempering was continued for 3 hours at $1100^{\circ} \mathrm{F}$. Double tempering was always conducted with additional tempers as needed to meet the hardness requirements.

Following is a detailed description of the quenching experiments: 


\section{Die Insert \#4}

As a precaution, the surface of this insert was machined and all the heat checking marks and sharp details were eliminated. Even so, it still had multiple water lines, through holes and threaded blind holes. A square grid of 1/8" diameter, 1/8" deep holes, one inch apart was drilled for distortion measurements before and after treatment. The die is 14.5 inches long, 9.75 inches wide and 4 inches thick as illustrated in Figure 6.1. The die was quenched in a vertical position. The cooling curves during quenching are shown in Figure 6.2. Note the severity of the quench. The quench was interrupted before transformation to allow core and surface temperatures to approach each other to within $100^{\circ} \mathrm{F}$. Except for this interruption, the die was cooled almost continuously to $200^{\circ} \mathrm{F}$. Nevertheless it survived the oil quench without detectable cracking.

The dimensional changes were measured with a coordinate measuring machine. The $Z$ distortion (perpendicular to the die surface) of the large side of the die, Side $I$ is shown in Figure 6.3 and 6.4. This side bulged 0.030 inches. The $\mathrm{X}-\mathrm{Y}$ distortion (in the die surface plane) is shown as a vector plot in Figure 6.5. It shows that the die shrunk 0.030 inches in length. The $Z$ distortion (perpendicular to the die surface) of the other large side, Side 3 is illustrated in Figure 6.6 and 6.7. Side 3 bulged 0.030 inches. The $\mathrm{X}-\mathrm{Y}$ distortion (in the die surface plane) is shown as a vector plot in Figure 6.8 .

The distortion of Die Insert \#4 resulting from this oil quench is slightly larger than what is typically observed in six or ten bar nitrogen gas quenching. However, it is common procedure to allow for such distortion during quenching. After quenching and tempering, dies are finished 
by Electro-Discarge Machining, grinding and polishing. These methods can bring the die to final size in the hardened condition. The benefits of better properties provided by the faster oil quench are therefore feasible.

\section{Die Insert \#6}

This insert, identical to die \#4 was not machined, and so all the heat check marks and sharp details were left in place. The insert is 14.5 inches long, 9.75 inches wide and about 5-6 inches thick as illustrated in Figure 6.9. It also had multiple water lines, through holes and threaded blind holes. A square grid of $1 / 8^{\prime \prime}$ diameter, 1/8" deep holes, one inch apart was drilled for distortion measurements before and after heat treatment. Both sides of the die are shown in Figure 6.9. The die was secured in a vertical position in the quenching basket. However, it tipped sideways during handling in the furnace and leaned in the fixture on the highest details. This pulled the embedded thermocouples away from their original positions and brought the thermocouple junctions closer to the surface. Consequently, the temperature interrupt could not be controlled as intended. The cooling curves during quenching are shown in Figure 6.10. This die cracked during the quench. No further analysis was conducted.

\section{Die Insert \#7}

This insert was not machined and all the heat check marks and sharp details were left in place. It had multiple water lines, through holes and threaded blind holes. A square grid of 1/8" diameter, 1/8" deep holes, one inch apart was drilled for distortion measurements. The die is 
14.6 inches long, 7.8 inches wide and 7.9 inches thick. The die is shown in Figure 6.1.1. The die was quenched in a horizontal position. The cooling curves during quenching are shown in Figure 6.12 and 6.13. The severity of the quench particularly at the surface is apparent. The quench was interrupted before the transformation to allow the core and surface temperatures to come within $100^{\circ} \mathrm{F}$ from each other. Except for this interrupt, the die was cooled almost continuously to $200^{\circ} \mathrm{F}$. Nevertheless, it survived the oil quench without detectable cracking. The distortion of the large side, Side 1, is shown in Figure 6.14. Side 1 bulged 0.010 inches. The vector plot of Side 1 is illustrated in Figure 6.15. It shows that the die shrunk 0.010 inches in length.

\section{Die Insert \#8}

This insert as shown in Figure 6.16 has the shape of a doughnut. It is about 20 inches in diameter and 8 inches thick. It was milled before heat treatment to remove a gross crack thus creating a one inch wide slot. All the other welded areas and details were left in place. The insert also had multiple water lines, through holes and threaded blind holes. A radial grid of 1/8" diameter, 1/8" deep holes was drilled for distortion measurements before heat treatment. The die was positioned on the flat bottom side in the quenching basket. The cooling curves during quenching are shown in Figure 6.17. This die cracked during the quench. No further analysis was conducted. 


\section{Die Insert \#9}

This insert was not machined and all the heat check marks and sharp details were left in place. It had multiple water lines, through holes and threaded blind holes. A square grid of 1/8" diameter, 1/8" deep holes, 1" apart was drilled for distortion measurements before heat treating. The die is shown in Figure 6.18. It is 16 inches long, 16 inches wide and 5-6 inches thick. The die was quenched in a horizontal position. The cooling curves during quenching are plotted in Figure 6.19. The quench was interrupted just before the transformation at the surface and the core and surface temperatures were equalized to within $100^{\circ} \mathrm{F}$. It was also placed back in the oil bath but the quench was interrupted for two short periods by pulling the die out of the oil for five minutes during the transformation to allow further equalization of the surface and core temperatures. However, the die cracked during the transformation segment of the quench and no further analysis was conducted. In this case three factors may have joined to cause the cracking:

(a) Existing cracks and sharp details in the insert;

(b) Relatively large size of the die;

(c) The horizontal position of the die during the quench that brings the large bottom surface in contact with the cold oil causing uneven cooling.

\section{Ford Insert \#1 (HI3)}

This type of insert, shown in Figure 6.20, is currently in used in production at the Ford Rawsonville plant. It weighs 84 pounds and is $9.5^{\prime \prime} \times 9.5^{\prime \prime} \times 3.25^{\prime \prime}$ in size. A scrapped insert was 
available for establishing the cooling curves during interrupted quenching. The insert was instrumented with four thermocouples located as follows: \#1 - in the center of the part; \#2 - in the middle of the largest side, $1 / 4 "$ from the surface; \#3 - in the middle of the small side, one inch from the surface; \#4 - at the comer of the part, one inch from the surface. Holes were drilled to accommodate thermocouples $\# 1$ and $\# 2$. The other thermocouples were attached to threaded holes that are an integral part of the insert. These threaded holes were also available for future measurements in production dies. In this manner, a relationship could be established between the temperature at the center and surface of the die and those in the comer and side.

The die was quenched in a vertical position. The cooling curves during quenching are shown in Figures $6.21,6.22,6.23$. The insert was cooled rapidly from the austenitizing temperature to the Ms, start of the martensitic transformation. The insert was then removed from of the oil quenchant and placed aside to cool in still air until it reached $200^{\circ} \mathrm{F}$, then the die was double tempered. This cooling mode is designated austempering and normally results in a martensitic structure on the surface with a lower bainite interior. No cracks were detected after quenching and tempering.

\section{Ford Inserts \#2, \#3 (KDA1)}

These inserts, shown in Figure 6.24 and 6.25 are production parts at the Ford Rawsonville plant. One weighs 84 pounds, the other 90 pounds. The inserts were instrumented with two thermocouples located as follows: 
(1) In the middle of the small side, one inch from the surface;

(2) At the comer of the part, one inch from the surface.

The thermocouples were attached to the inserts utilizing threaded holes that are an integral part of the insert design. Since the relationship has been established between the temperature at the center and surface of the insert and those in the comer and side for this type of die, the temperatures at the corner/side could be measured and the other temperatures estimated. The duration or timing of the oil quench of the interrupt was also known from Ford Insert \#1. The two inserts were quenched together in the same basket, in a vertical position. The cooling curves during quenching are plotted in Figure 6.26, 6.27 and 6.28. The inserts cooled rapidly from the austenitizing temperature to the Ms, start of the martensitic transformation. The inserts were then removed from the oil quenchant and left to cool in still air to $200^{\circ} \mathrm{F}$, followed by double tempering to Rc 46. This cooling mode should result in a tempered martensite structure on the outside of the part with lower bainite inside. No cracks were detected after quenching and tempering.

\subsection{RESULTS AND DISCUSSION}

A summary of interrupted oil quench experiments is shown in the Table 6.1. Of the five inserts that were martempered, three cracked and two did not. The three inserts that were austempered did not crack. It is also noted that the dies that were in the oil quench with vertical 
part of the insert design. Since the relationship has been established between the temperature at the center and surface of the insert and those in the comer and side for this type of die, the temperatures at the corner/side could be measured and the other temperatures estimated. The duration or timing of the oil quench of the interrupt was also known from Ford Insert \#1. The two inserts were quenched together in the same basket, in a vertical position. The cooling curves during quenching are plotted in Figure 6.26, 6.27 and 6.28. The inserts cooled rapidly from the austenitizing temperature to the Ms, start of the martensitic transformation. The inserts were then removed from the oil quenchant and left to cool in still air to $200^{\circ} \mathrm{F}$, followed by double tempering to Rc 46 . This cooling mode should result in a tempered martensite structure on the outside of the part with lower bainite inside. No cracks were detected after quenching and tempering.

\subsection{RESULTS AND DISCUSSION}

A summary of interrupted oil quench experiments is shown in the Table 6.1. Of the five inserts that were martempered, three cracked and two did not. The three inserts that were austempered did not crack. It is also noted that the dies that were in the oil quench with vertical orientation did not crack but the horizontally positioned dies did. There are significant differences between oil queching dies that have been used compared to quenching new dies. Used dies often have heat checking cracks on the surface. Internal cracks initiated at the water lines may also be present. These prior cracks increase the susceptibility of a used die to quench cracking. New dies are commonly 
only rough machined before quenching. The final details are machined or EDMed only after the heat treating has been completed. These final details include sharp radii, comers and other high stress concentration details that are-likely to start quench cracks. In the used dies all these details are in place, increasing the probability of cracking during the quench.

The costs associated with machining intricate shapes of new H13 tool steel for this study exceeded available funds. Except for the study of simple blocks, these machining costs are so high that it was necessary to study the effect of oil quenching on used dies. The information gained from the quenching experiments with used dies was helpful in establishing quenching times etc. for new dies.

Two types of quenching processes were employed in this study as indicated in Figure 6.29. The first one is martempering in which the part is cooled rapidly from the austenitizing temperature to just above the Ms or start of the martensitic transformation. The die is held above the oil tank until the temperature equalizes, or the inside and outside temperatures are within $100-200^{\circ} \mathrm{F}$. The oil quench is then continued to cool the pan to about $200^{\circ} \mathrm{F}$ then the die is double tempered. Martempering targets a tempered martensitic structure. By interrupting the quench and equalizing the outside and inside temperatures the quenching stresses and the distortion are minimized compared to a direct quench. 
The other quenching process is austempering. In this process, the part is also cooled rapidly from the austenitizing temperature to just above the Ms, start of the martensitic transformation then the die is allowed to cool in air at a slower rate. By keeping the part at this temperature for a longer time, most of the austenite transforms into lower bainite. The slow air cooling is continued until the part is warm, or about $200^{\circ} \mathrm{F}$, then it is double tempered to desired hardness. Austempering normally results in a tempered martensite structure on the outside of the part with lower bainite inside. Austempering further minimizes stresses by allowing the steel time to accommodate the tranformation stresses generated during the phase transformation without cracking. The thermal fatigue resistance of bainitic $\mathrm{H} 13$ is only slightly less than tempered martensite H13. This is therefore a compromise of good thermal fatigue resistance with less distortion and probability of cracking. The structure of the surface of the die is more significant for the thermal fatigue performance than the core structure.

\subsection{IN PLANT EVALUATION OF KDA1 INSERTS}

Parallel to the thermal fatigue testing, the participants in the program initiated inplant evaluation of KDA1 inserts. At the time of this writing only preliminary results on two types of inserts have been made available: 


\section{The Chrysler Ejector Core}

This insert, shown in Figure 7.1 was manufactured by American Tool \& Mold (ATM) in St. Joseph, Michigan for die 612-307 to produce input clutch retainer 4446635. The insert was operated for only 15,400 shots and returned to the die maker for evaluation. The following observations were made by the die maker as described in a letter from Mr. Paul Palmer, plant manager:

1) Cracking at the top of the finger slot openings and running around the core.

2) Typical gate washout with evidence of benching on the chucking diameter with grinder.

3) Same stress cracks running laterally at the top of the ejector pin sleeve hole.

The ATM conclusion was that no major differences were found in the performance of this material in comparison to conventional $\mathrm{H}-13$ that would substantiate its additional cost. The damage mentioned in the letter is shown in Figures 7.2, 7.3 and 7.4. According to the die maker the damage patterns are similar to those observed in $\mathrm{H} 13$. It is not clear however if this KDAl insert, had it been left in production, would have lasted for a longer or shorter life than an identical one made of H13. It also seems that some of the damage may be related to the quenching operation. The results fail to provide an indication of the relative life of $\mathrm{H} 13$ or KDA1 dies. 
This trial illustrates the difficulty in evaluating the performance of inserts. In the absence of clear, quantitative criteria, the evaluation becomes g!lalitative and the conclusions may be premature. The visual observations, while meaningful, may not be sufficient in comparing differences in the performance of the die steels. One way to address this problem is to test the KDAl side by side with $\mathrm{H} 13$, on identical inserts in a multi-cavity die with periodic inspection of the inserts or the parts made for these inserts. The inserts should be left in production until repair or replacement is imminent. The total number of shots for the particular insert, and the condition of the insert at the periodic inspection intervals are recorded. When repeated for a number of parts, or identical inserts in different cavities of the same die to eliminate any possible local effects, such a monitoring program can provide a clearer picture of die steel performance.

\section{The Ford Inserts}

Early in the program the Ford Rawsonville plant made two KDAl inserts and utilized them in production. The inserts and respective cavities are part of a four cavity die shown in Figure 7.5. Two insert/cavity sets i.e. \#29, \#31 were made of H13 and employed along with two inserts that were made of KDAI i.e \#30 and \#32. The KDA1 and $\mathrm{H} 13$ inserts were inspected periodically for evidence of heat checking. The heat checking damage became apparent around 50,000 shots. This damage is mainly 
occurring along the circumferencial radius of the cavity, and is more pronounced across the gates in the region indicated by the arrows in Figure 7.6.

An attempt was made to quantify the heat checking damage utilizing a similar procedure as employed in the immersion thermal fatigue test at CWRU. Aluminum parts cast in each insert were made available after 59,000 and 90,000 shots. The heat checking damage provides a positive image of the cracks, or fine fins along the perimeter. The testing procedure shown in Figure 7.7 was utilized. It comprises a rotary table with an attached indicator. The tip of the indicator has wedge shape and can follows the shape of the fins. By rotating the table, a profile of the fins was generated with their respective height and length. In most cases the fins are not continuous but short segments.

A typical profile is shown in Figure 7.8. By integrating the area of the fins (length $x$ height) for 80 each part, a "Total Crack Area" value was generated, similar to the one used in the CWRU test as shown in Figure 7.9. This value is plotted versus the number of shots, and allows a comparison between parts of identical geometry. In this case, at 59,000 and 90,000 shots, the total crack area for the KDA1 inserts is larger than the total crack area for the H13 inserts. These results are not final; the inserts were still in production at the time of this writing. 


\section{TABLES AND FIGURES}


Table.2.1 The composition of five steels

\begin{tabular}{|c|c|c|c|c|c|}
\hline \multirow{2}{*}{$\begin{array}{c}\text { Elements } \\
\text { wt\% }\end{array}$} & \multicolumn{5}{|c|}{ Materials } \\
\cline { 2 - 6 } & H13 & TQ1 & QRO90 & RPU & Dievar \\
\hline $\mathrm{C}$ & 0.4 & 0.35 & 0.37 & 0.38 & 0.35 \\
\hline $\mathrm{Si}$ & 1 & 0.4 & 0.3 & 0.4 & 0.2 \\
\hline $\mathrm{Mn}$ & 0.4 & 0.43 & 0.63 & 0.4 & 0.5 \\
\hline $\mathrm{P}$ & 0.001 & 0.001 & 0.001 & & \\
\hline $\mathrm{S}$ & 0.01 & 0.01 & 0.015 & & \\
\hline $\mathrm{Cr}$ & 5.25 & 5.2 & 2.46 & 5.2 & 5 \\
\hline $\mathrm{Mo}$ & 1.5 & 1.8 & 2.22 & 2.8 & 2.3 \\
\hline $\mathrm{V}$ & 1 & 0.55 & 0.84 & 0.6 & 0.6 \\
\hline $\mathrm{Cu}$ & & & 0.2 & & \\
\hline Fe & Bal & Bal & Bal & Bal & Bal \\
\hline
\end{tabular}




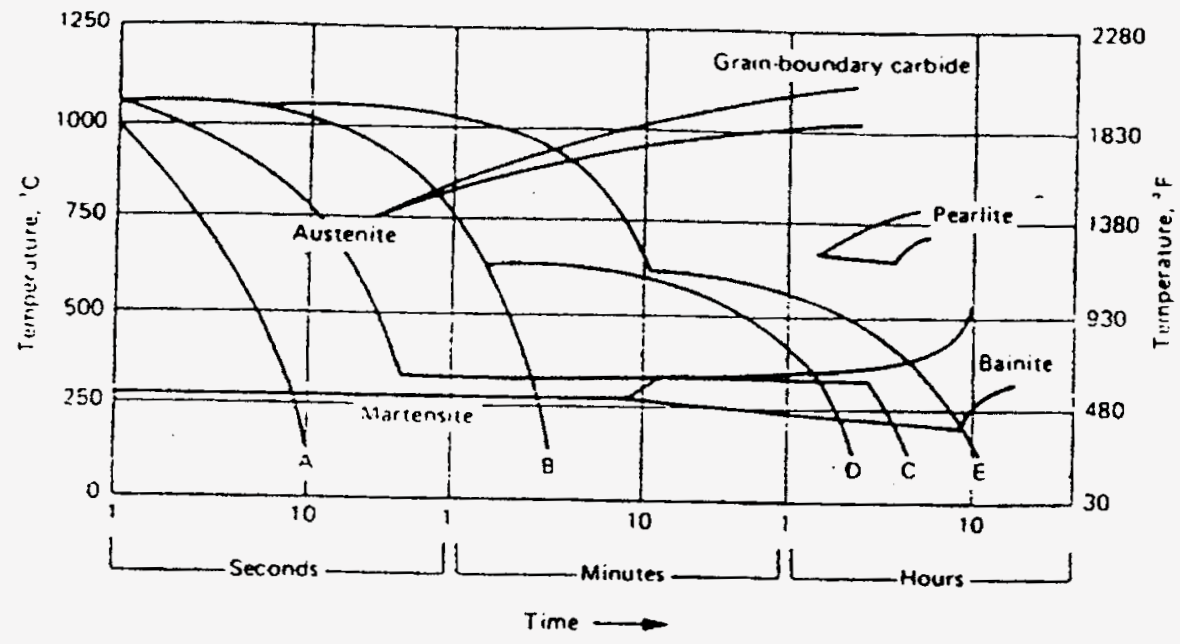

Fig 2.1(a) CCT graph of $\mathrm{H13}$ austenized at $1900^{\circ} \mathrm{F}$

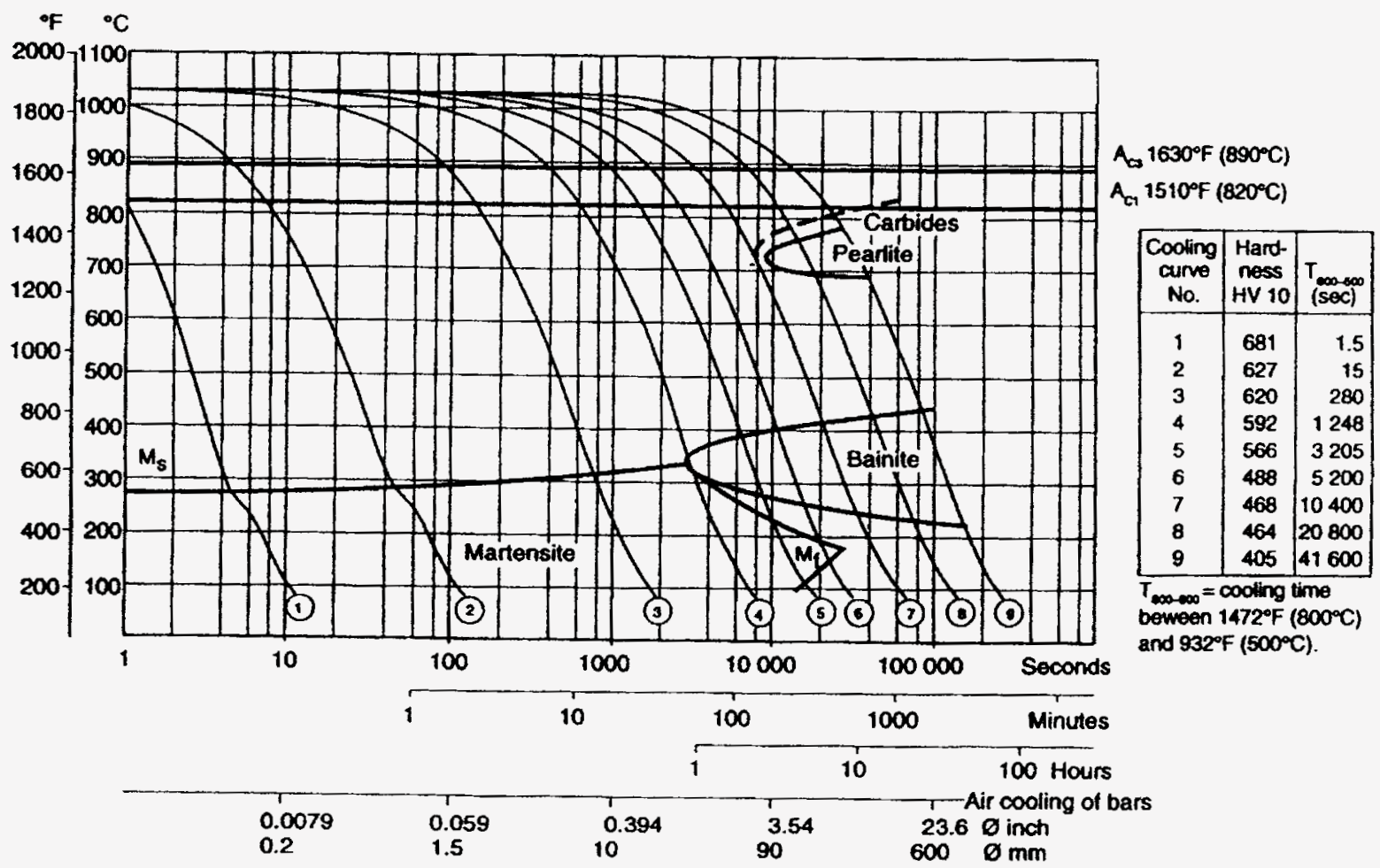

Fig 2.1(b) CCT graph of Dievar austenized at $1875^{\circ} \mathrm{F}$. Holding time 30 minutes 


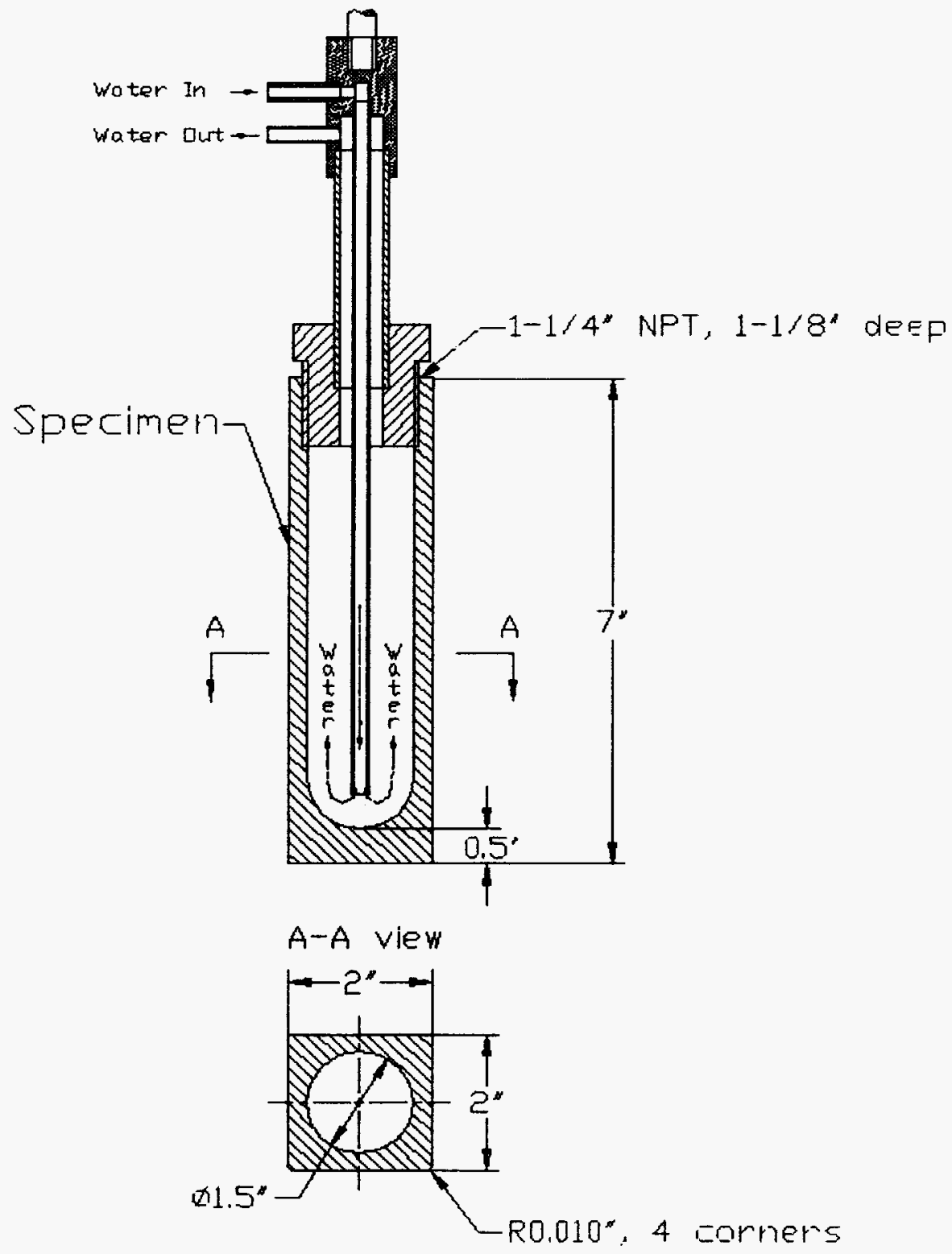

Fig.2.2 The dimensions of specimens for thermal fatigue test and cooling system 


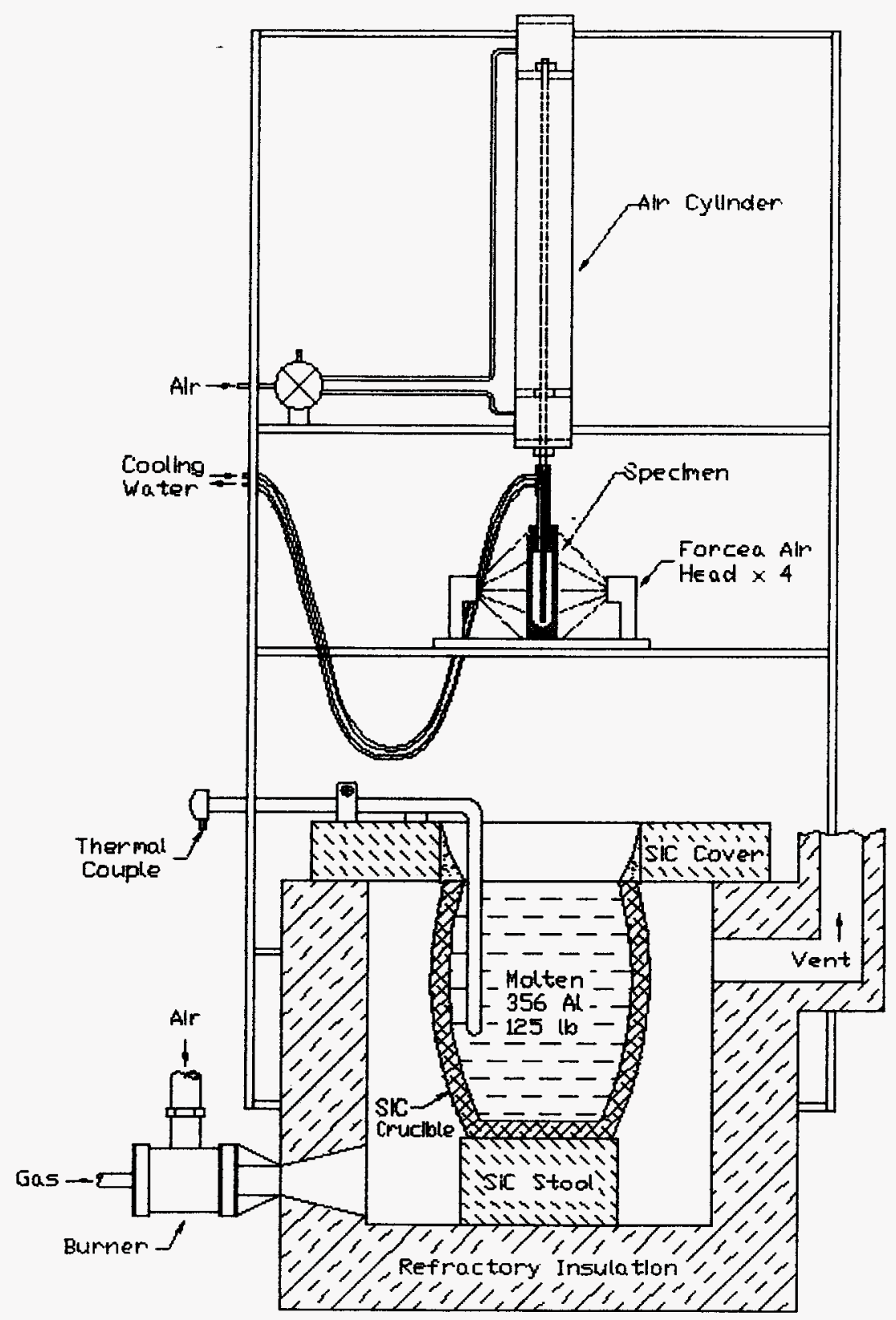

Fig.2.3 Thermal fatigue immersion test equipment 


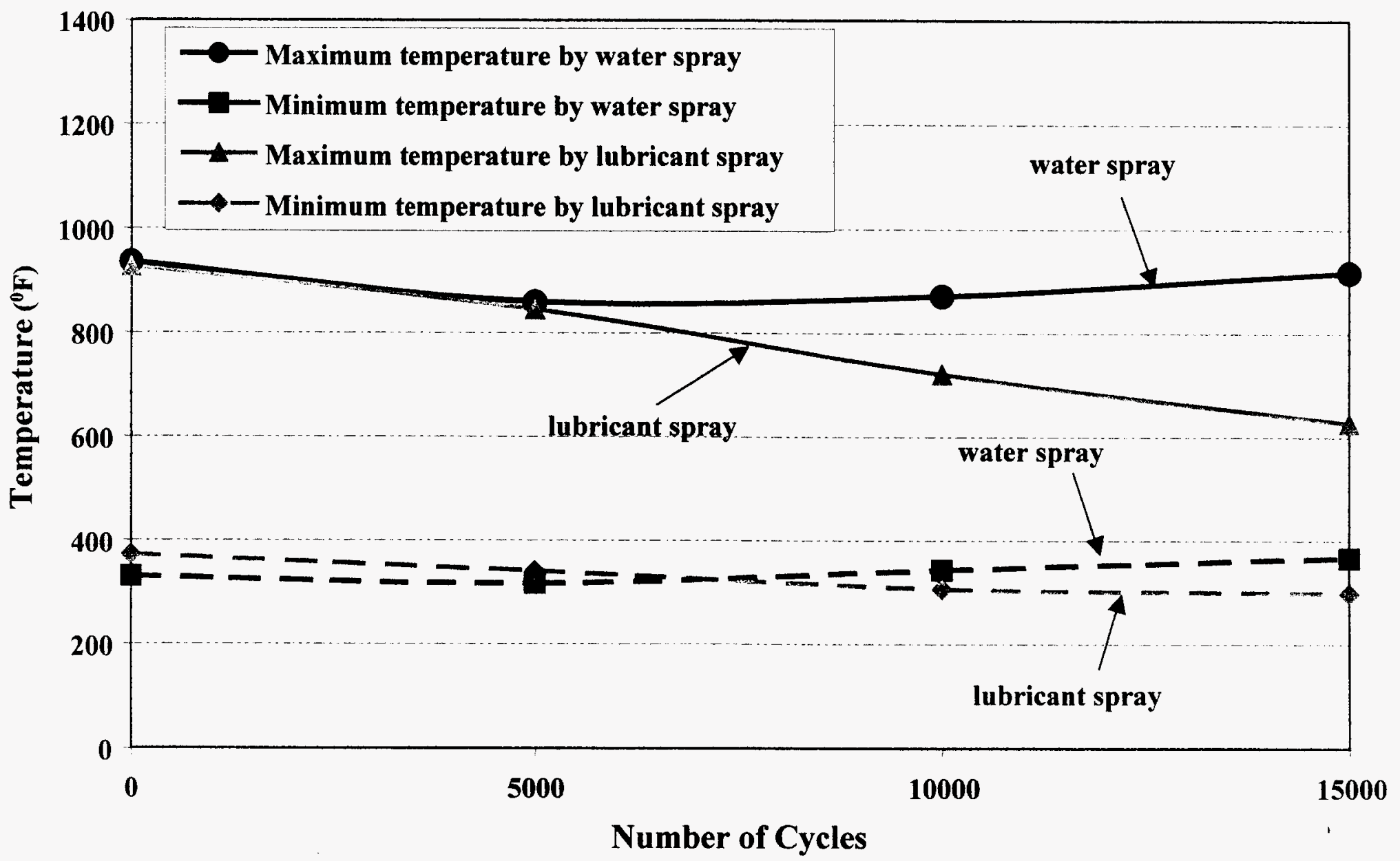

Fig.2.4 Temperature fluctuations with Cycles--Lubricant vs. Water 


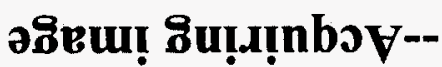

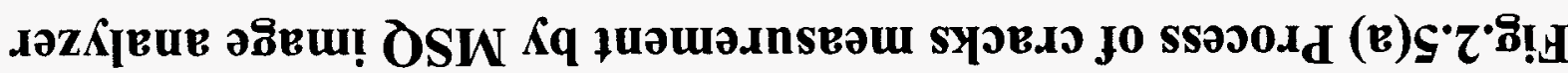

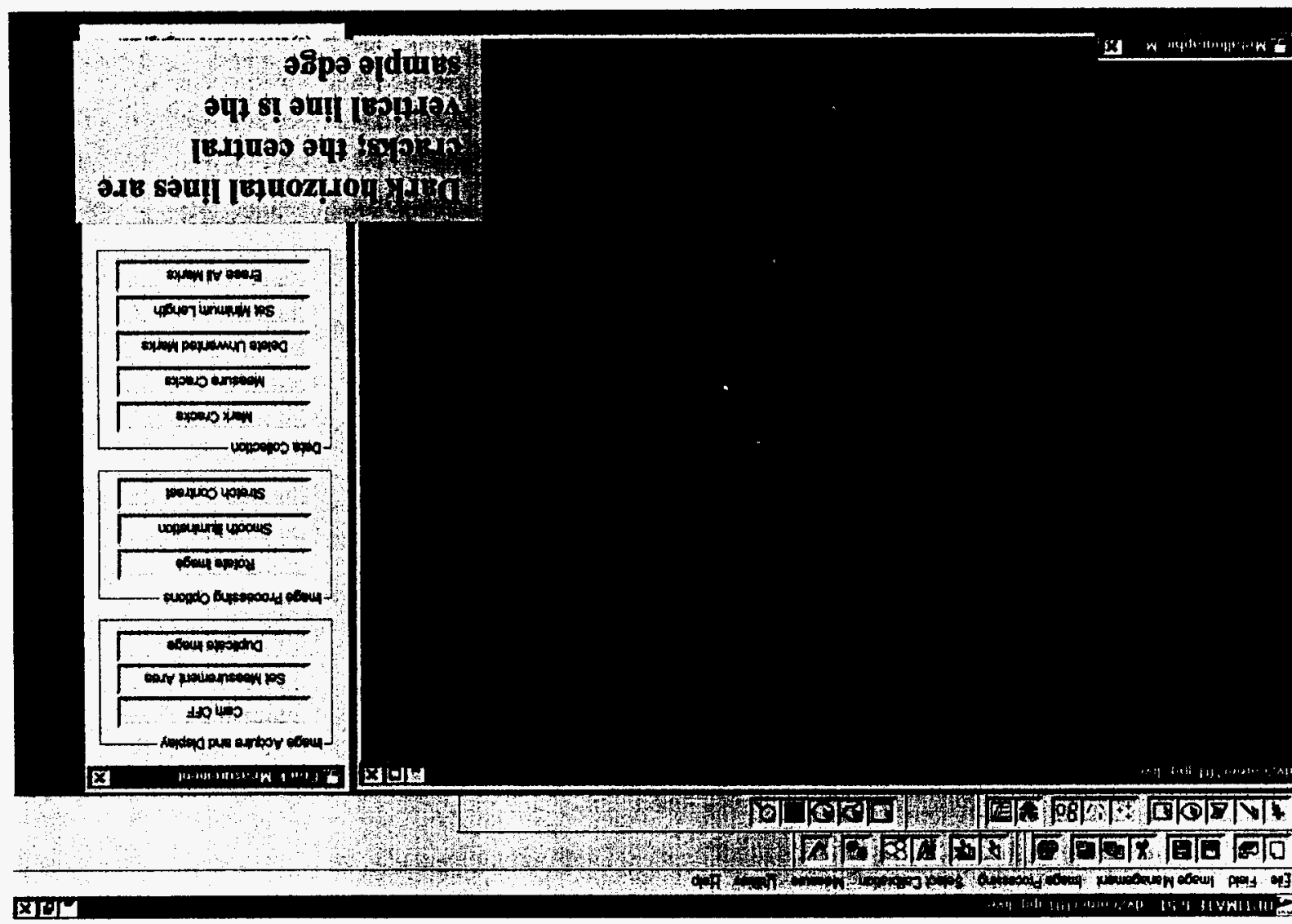




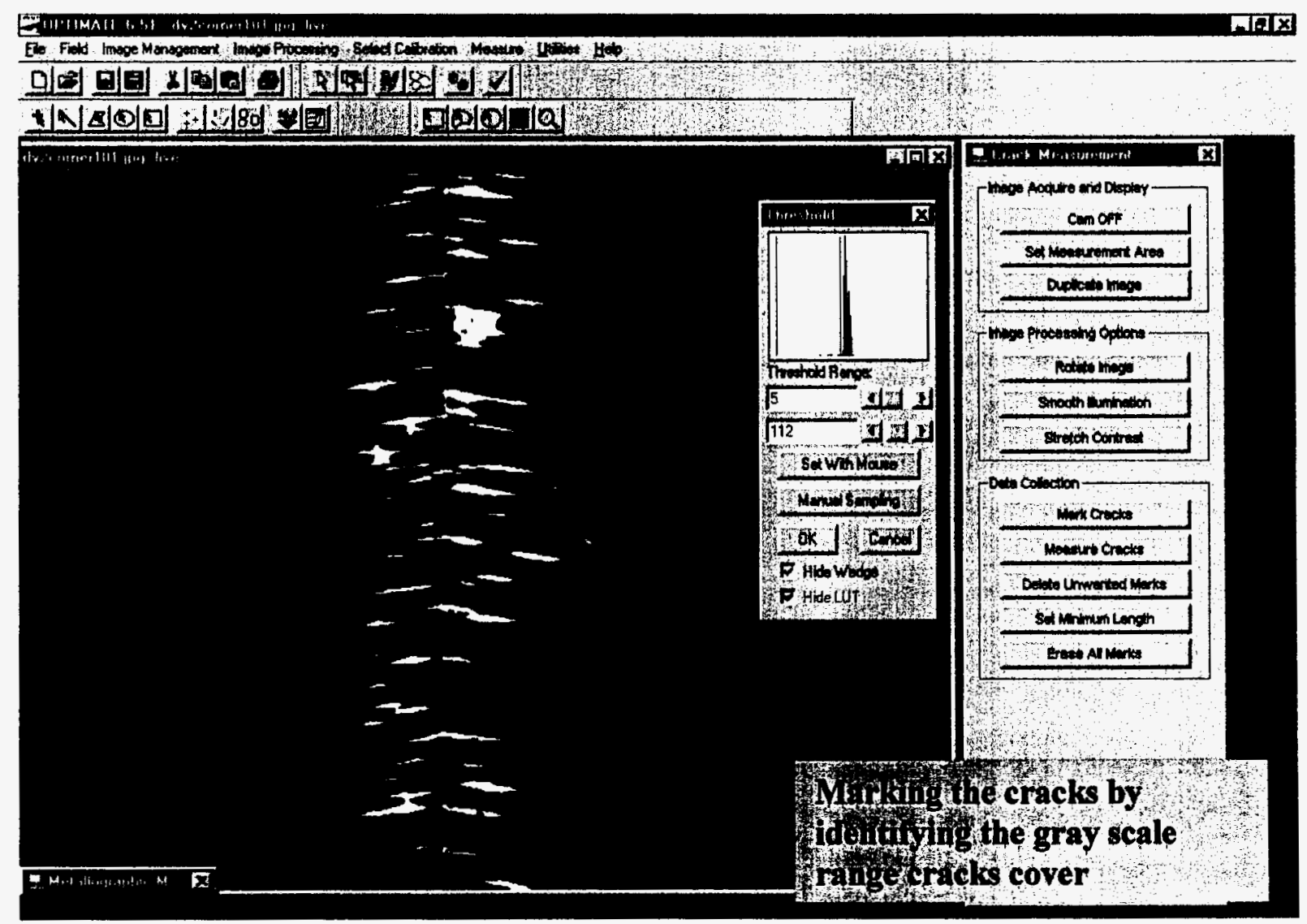

Fig.2.5(b) Process of cracks measurement by MSQ image analyzer --Marking the cracks 


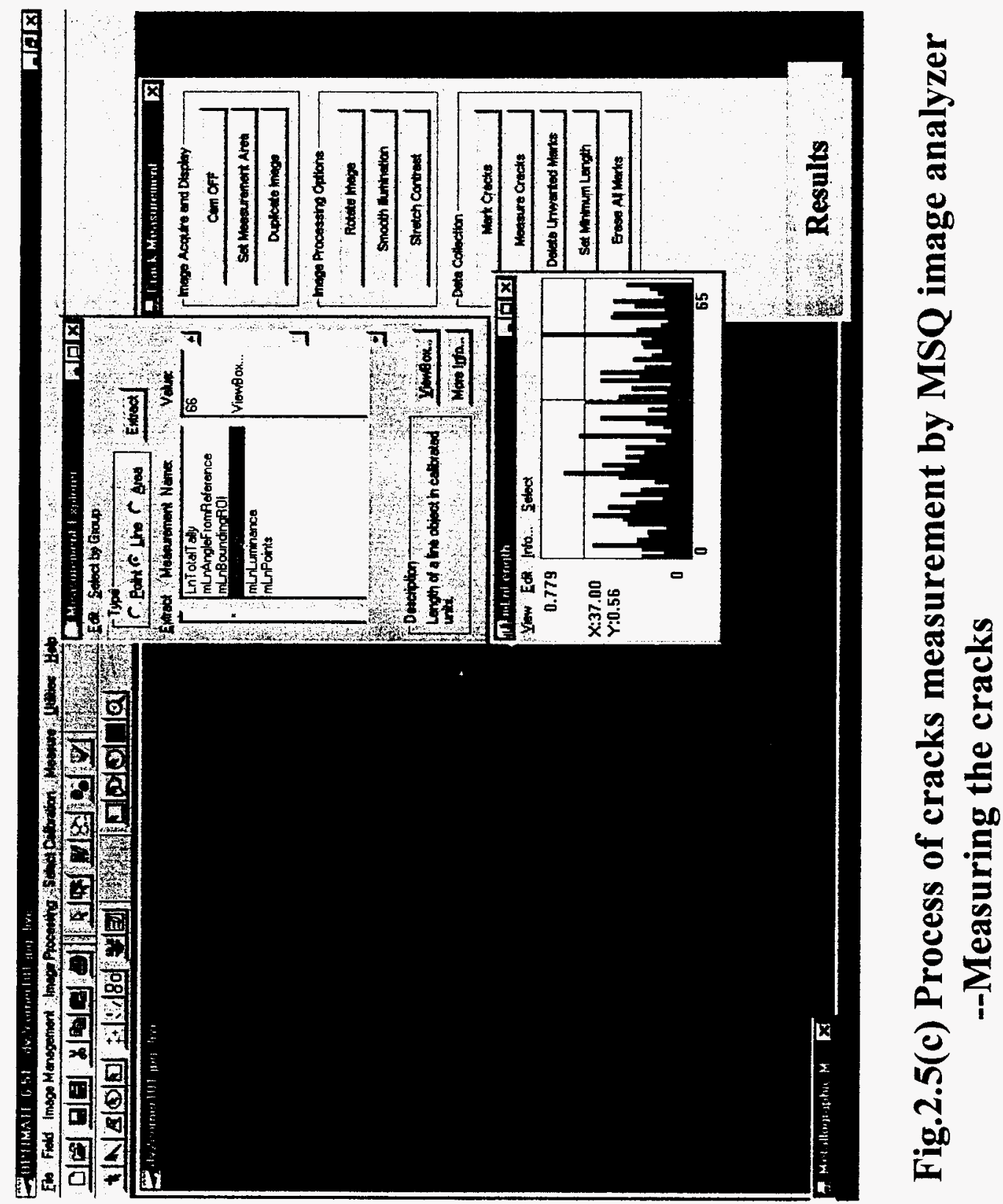




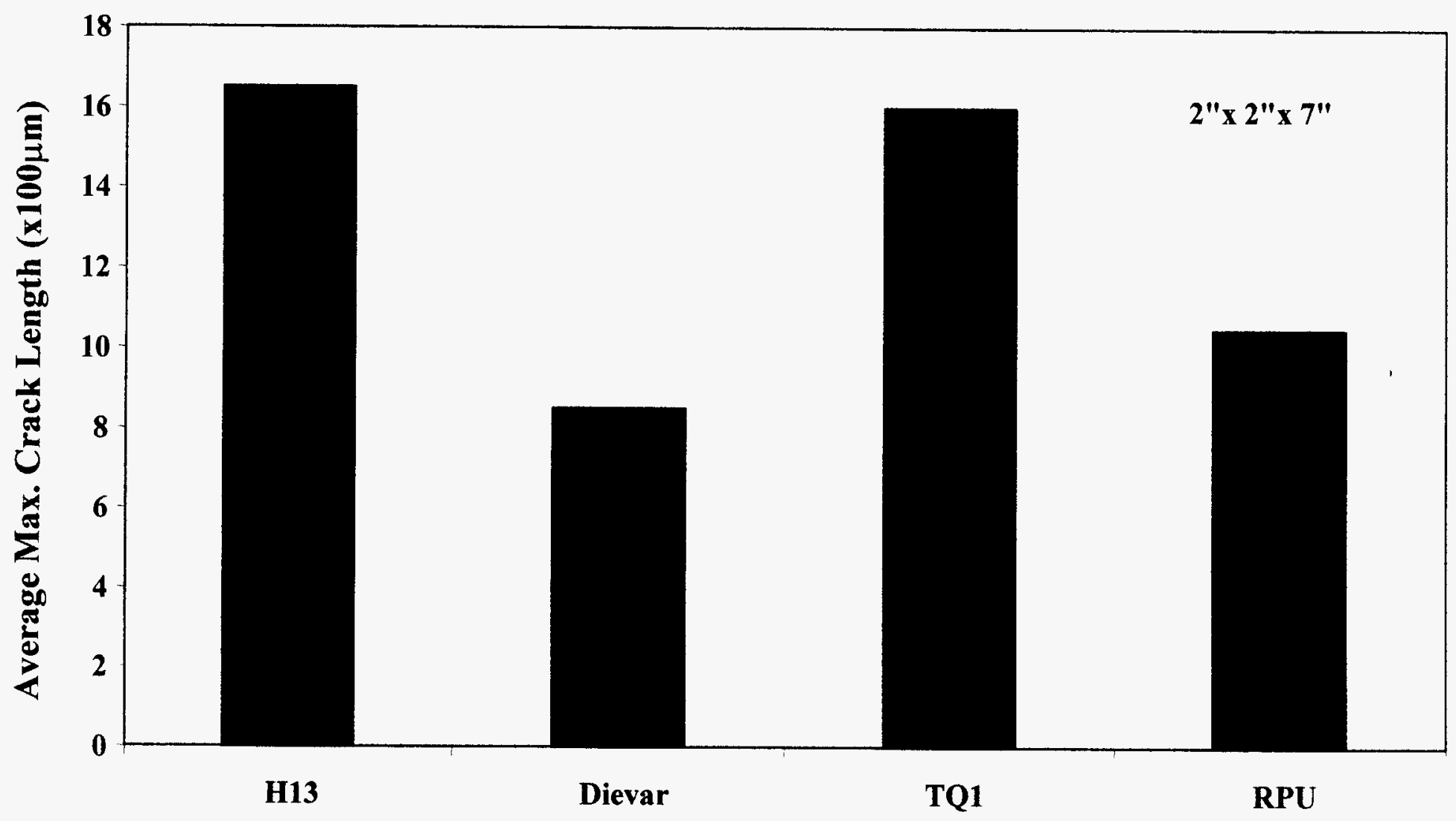

Fig.3.1(a) Average maximum crack length of Dievar,TQ1,RPU and $\mathrm{H13}$ after 15,000 cycles for $2 " x 2 " x 7 "$ specimens 


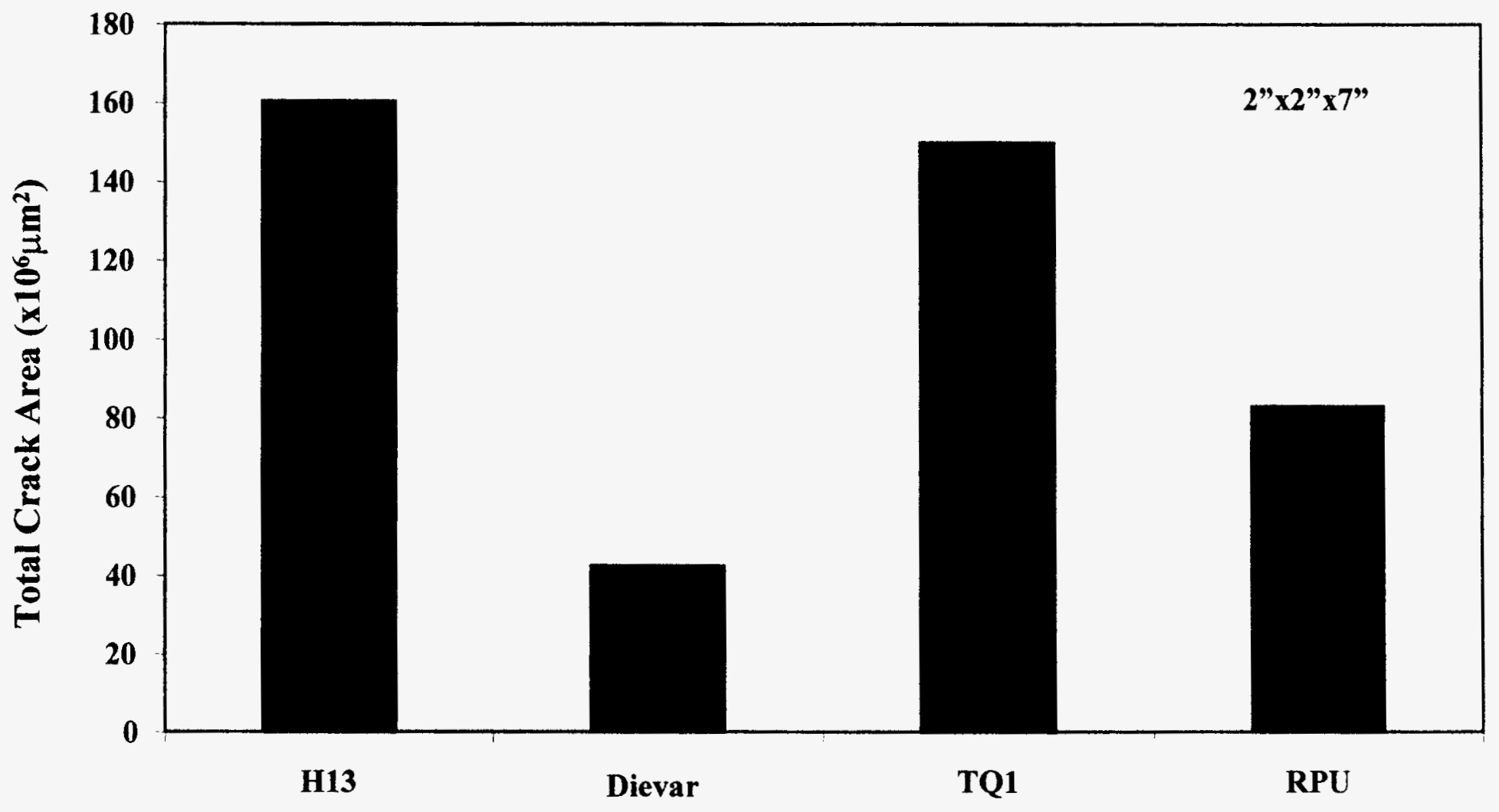

Fig.3.1(b) Total crack area of Dievar,TQ1,RPU and H13 after 15,000 cycles for $2^{\prime \prime} \times 2 " x 7 "$ specimens 


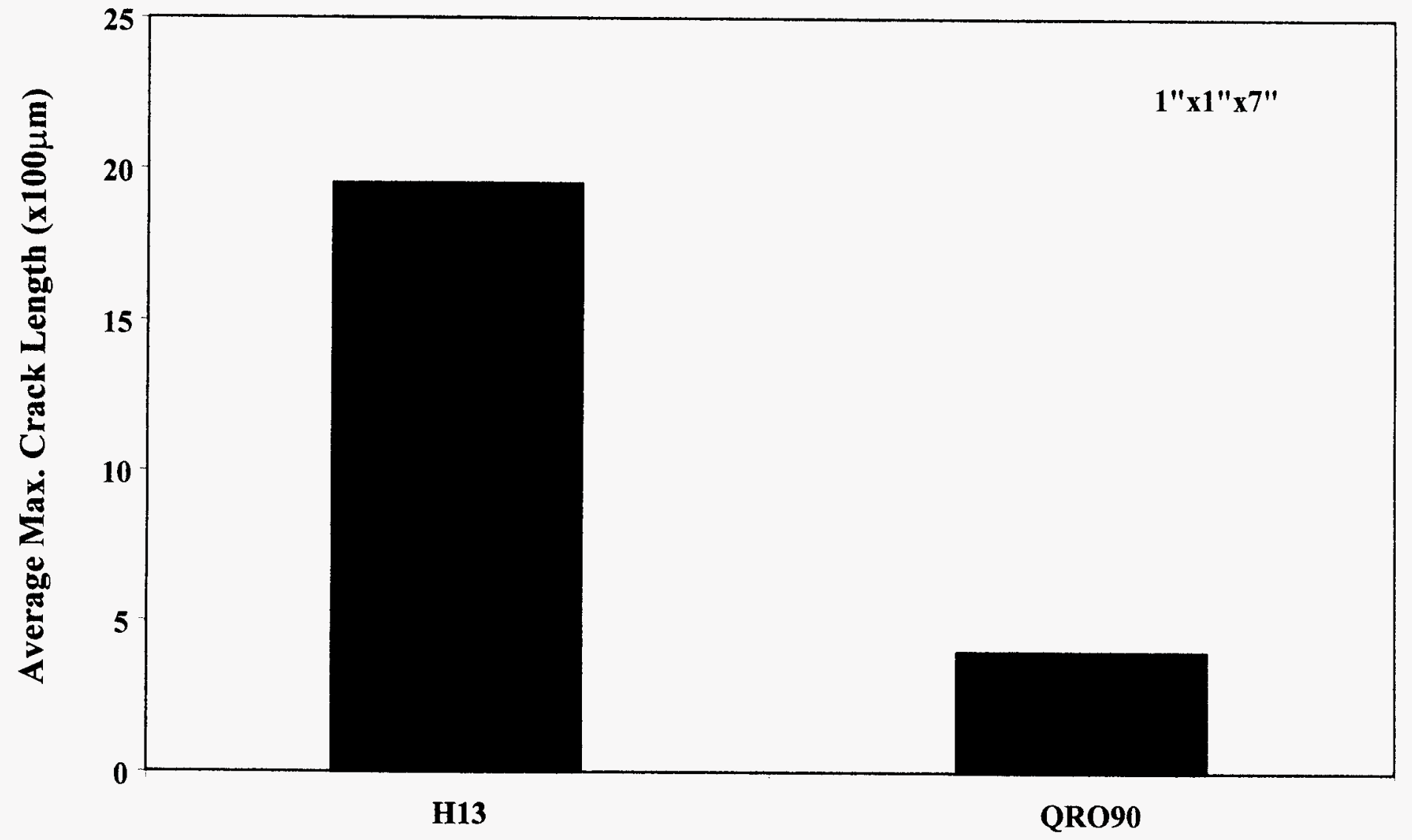

Fig.3.2(a) Average maximum crack length of QRO90 and H13 after 15,000 cycles for $1 " x 1 " x 7 "$ specimens 


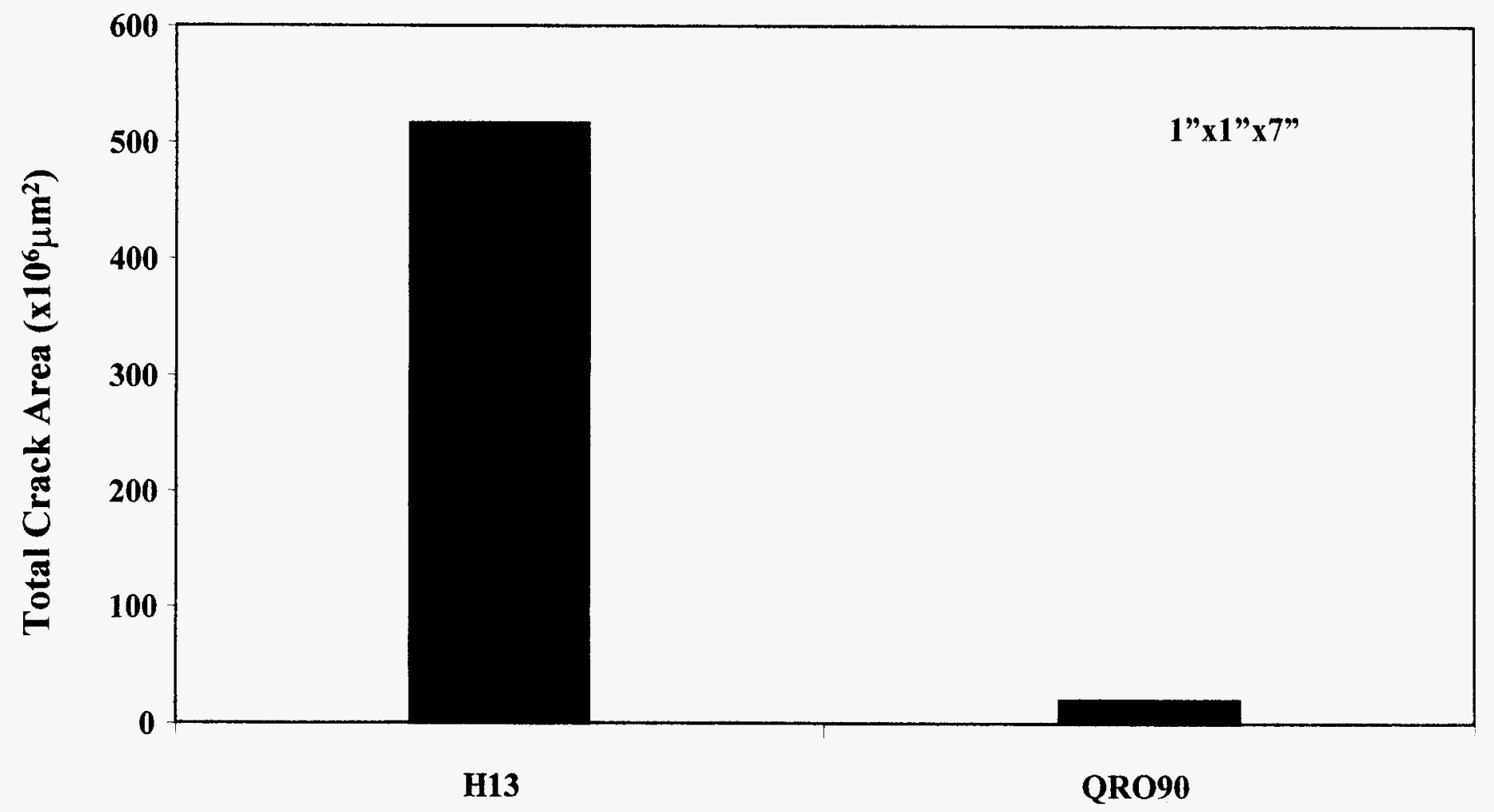

Fig.3.2(b) Total crack area of QRO90 and H13 after 15,000 cycles for 1 "x1"x7" specimens 


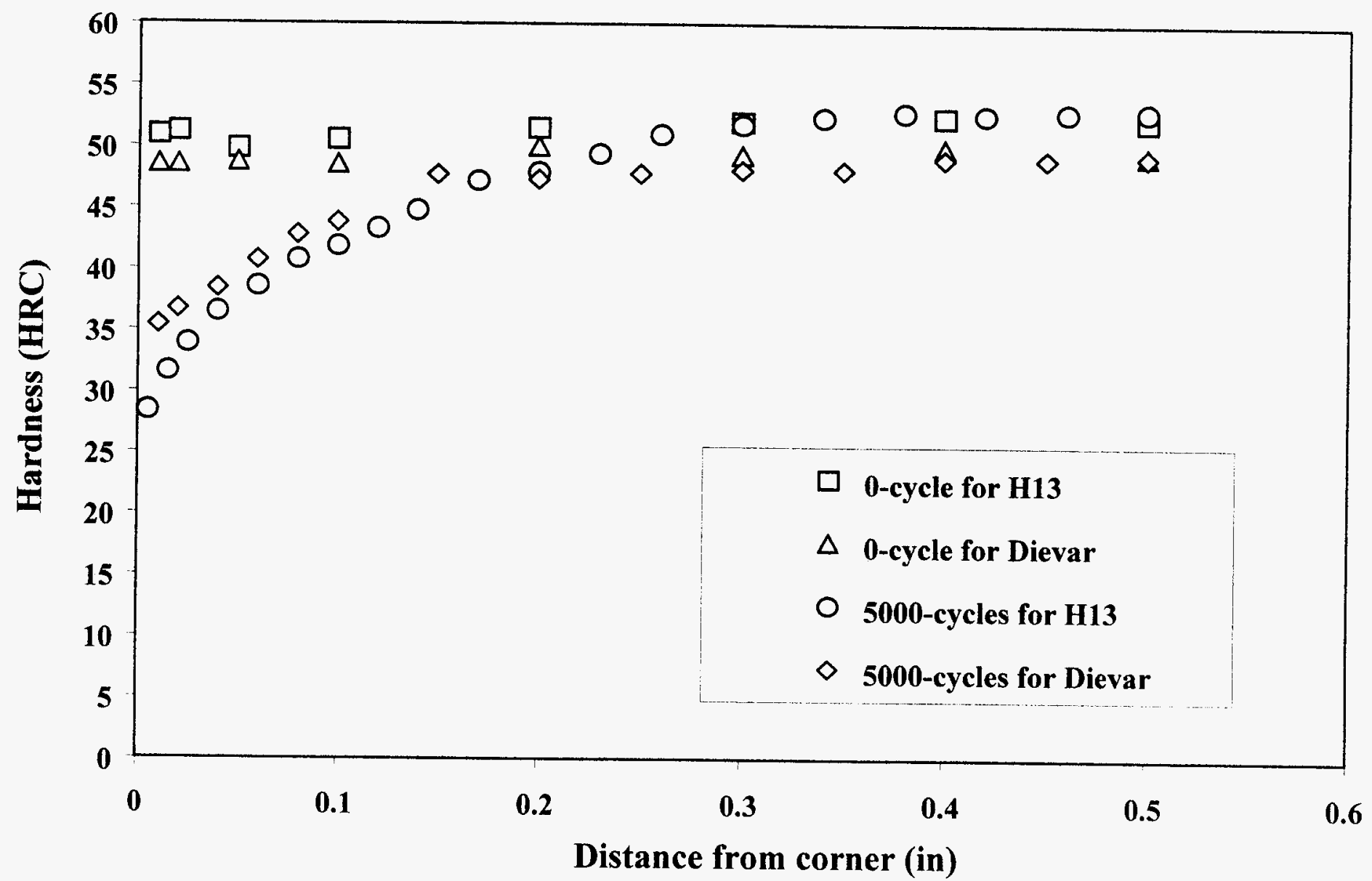

Fig. 3.3(a) Softening of $\mathrm{H13}$ and Dievar after 5,000 thermal cycles for $2 " x 2 " x 7 "$ specimens 


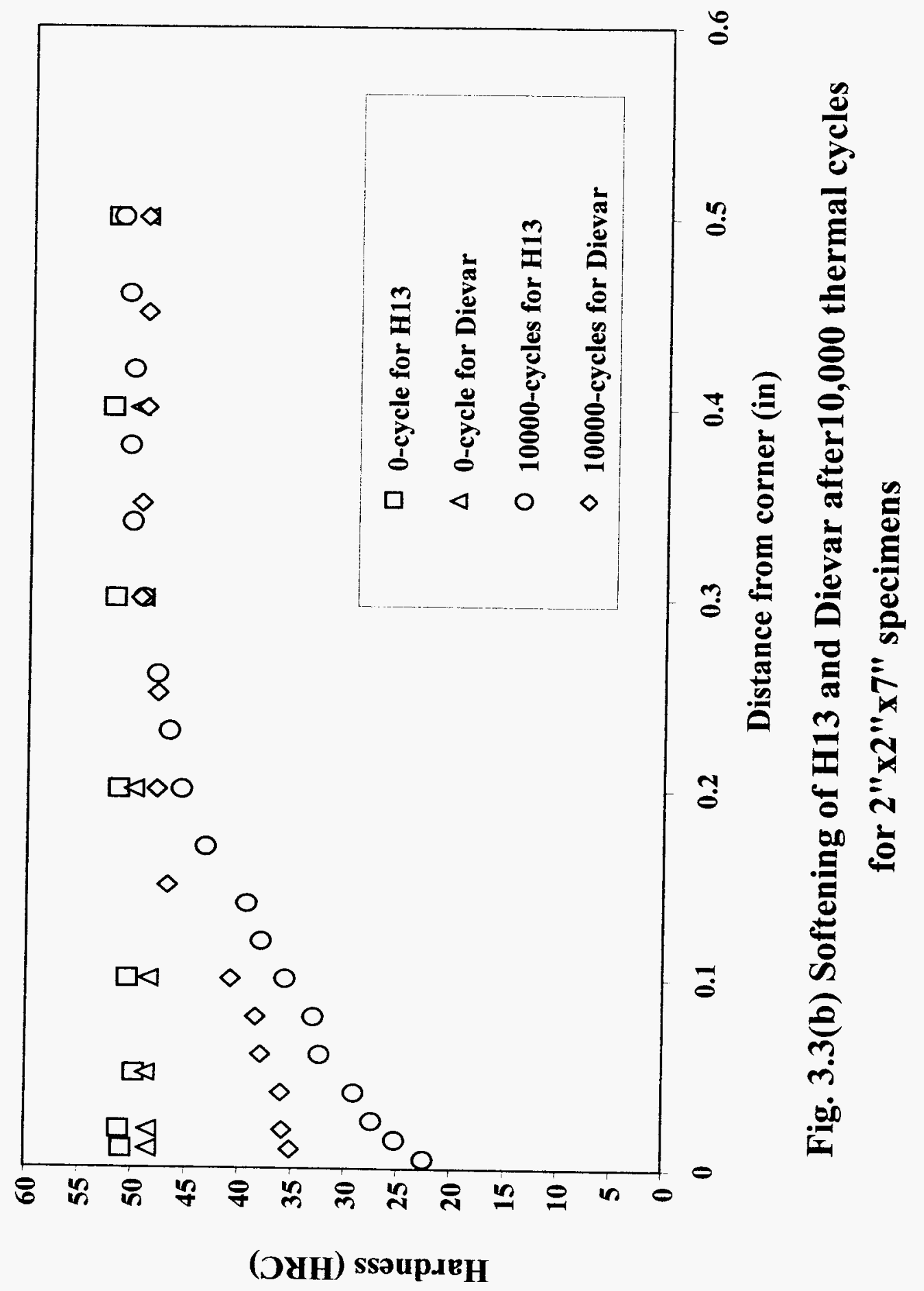




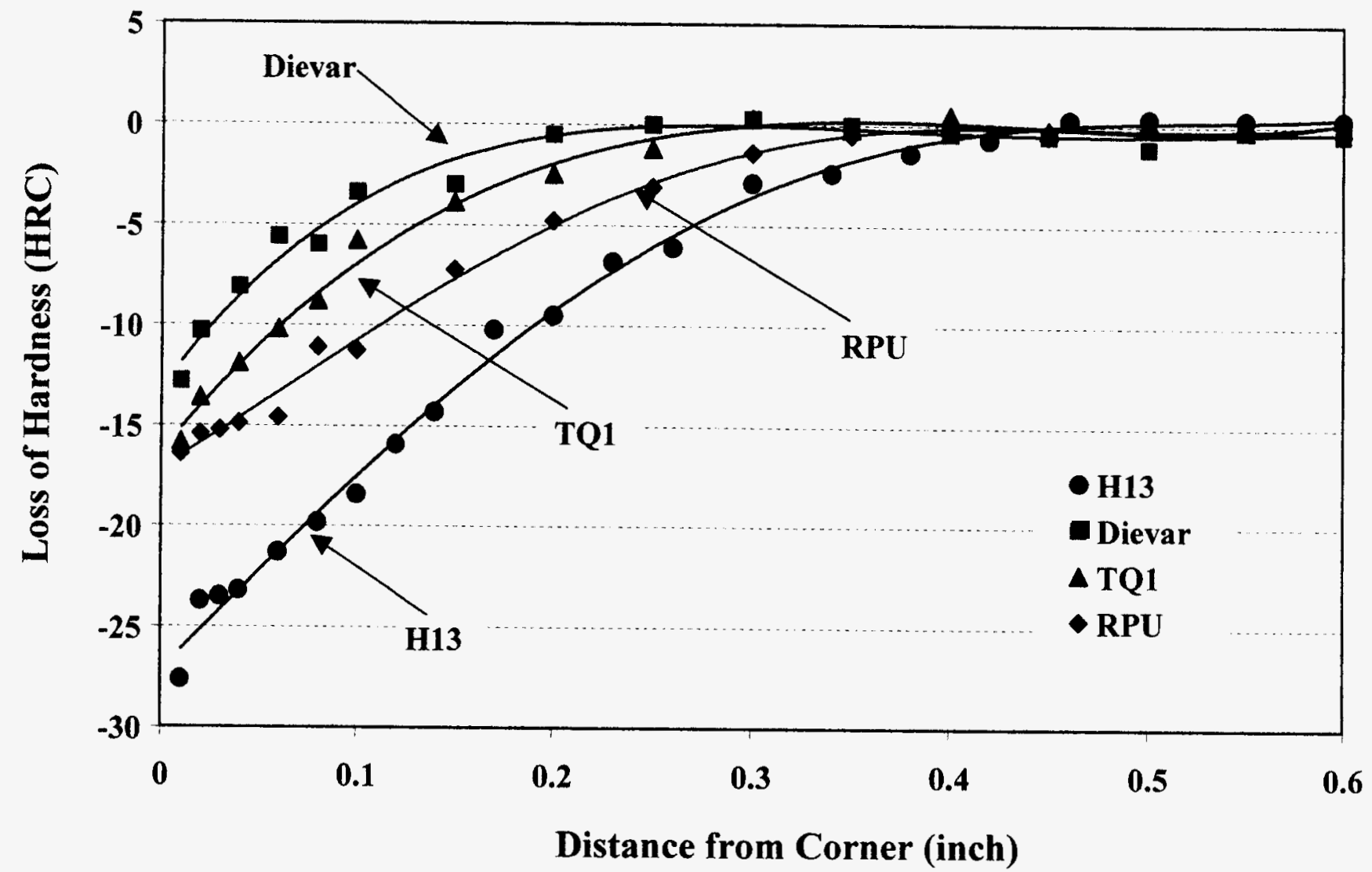

Fig. 3.4(a) Softening of Dievar,TQ1,RPU and H13 after 15,000 thermal cycles for $2 " x 2 " x 7 "$ specimens 


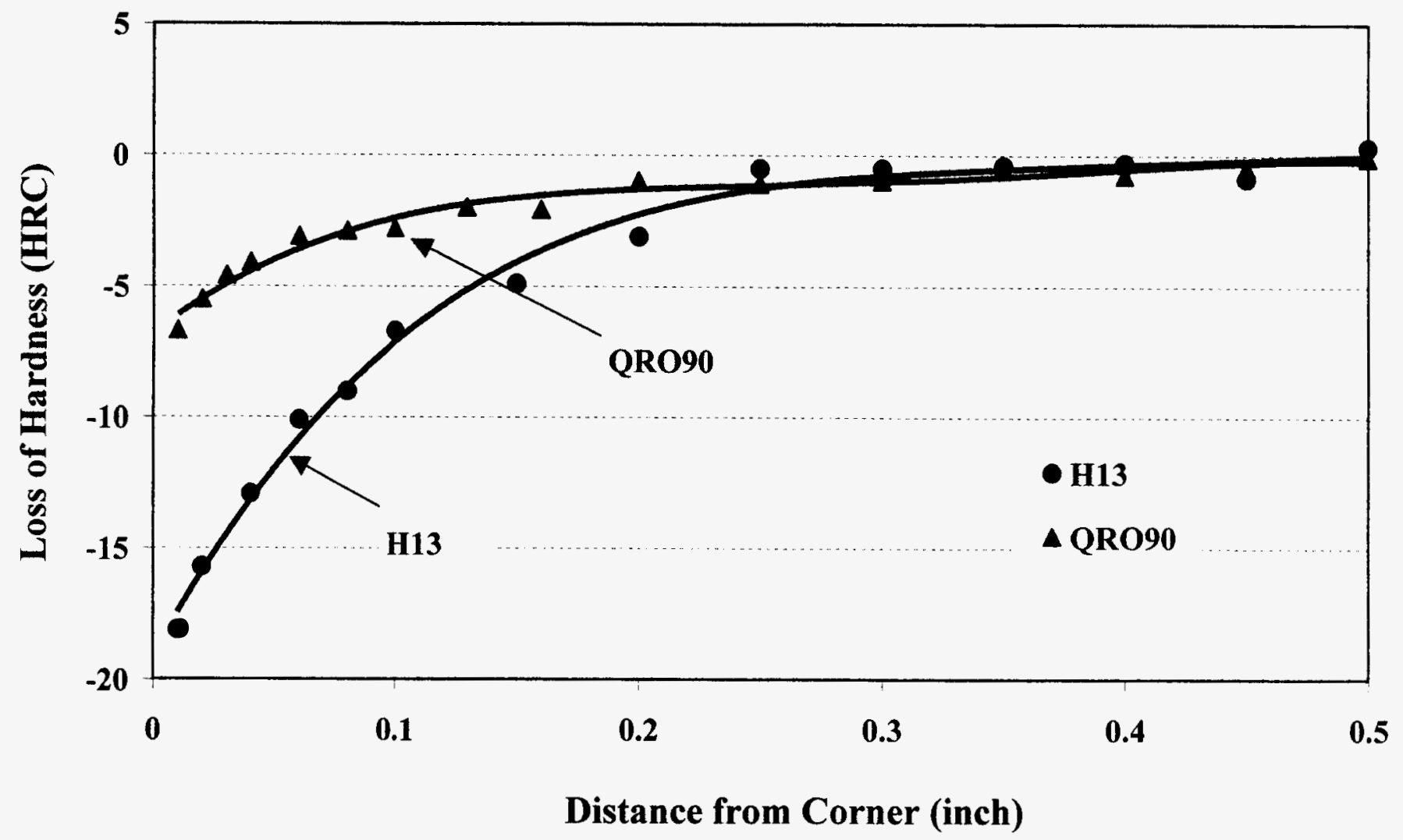

Fig.3.4(b) Softening of QRO90 and H13 after 15,000 thermal cycles for $1 " x 1 " x 7 "$ specimens 

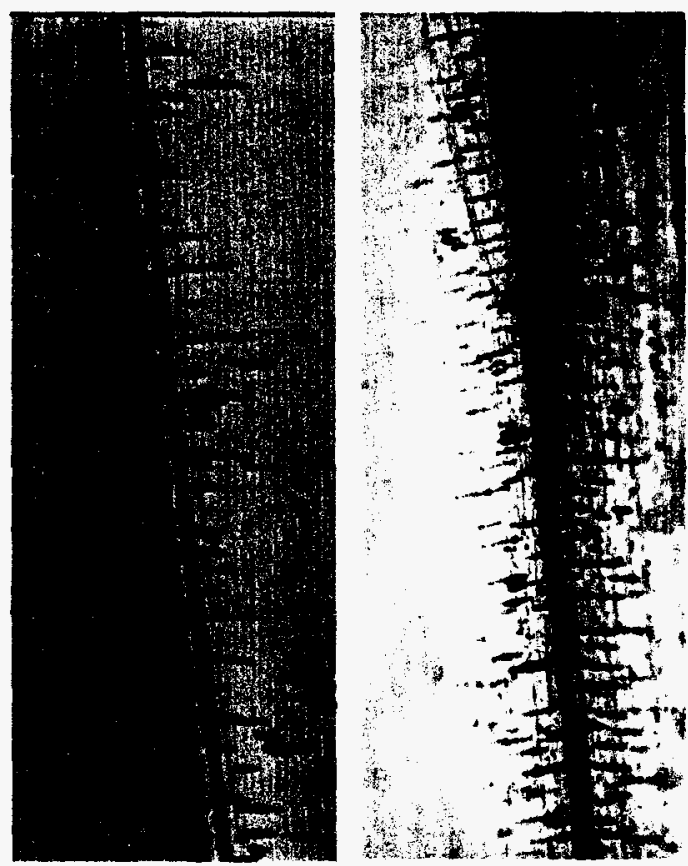

DIEVAR

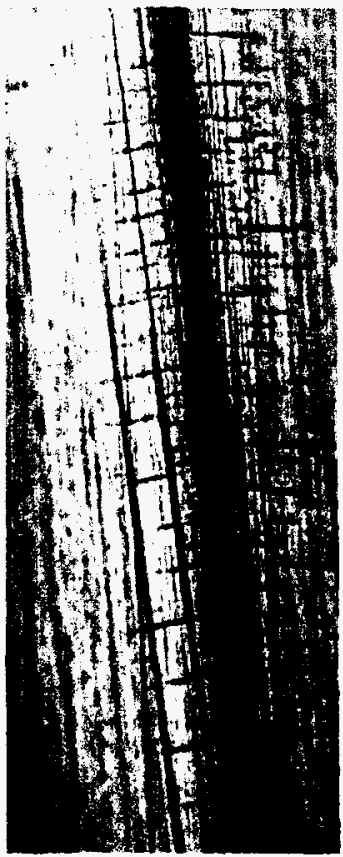

QRO90

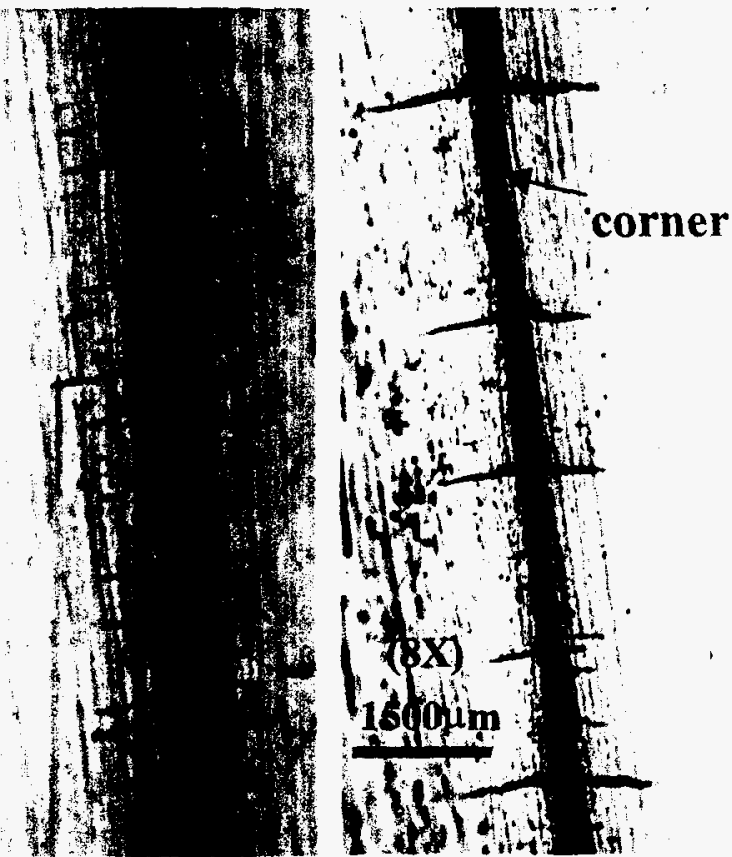

TQ1

H13

Fig.3.5 Thermal fatigue cracks in five die steels after 15,000 thermal cycles 


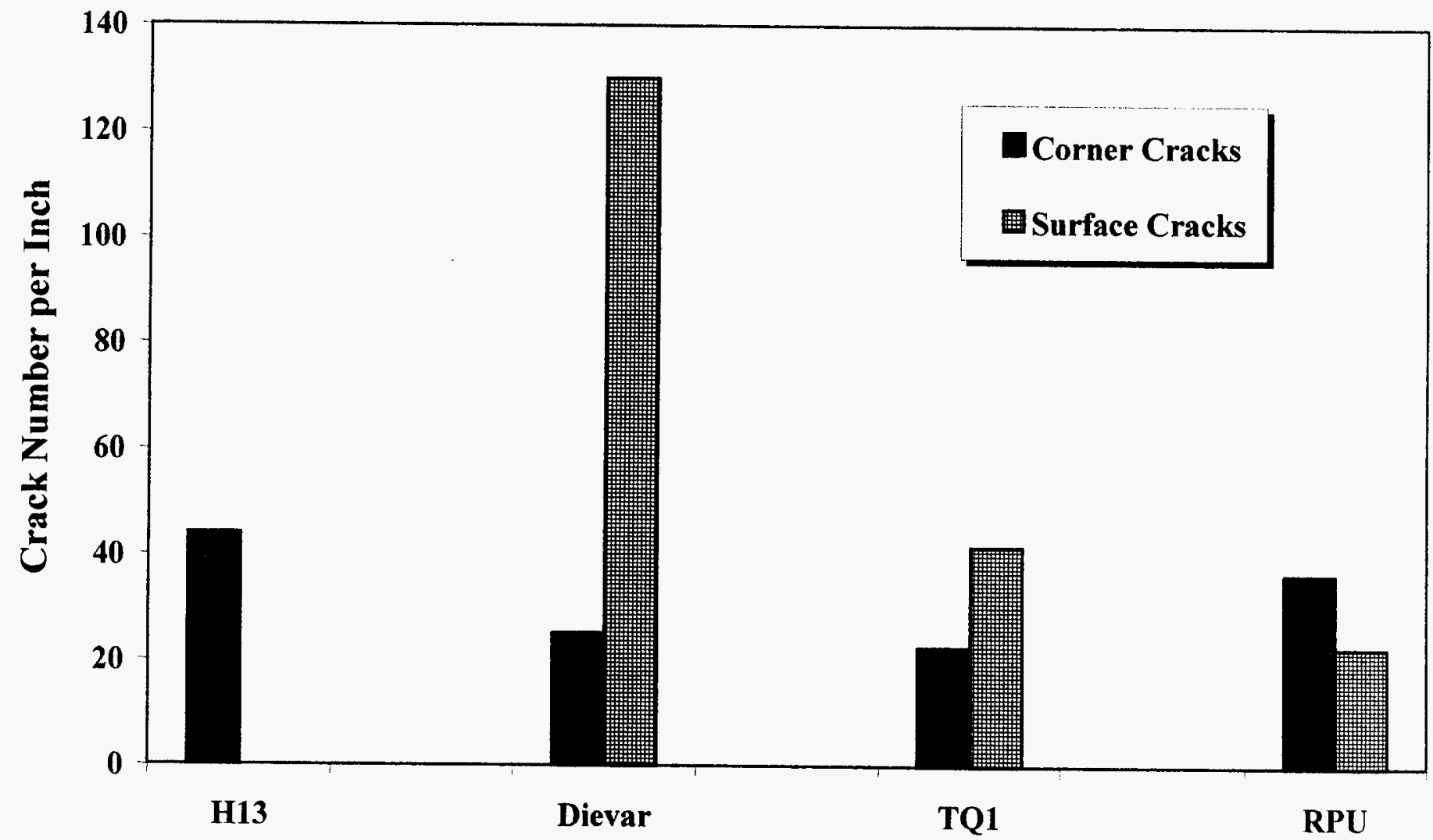

Fig. 3.6(a) Crack number of Dievar,TQ1,RPU and H13 after 15,000 thermal cycles for $2 " \mathrm{x} 2 " \mathrm{x} 7 "$ specimens 


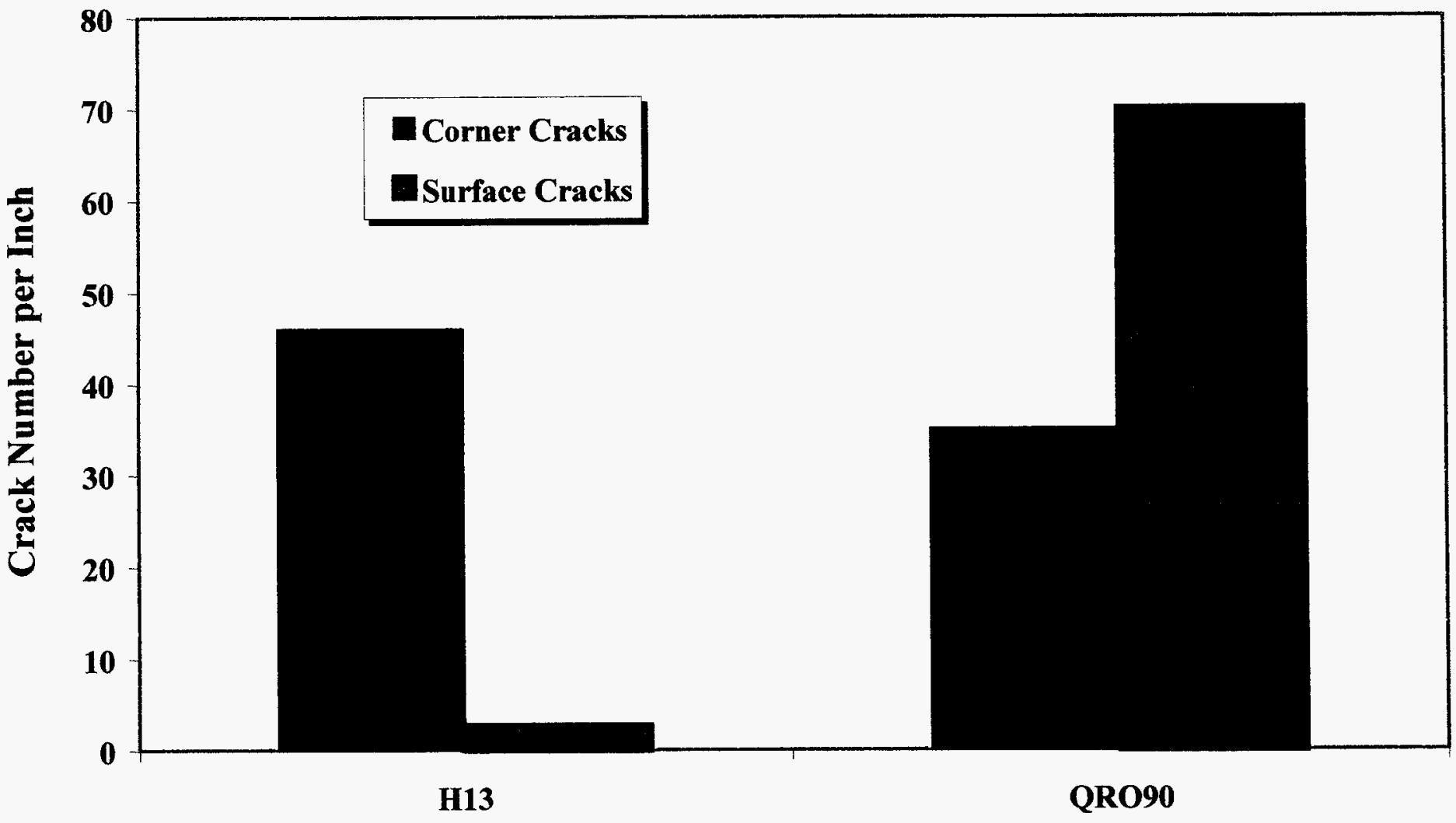

Fig. 3.6(b) Crack number of QRO90 and H13 after 15,000 thermal cycles for $2 " \times 2 " \times 7 "$ specimens 


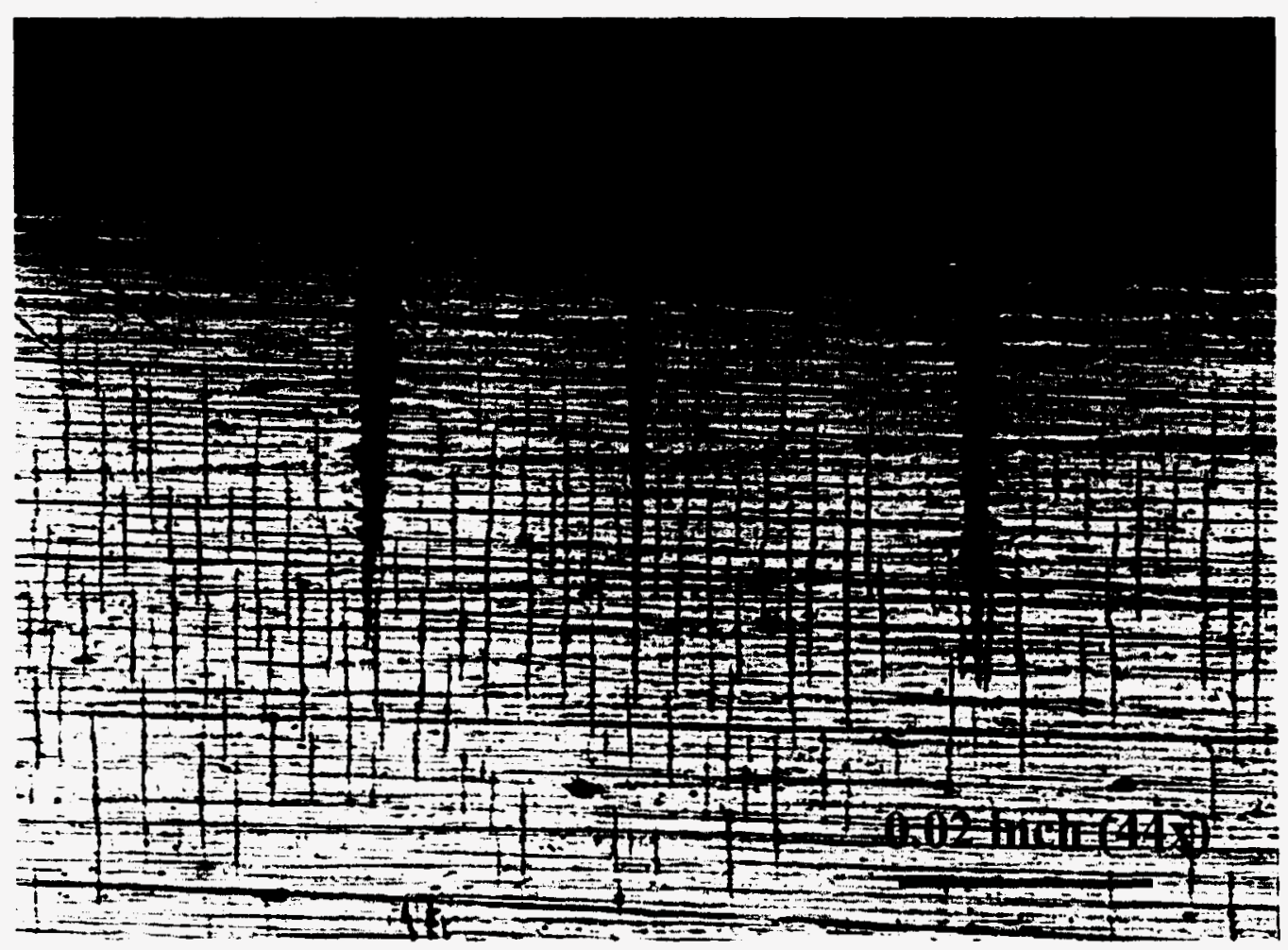

Fig. 3.7 Corner cracks and surface cracks of H13 


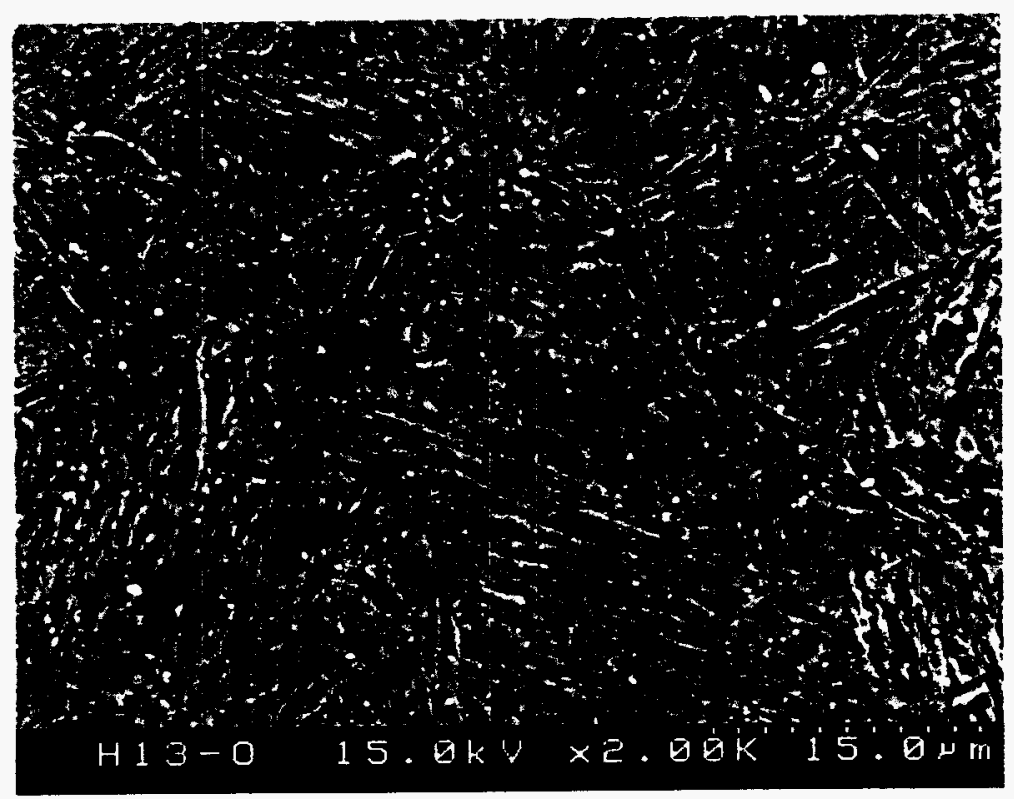

Fig. 3.8(a) Micrograph of the microstructure of H13, as quenched

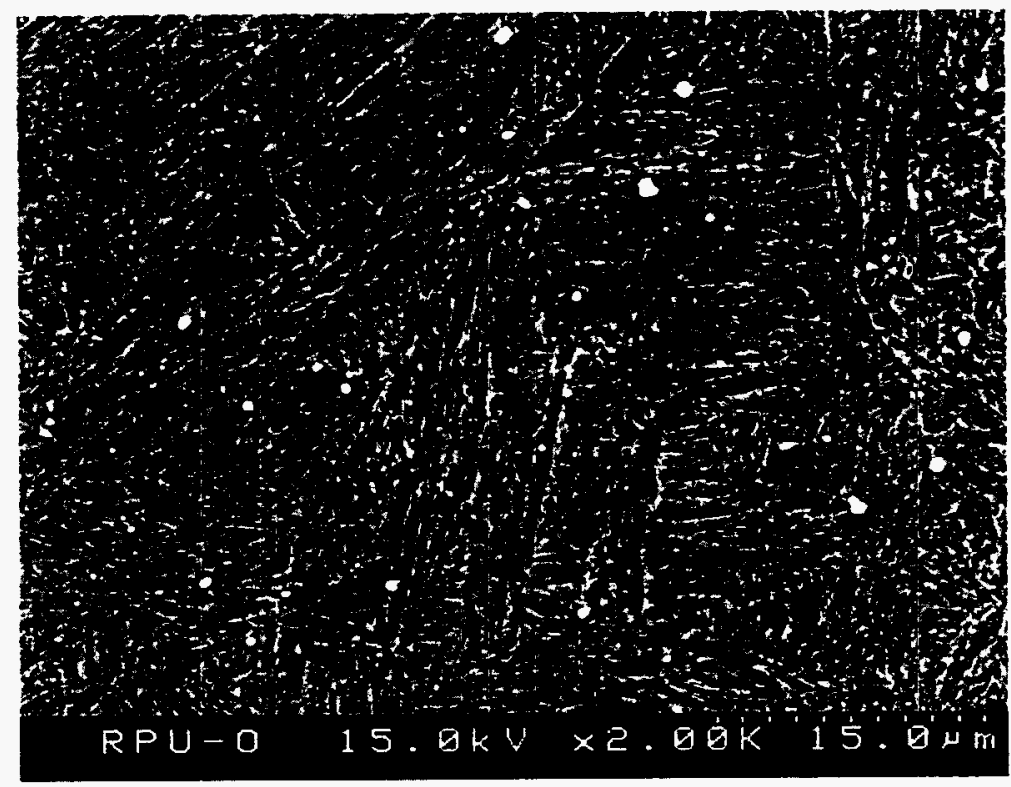

Fig.3.8(b) Micrograph of the microstructure of RPU, as quenched 


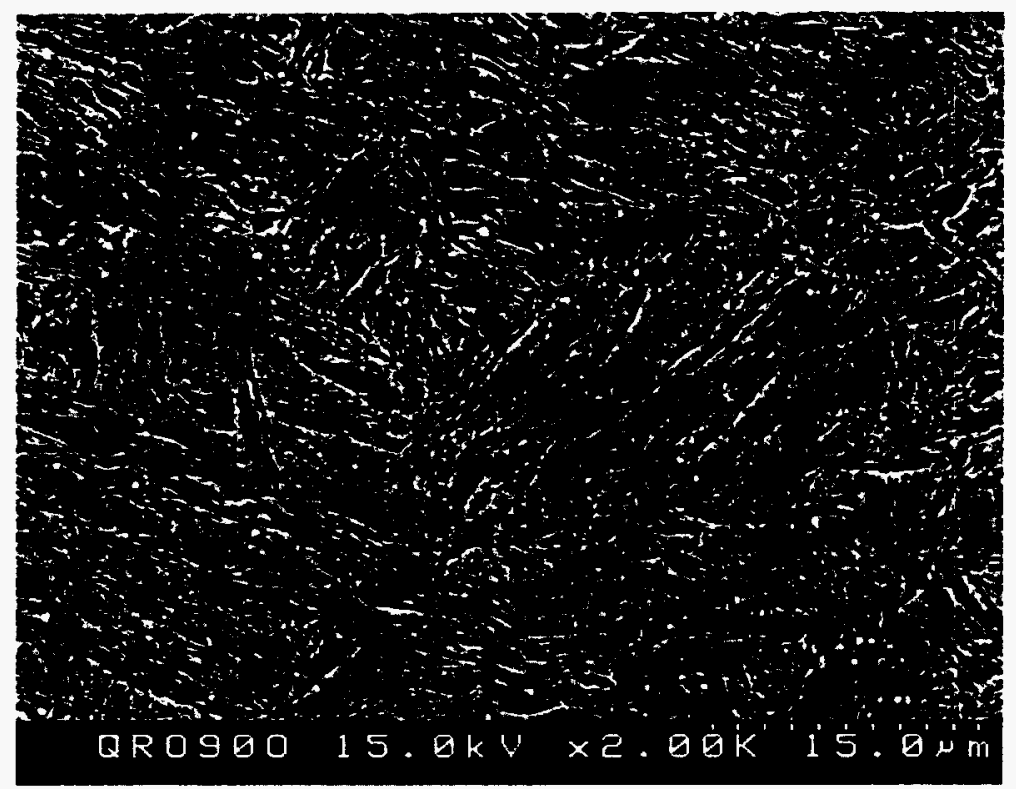

Fig. 3.8(c) Micrograph of microstructure of QRO90, as quenched

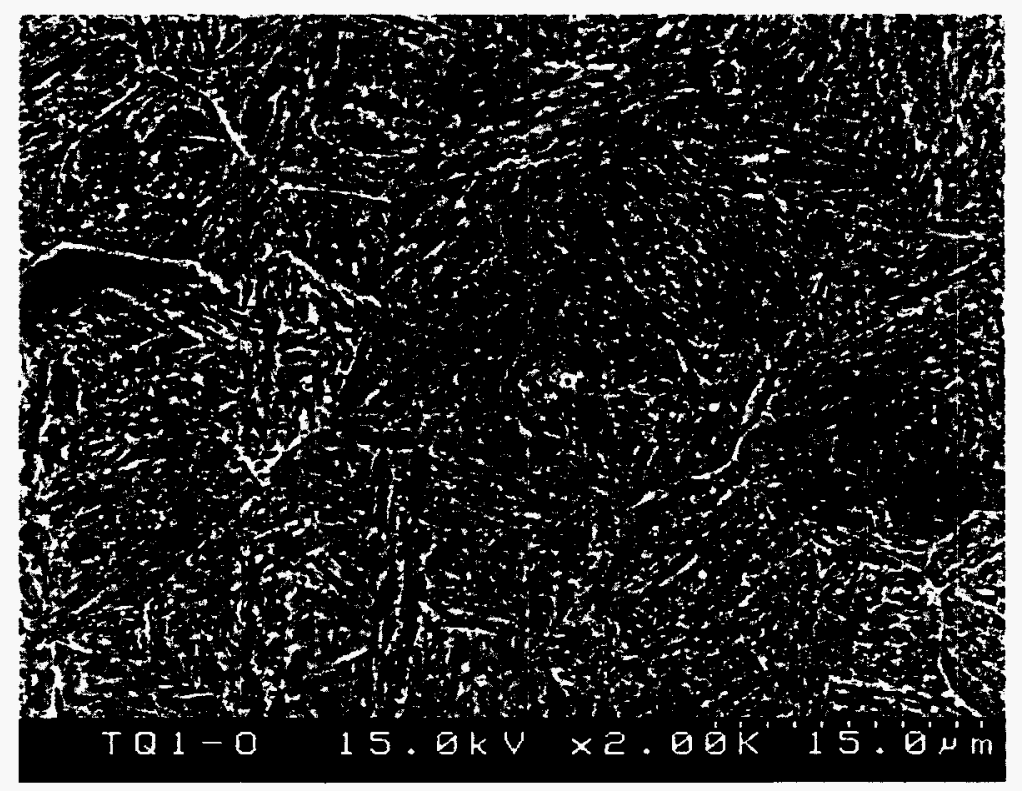

Fig.3.8(d) Micrograph of microstructure of TQ1, as quenched 


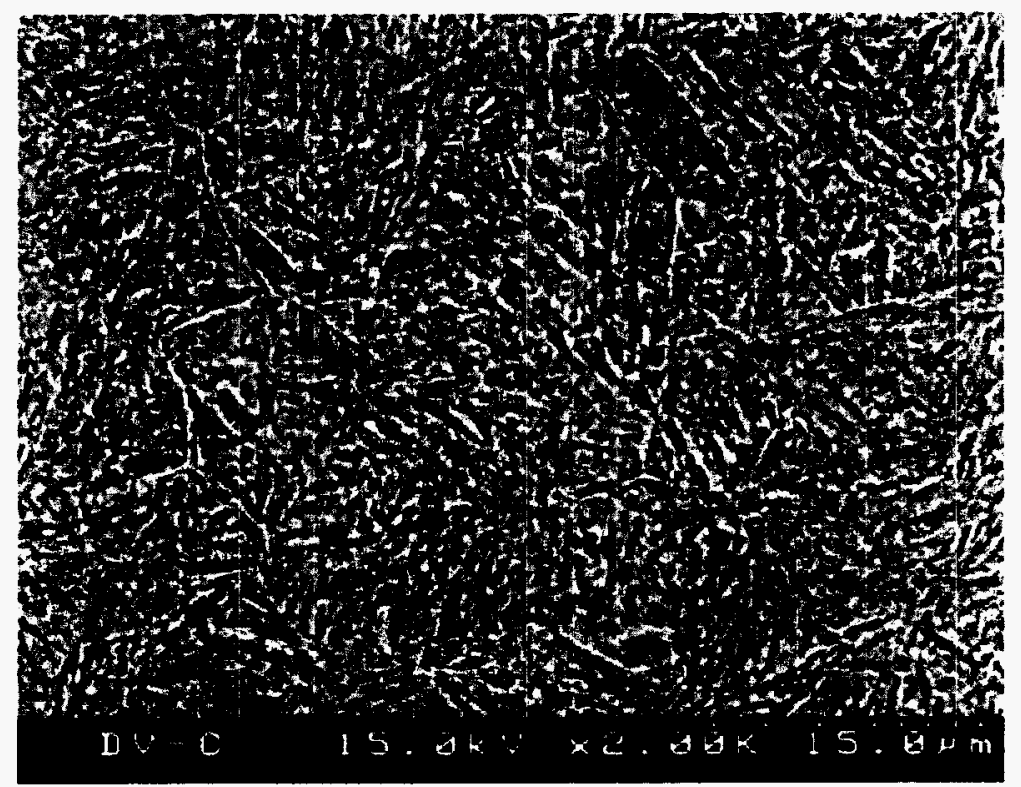

Fig.3.8(e) Micrograph of the microstructure of Dievar, as quenched 


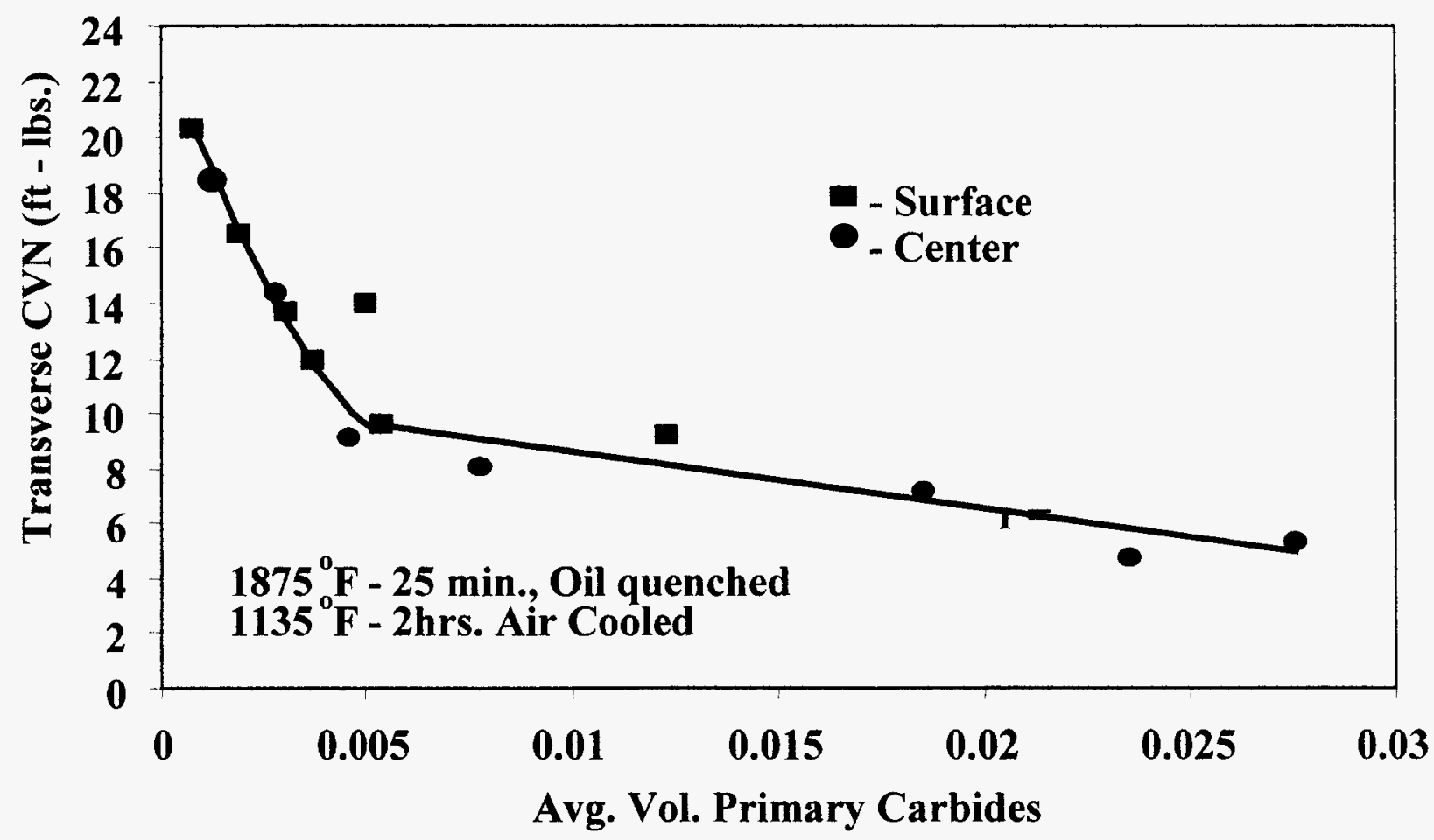

Fig.3.9 Effect of volume percent primary carbides on the transverse Charpy $\bar{v}$ notch impact toughness of $\mathrm{H} 13$ 


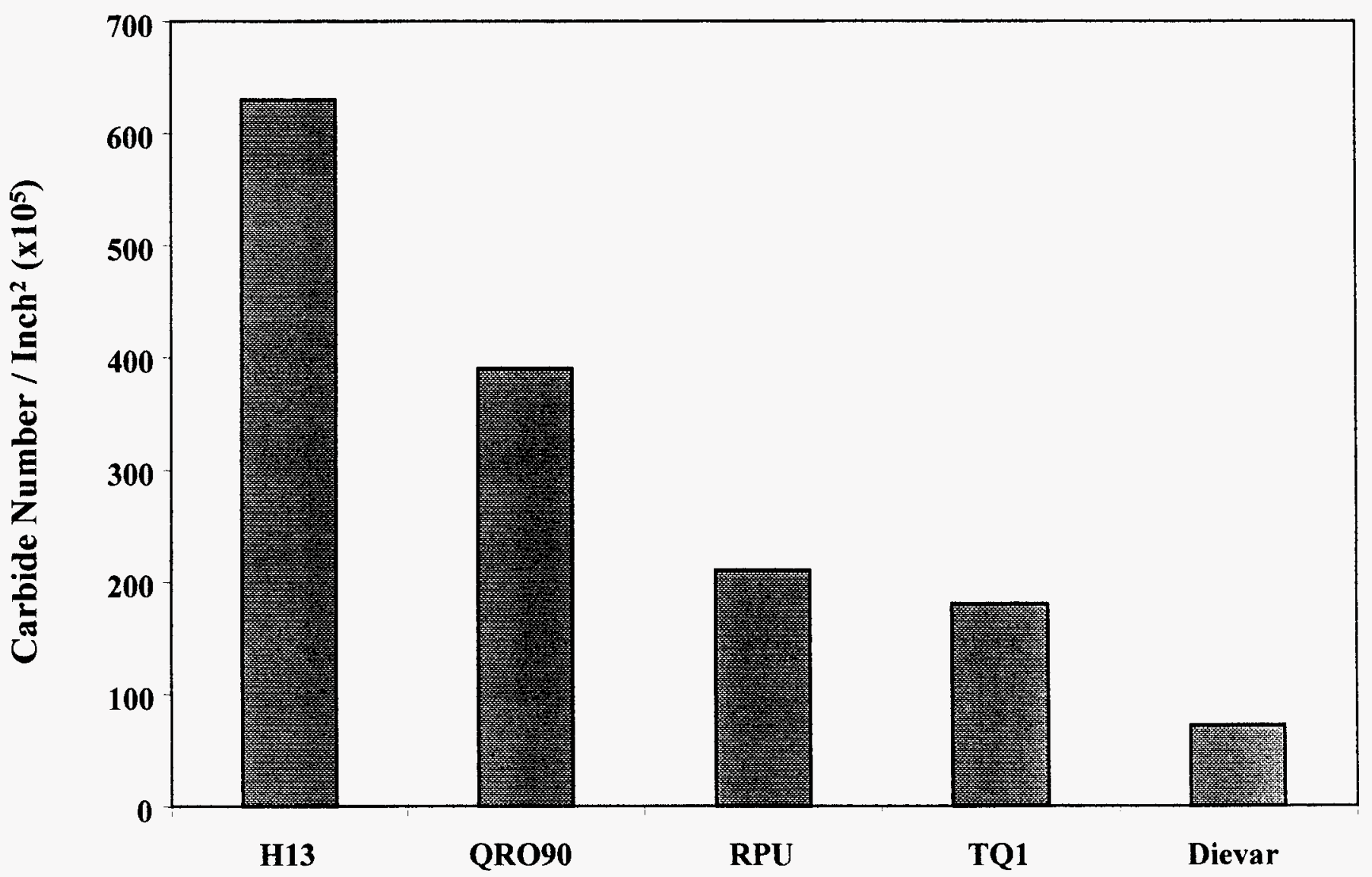

Fig .3.10 Carbide number in five steels as quenched conditions 


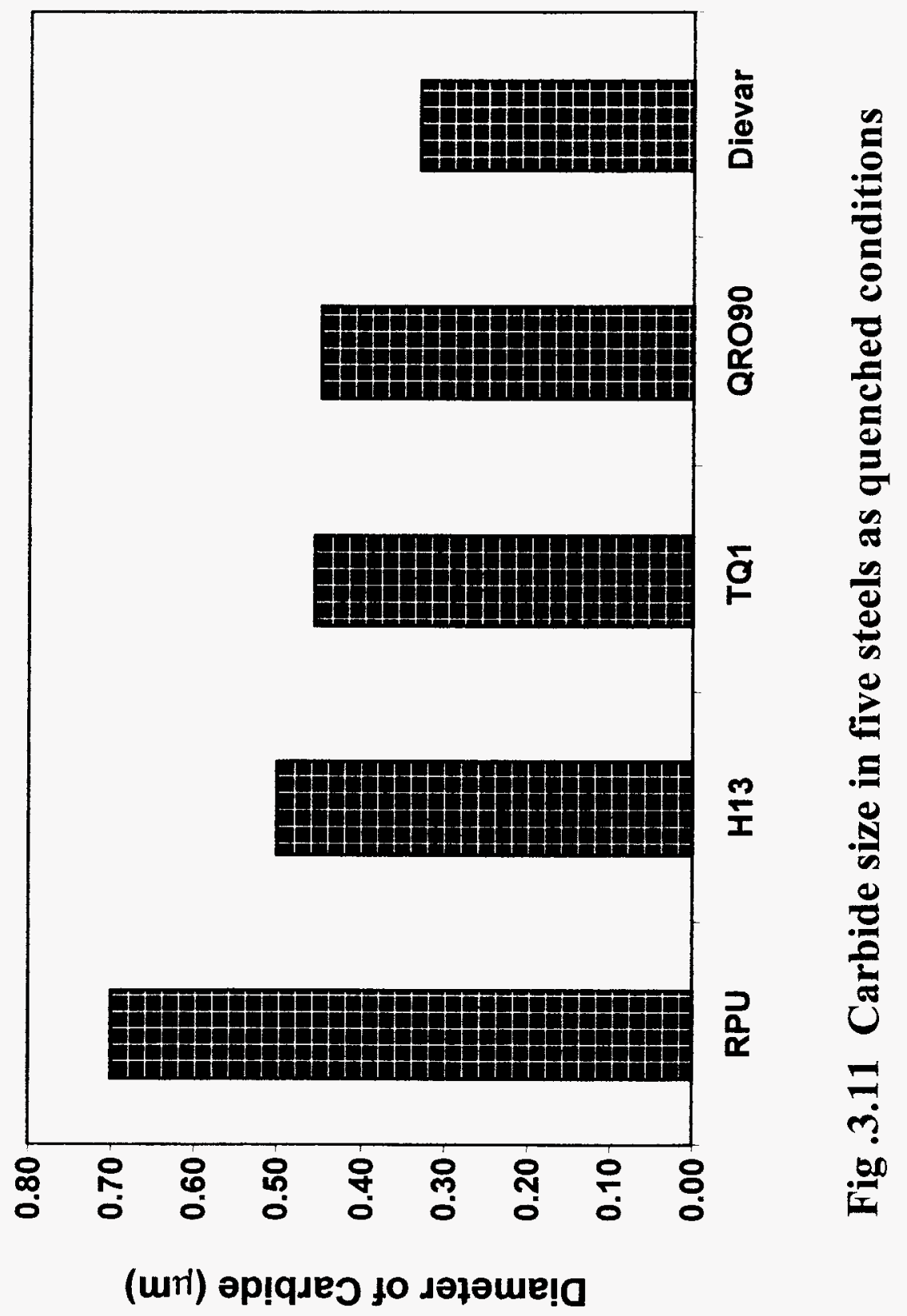




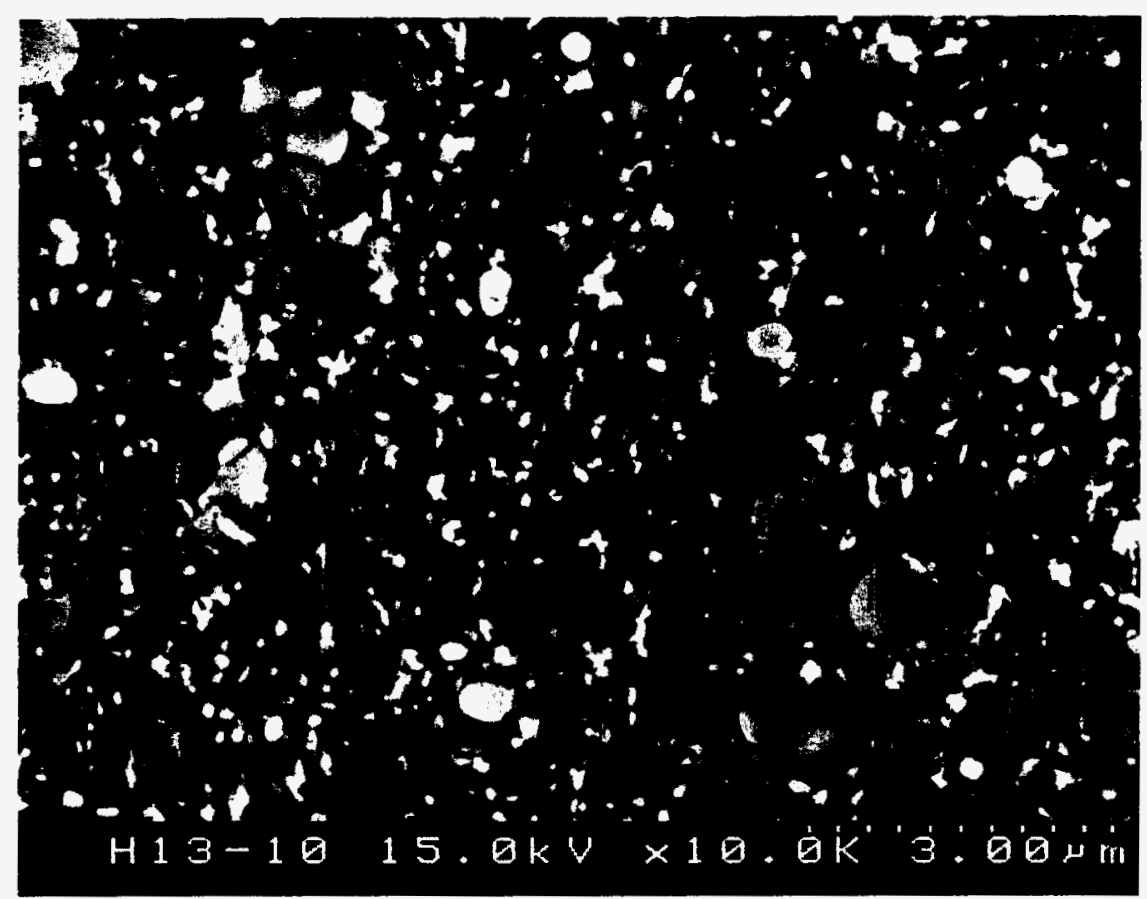

Fig. 12(a) SEM micrograph of H13 after 10-hour tempering under $1200^{\circ} \mathrm{F}$

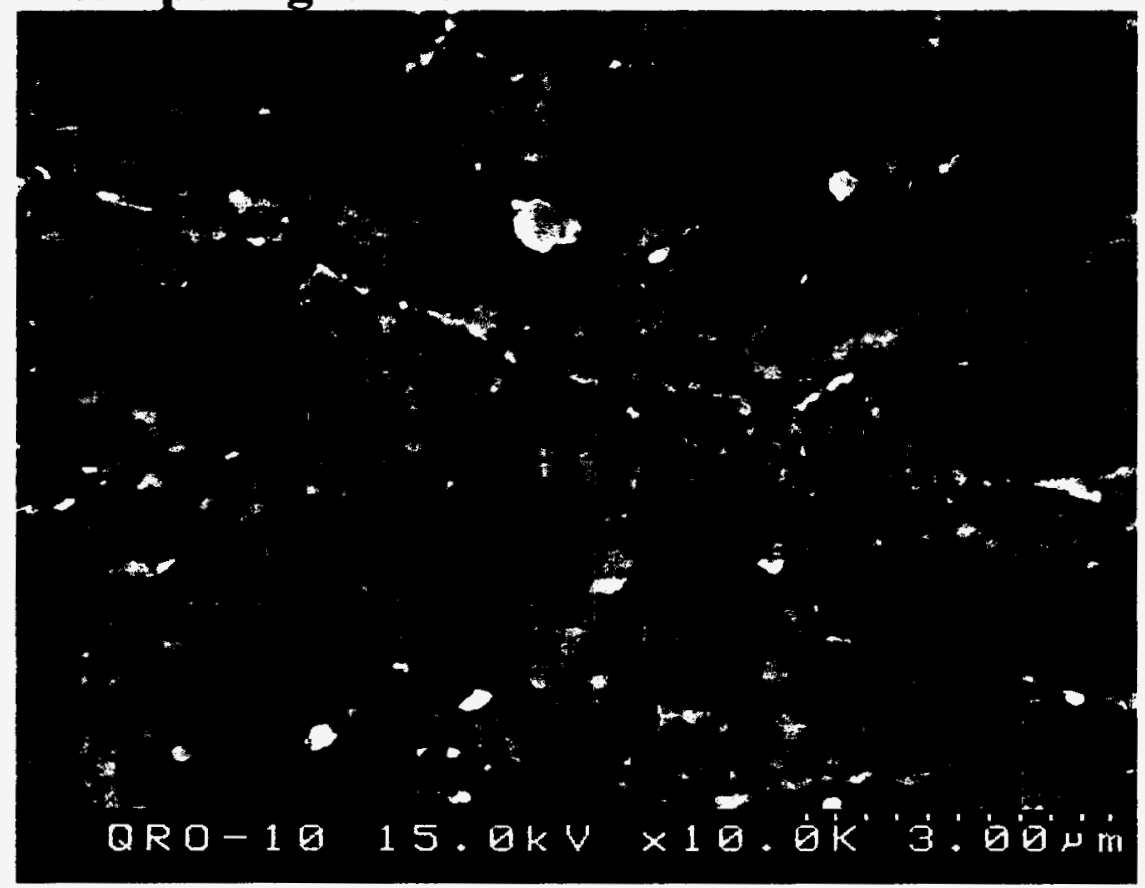

Fig. 12(b) SEM micrograph of QRO90 after 10-hour tempering under $1200^{\circ} \mathrm{F}$ 


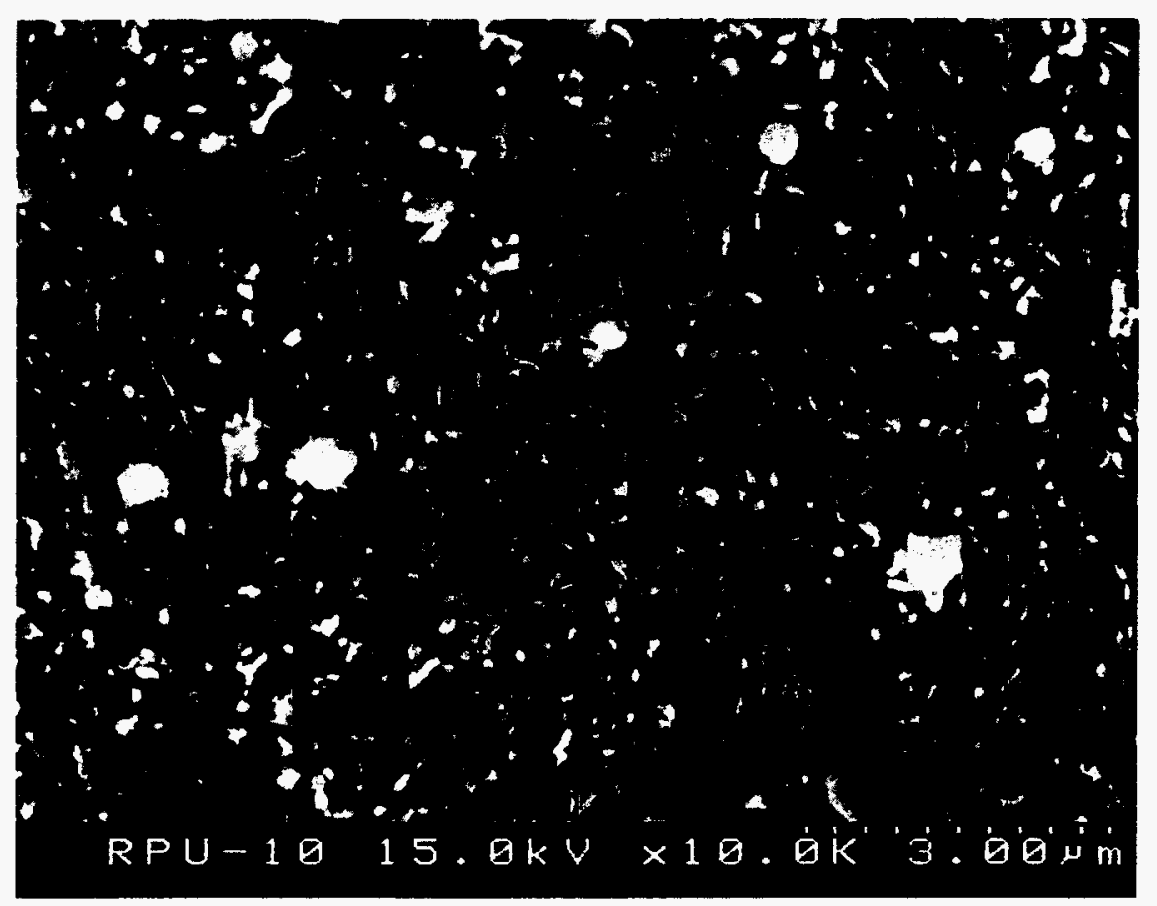

Fig. 12(c) SEM micrograph of RPU after 10-hour tempering under $1200^{\circ} \mathrm{F}$

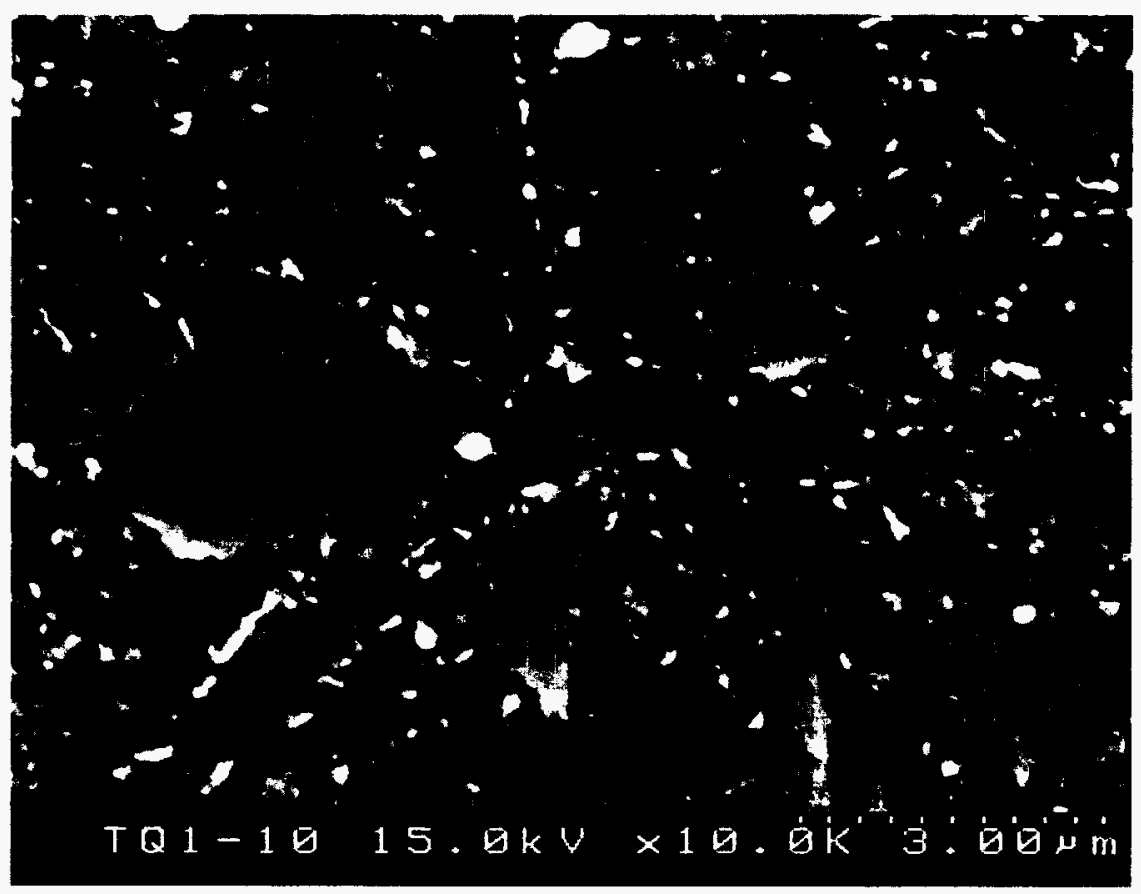

Fig. 12(d) SEM micrograph of TQ1 after 10-hour tempering under $1200^{\circ} \mathrm{F}$ 


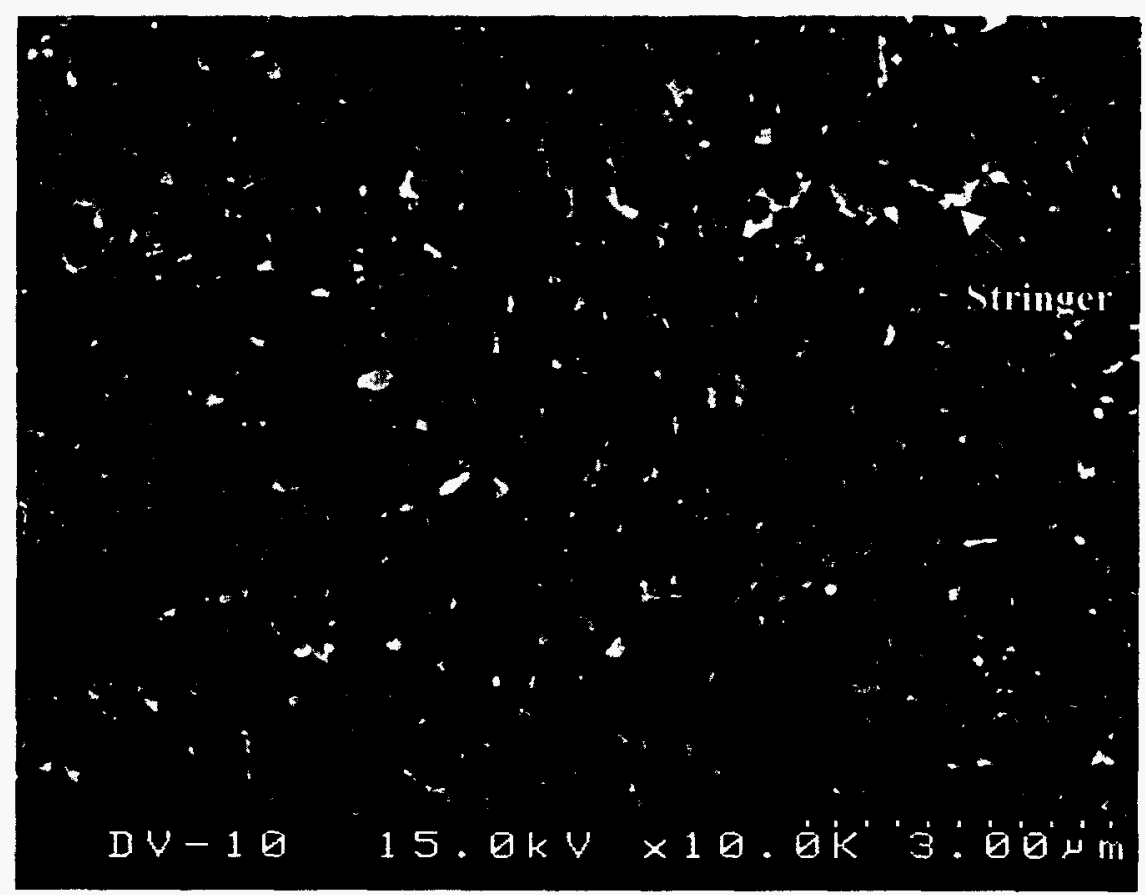

Fig. 12(e) SEM micrograph of Dievar after 10-hour tempering under $1200^{\circ} \mathrm{F}$ 


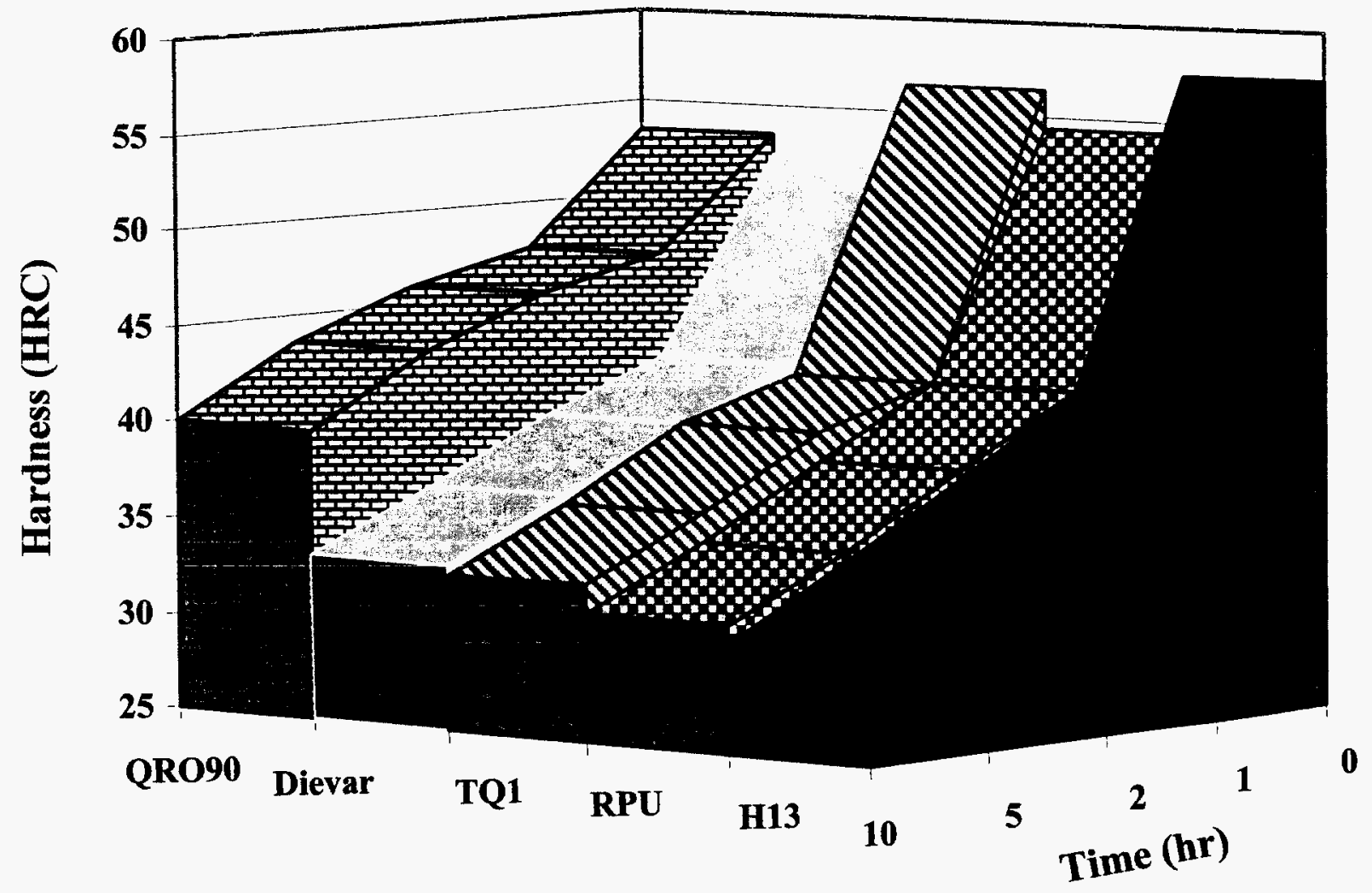

Fig .3 . 13 Effect of tempering time on the hardness of five steels 
Die 4 on Quenching lixture at Fuclid H.T.

\section{Figure 6.1}

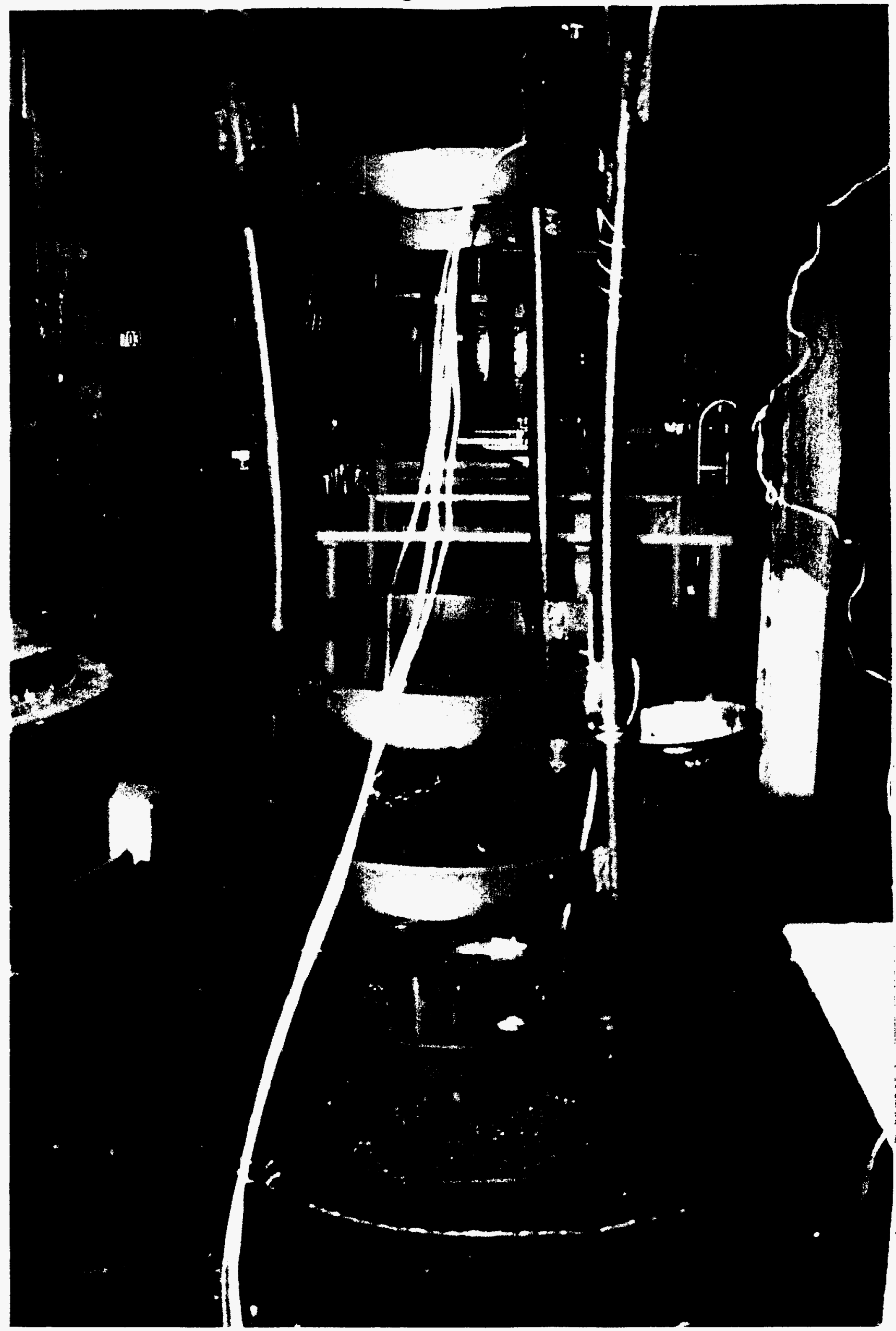


Figure 6.2:

\section{INTERRUPTED OIL QUENCH OF DIE \#4 AT EUCLID HEAT TREATING}

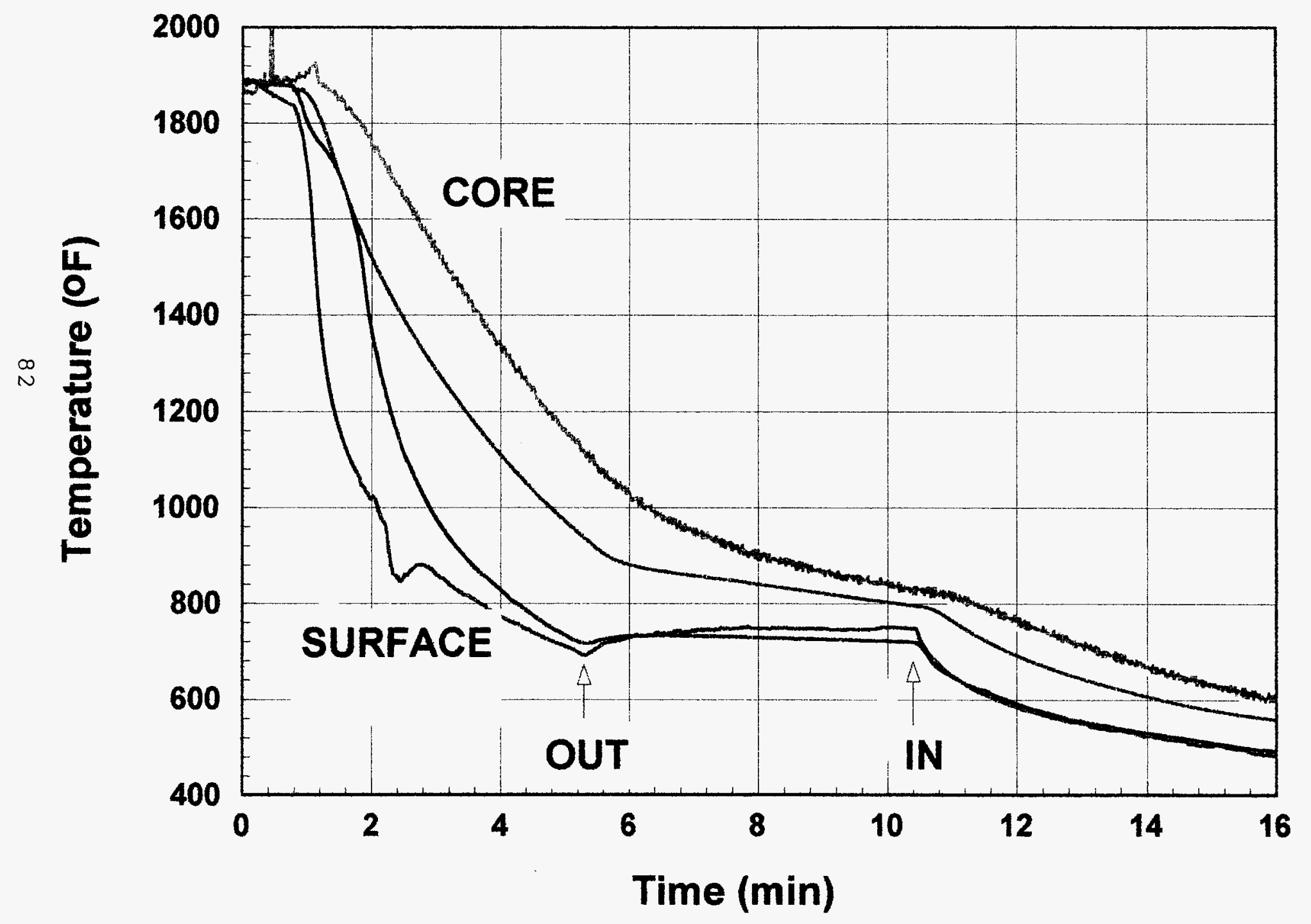


Fiqure 6.3: Surface Plot of Die 4 - Side 1 Interrupted Oil Quench

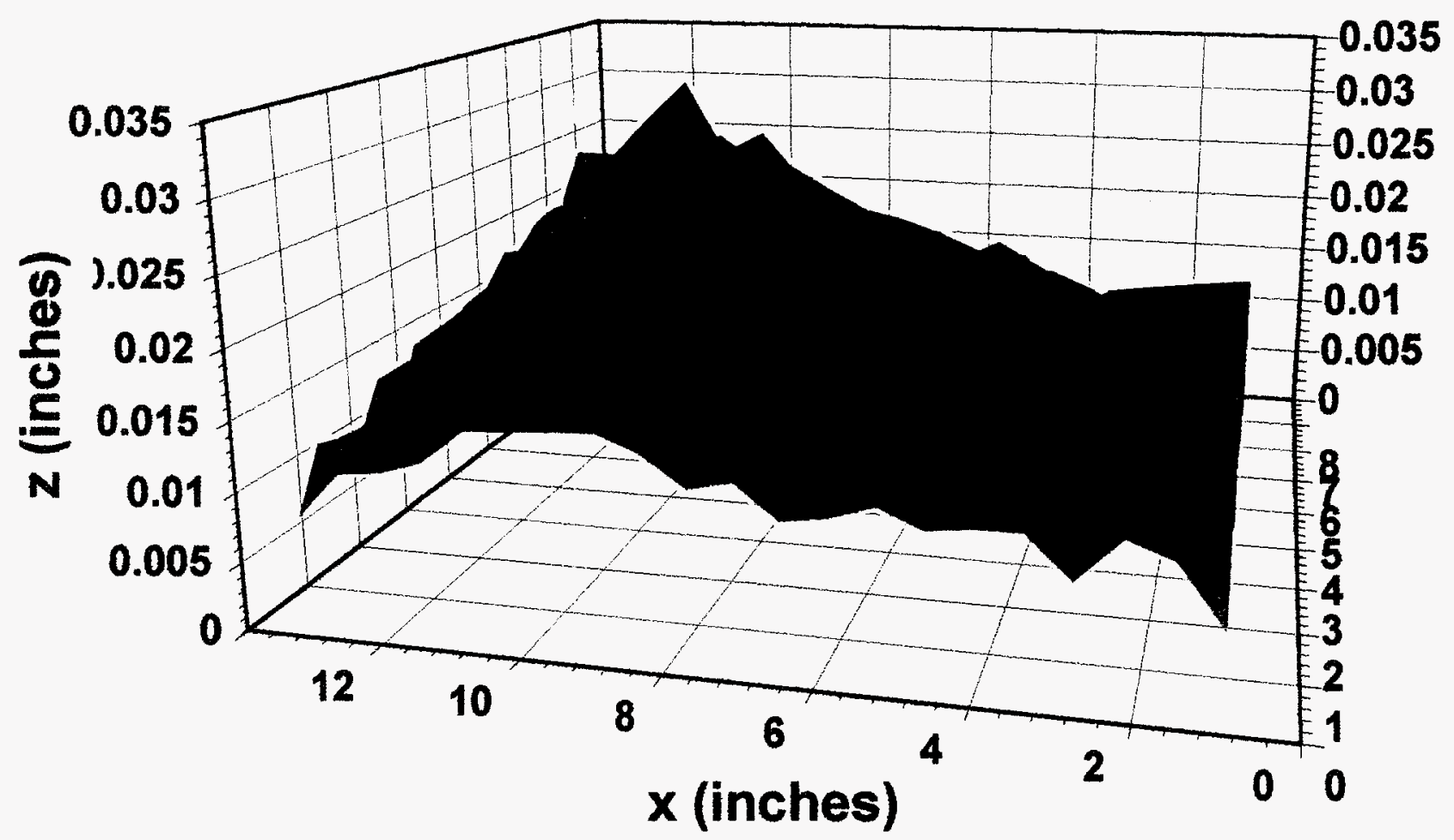

0.028 t
0.023 to 0.028
0.017 to 0.023
0.011 to 0.017
0.006 to 0.011
0.000 to 0.006
-0.006 to 0.000
-0.011 to -0.006
-0.017 to -0.011
-0.023 to -0.017
-0.028 to -0.023
-0.034 to -0.028

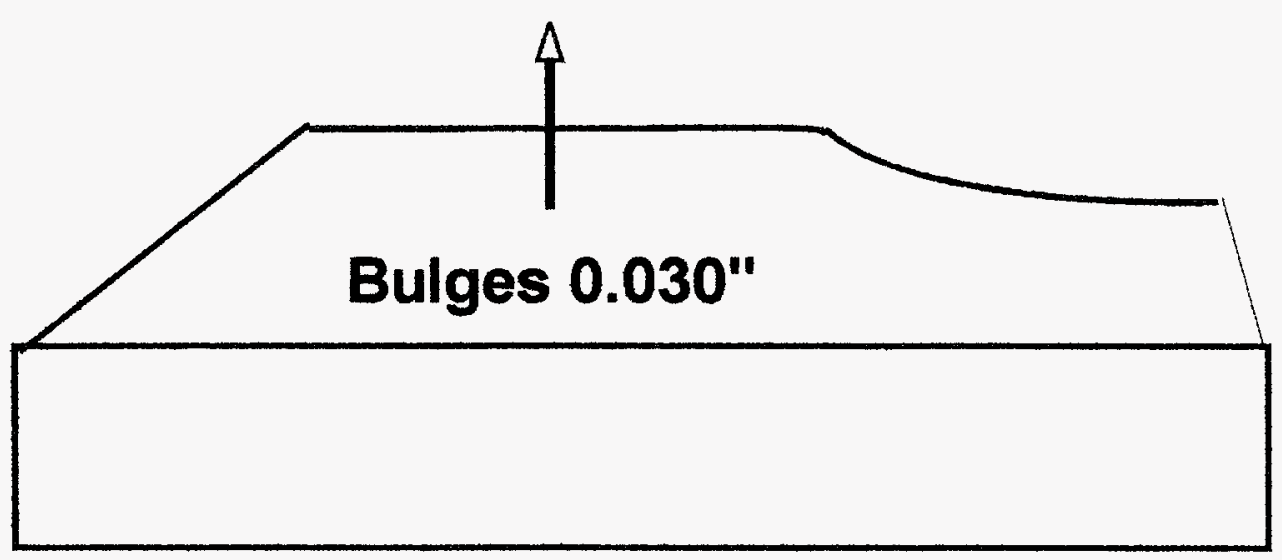


Figure 6.4:

\section{Contour Plot of Die 4 - Side 1 Interrupted Oil Quench}

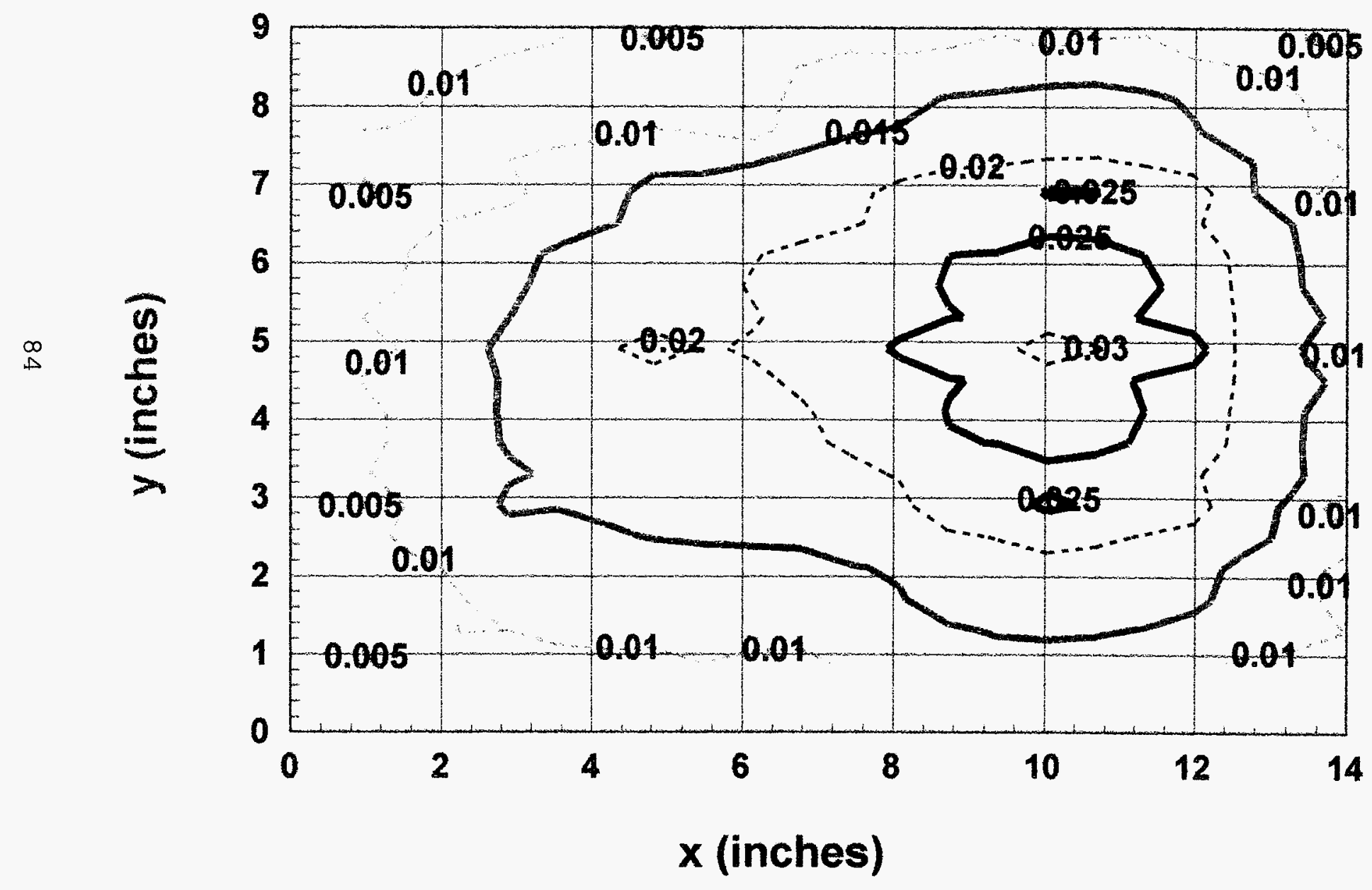

\begin{tabular}{|l|}
\hline $0.03+$ \\
0.03 to 0.03 \\
0.03 to 0.03 \\
0.02 to 0.03 \\
0.02 to 0.02 \\
0.02 to 0.02 \\
0.01 to 0.02 \\
0.01 to 0.01 \\
0.01 to 0.01 \\
0.01 to 0.01 \\
0.00 to 0.01 \\
0.00 to 0.00 \\
\hline
\end{tabular}


Figure 6.5: Vector Plot of Die 4 - Side 1 Interrupted Oil Quench at Eucid Heat Treating

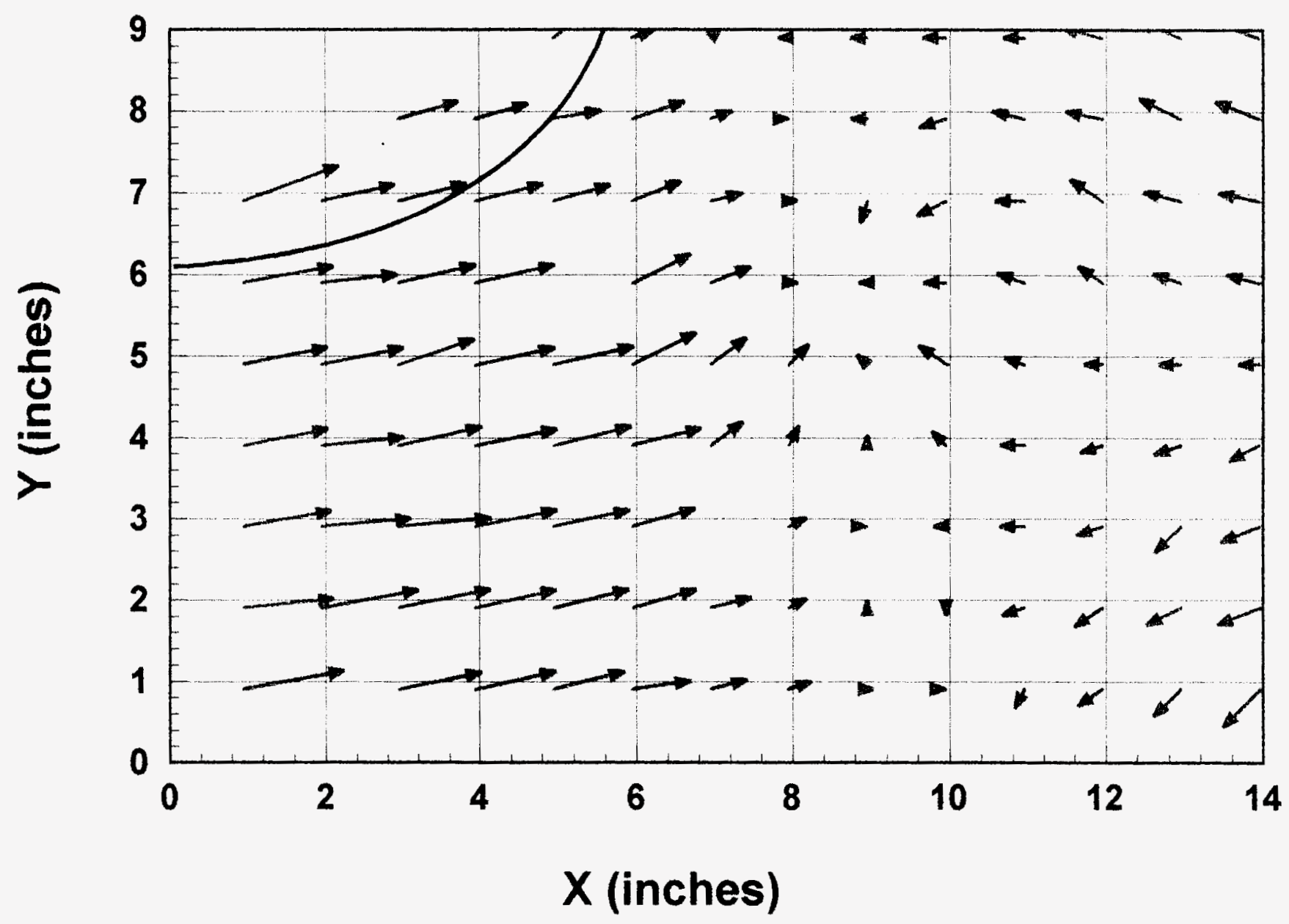

$\longrightarrow 0.015^{\prime \prime}$

The die block shrinks about $0.030^{\prime \prime}$ 


\section{Surface Plot of Die 4 - Side 3} Interrupted Oil Quench at Euclid

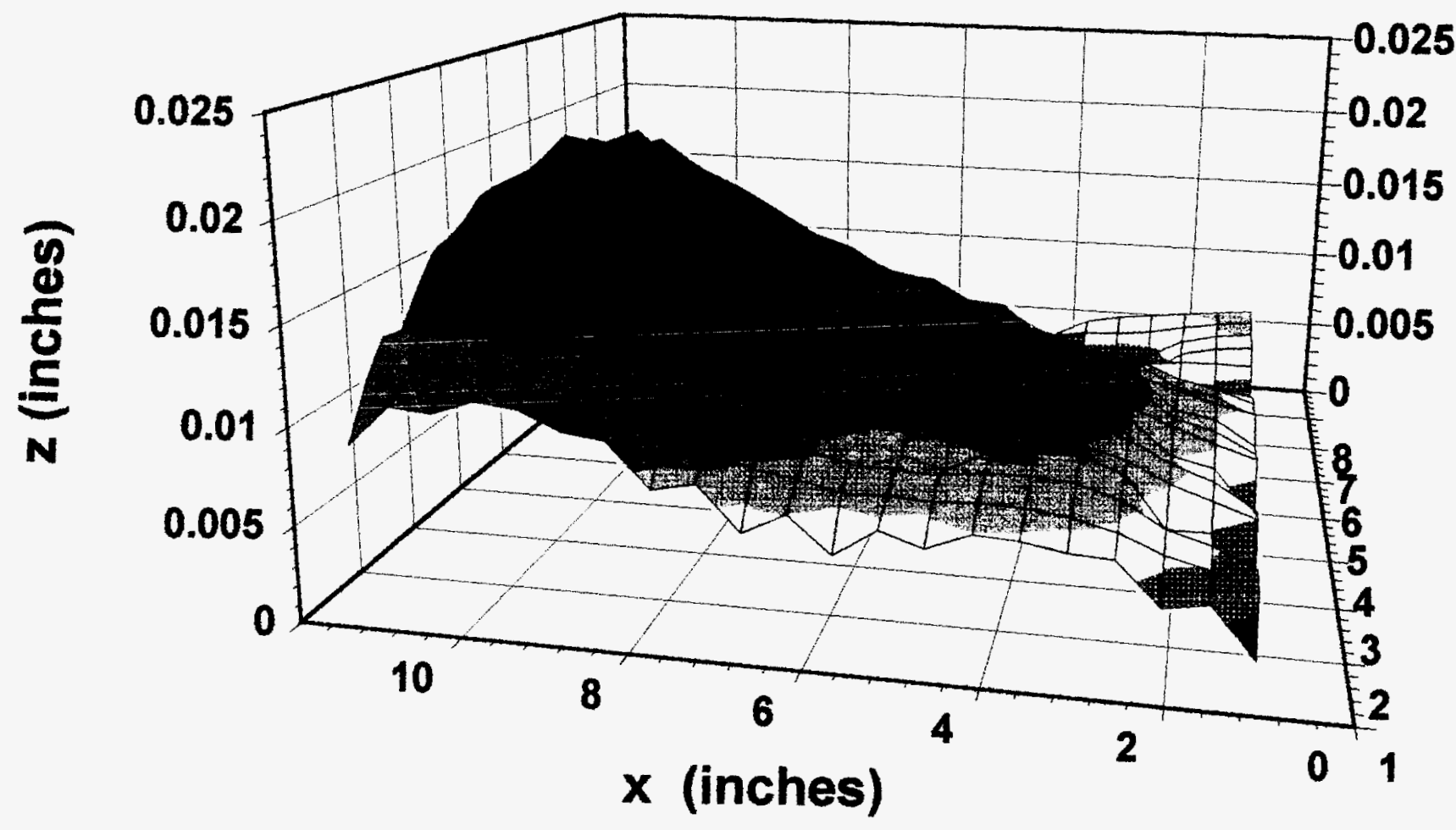

$0.02+$

0.02 to 0.02

0.02 to 0.02

0.01 to 0.02

0.01 to 0.01

0.01 to 0.01

0.01 to 0.01

0.01 to 0.01

0.01 to 0.01

0.00 to 0.01

0.00 to 0.00

0.00 to 0.00

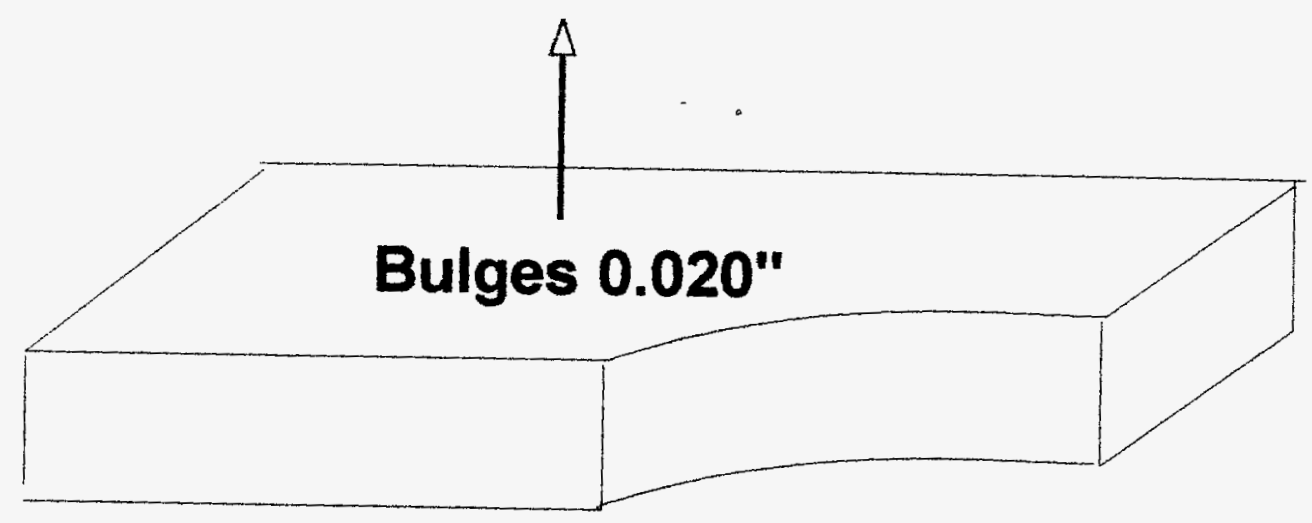


Figure 6.7:

\section{Contour Plot of Die 4 - Side 3 Interrupted Oil Quench at Euclid}

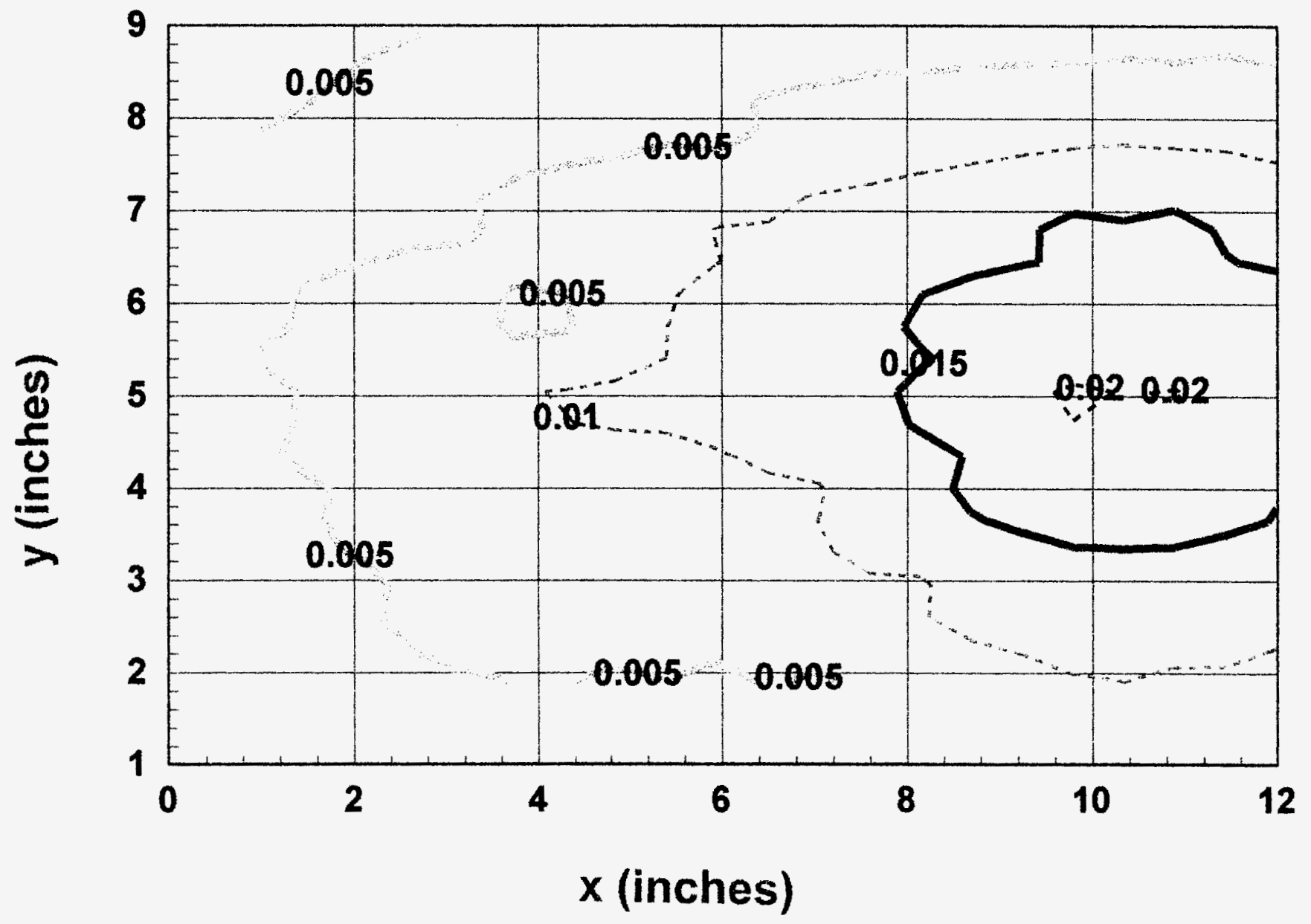

$0.019+$

0.017 to 0.019

0.016 to 0.017

0.014 to 0.016

0.012 to 0.014

0.010 to 0.012

0.009 to 0.010

0.007 to 0.009

0.005 to 0.007 0.003 to 0.005

0.002 to 0.003

0.000 to 0.002 
Figure 6.8: Vector Plot of Die 4 - Side 3 Interrupted Oil Quench at Euclid Heat Treating

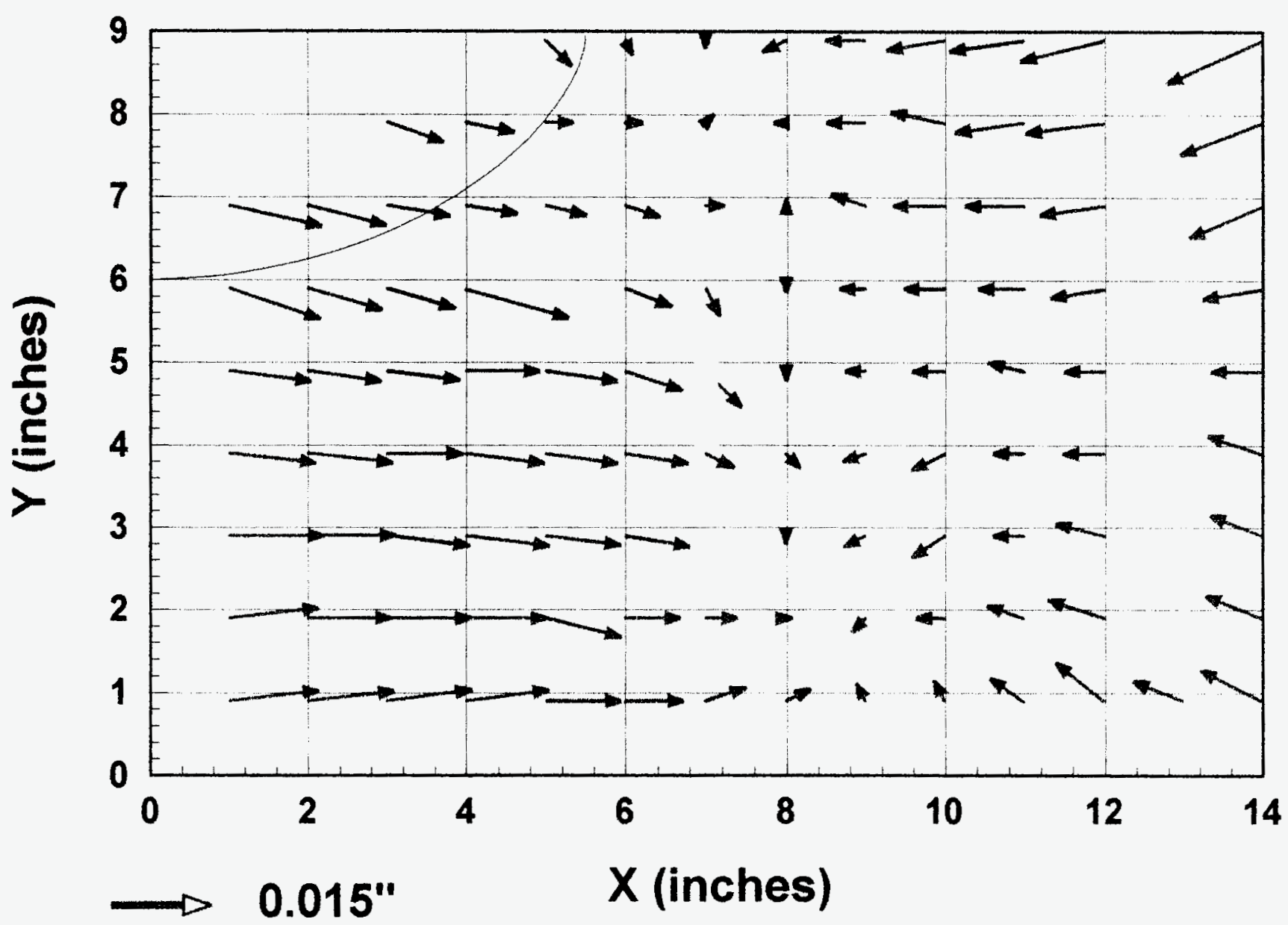




\section{Figure 6.9: Die Insert \#6}
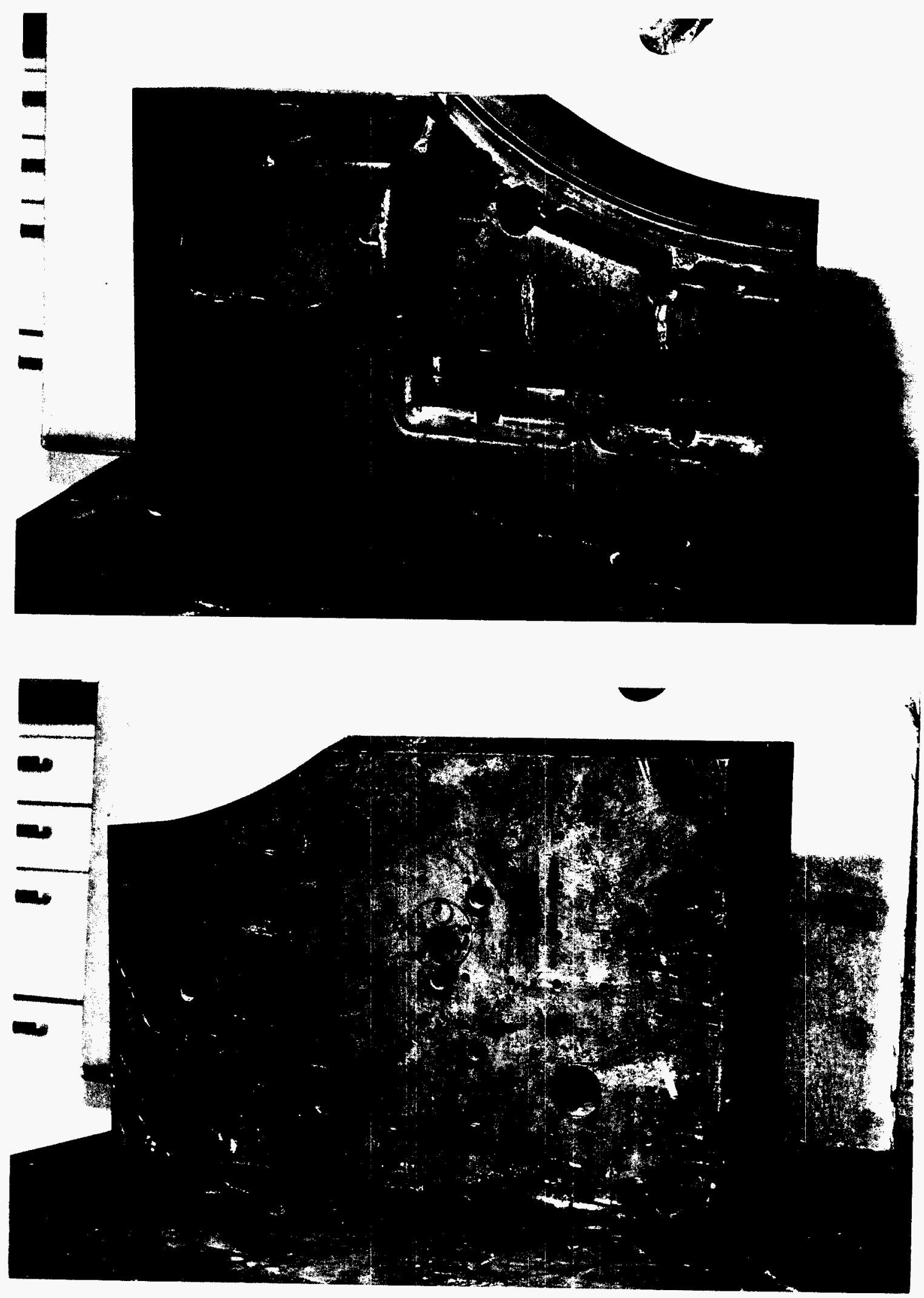


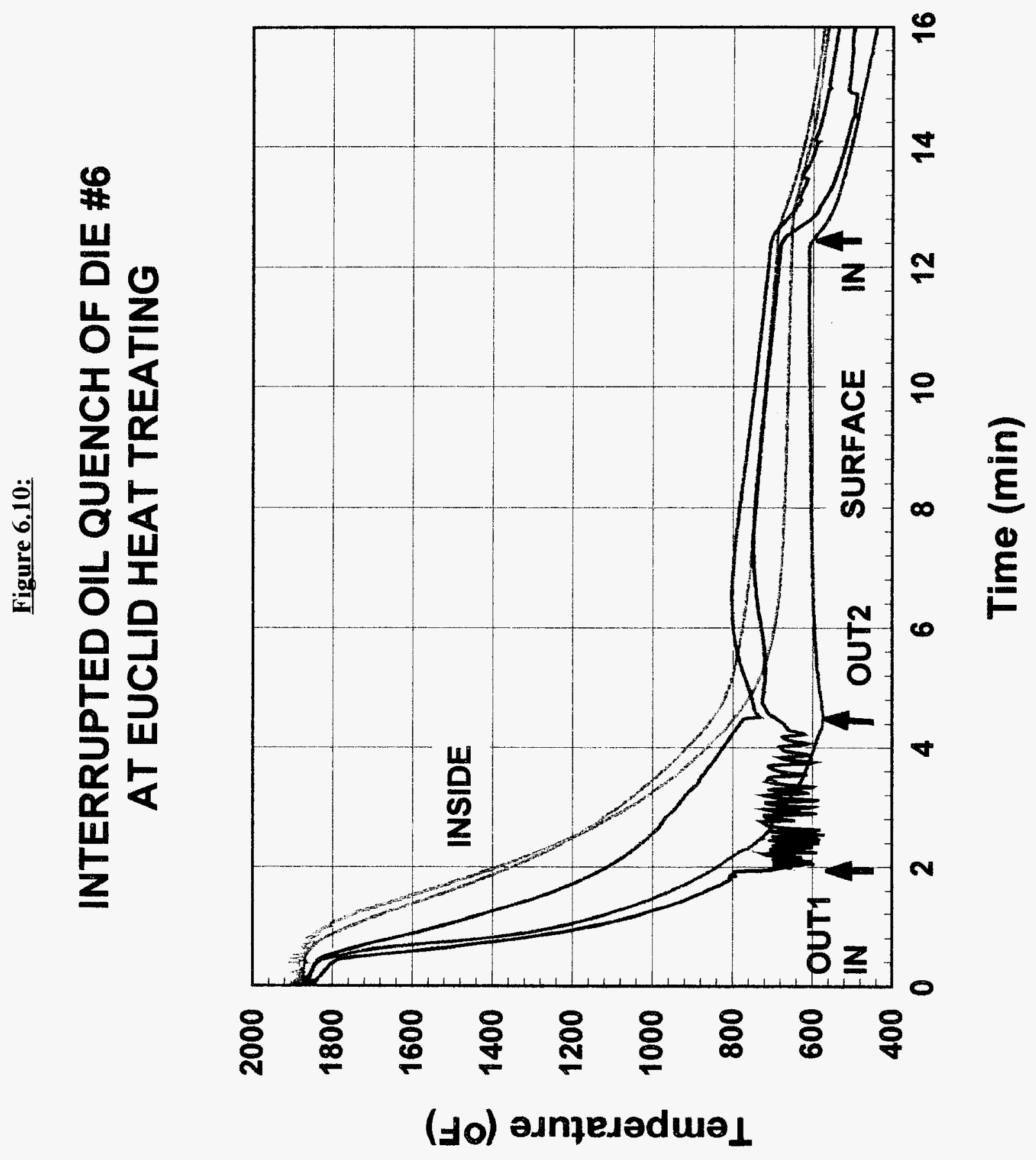


Figure 6.11: $\operatorname{Die} 7\left(14.6^{\prime \prime} \times 7.8^{\prime \prime} \times 7.9^{\prime \prime}\right)$
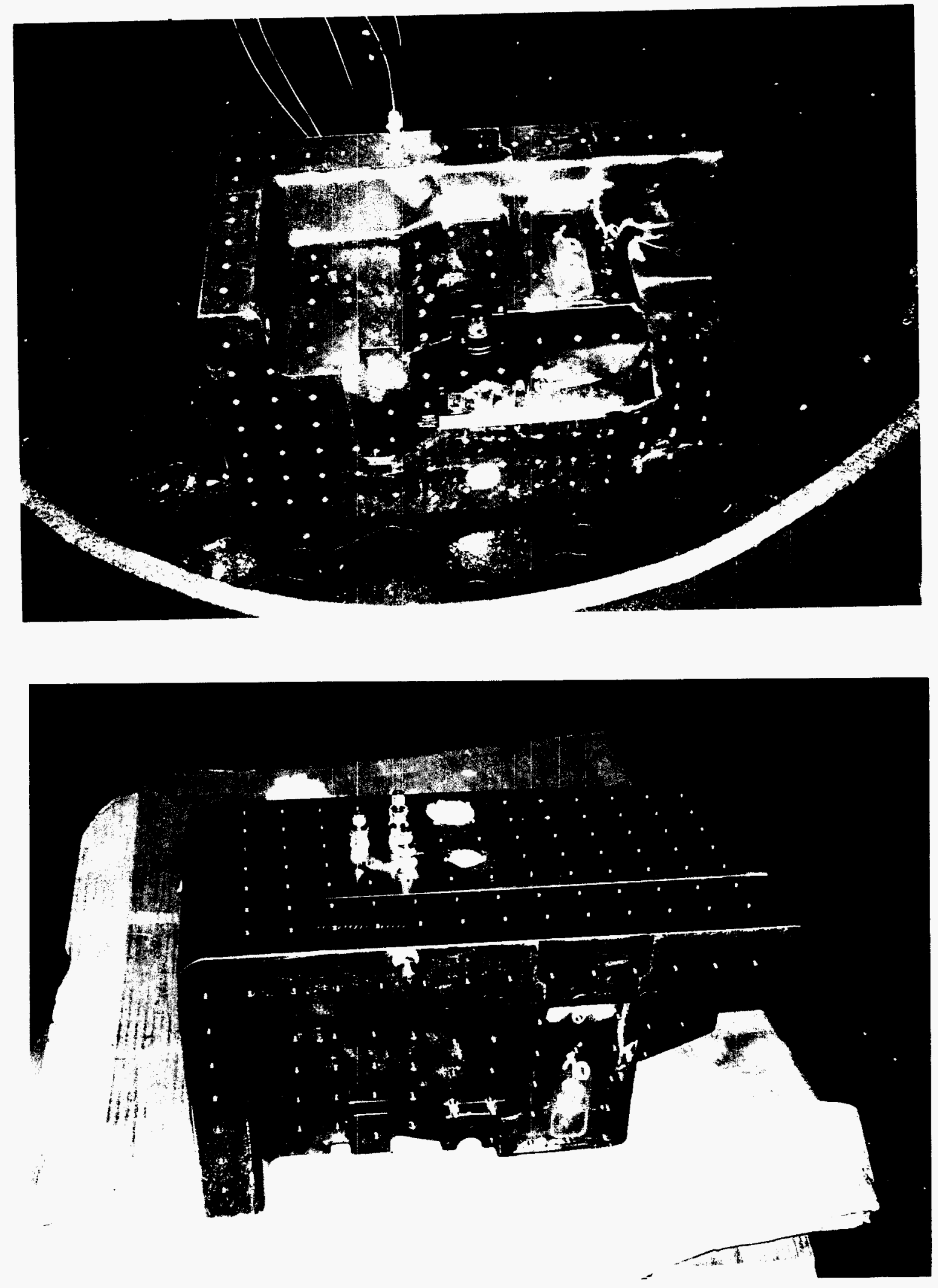


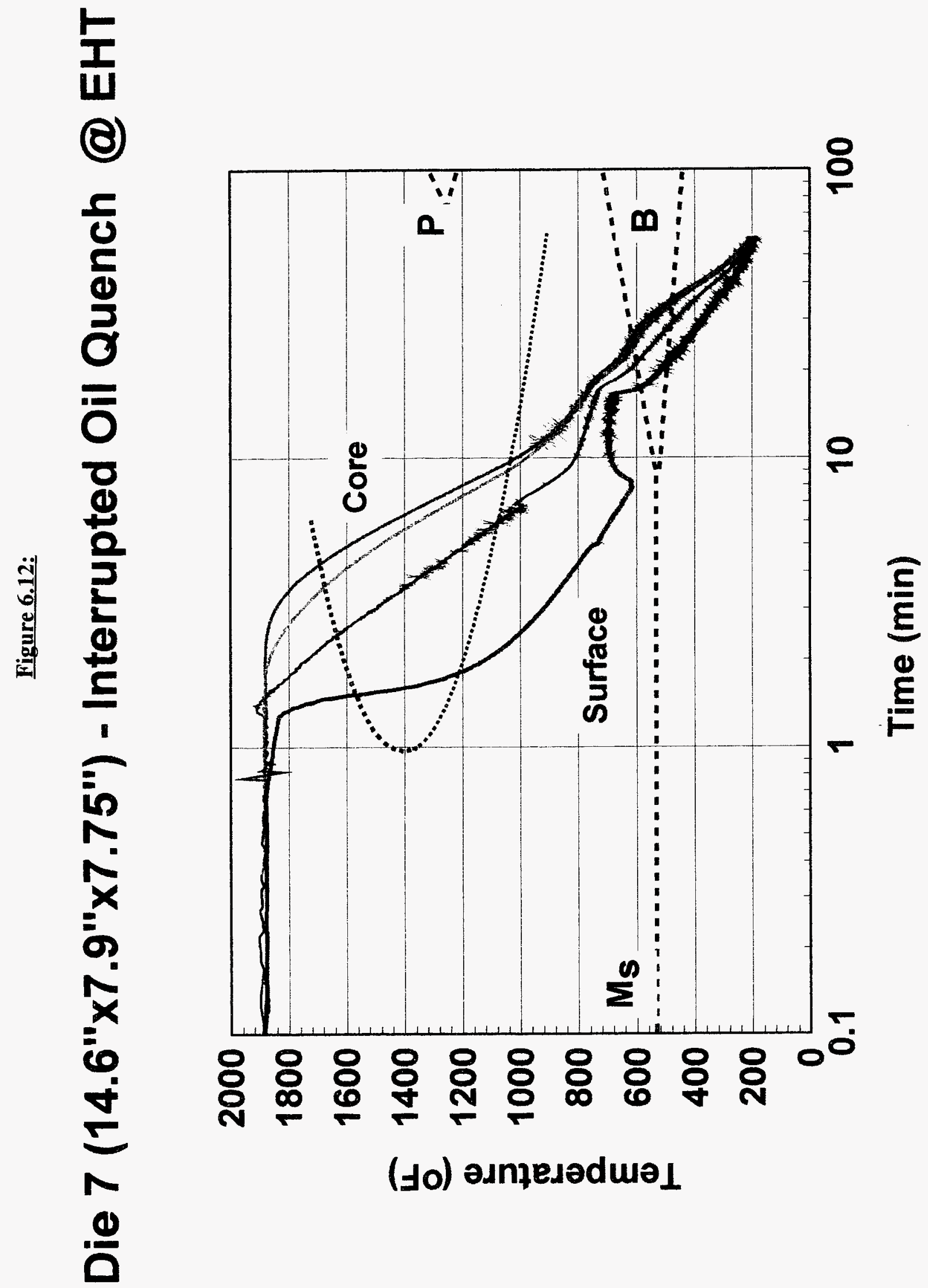


Figure 6.13:

\section{Die 7 (14.6"x7.9"x7.75") - Interrupted Oil Quench @ EHT}

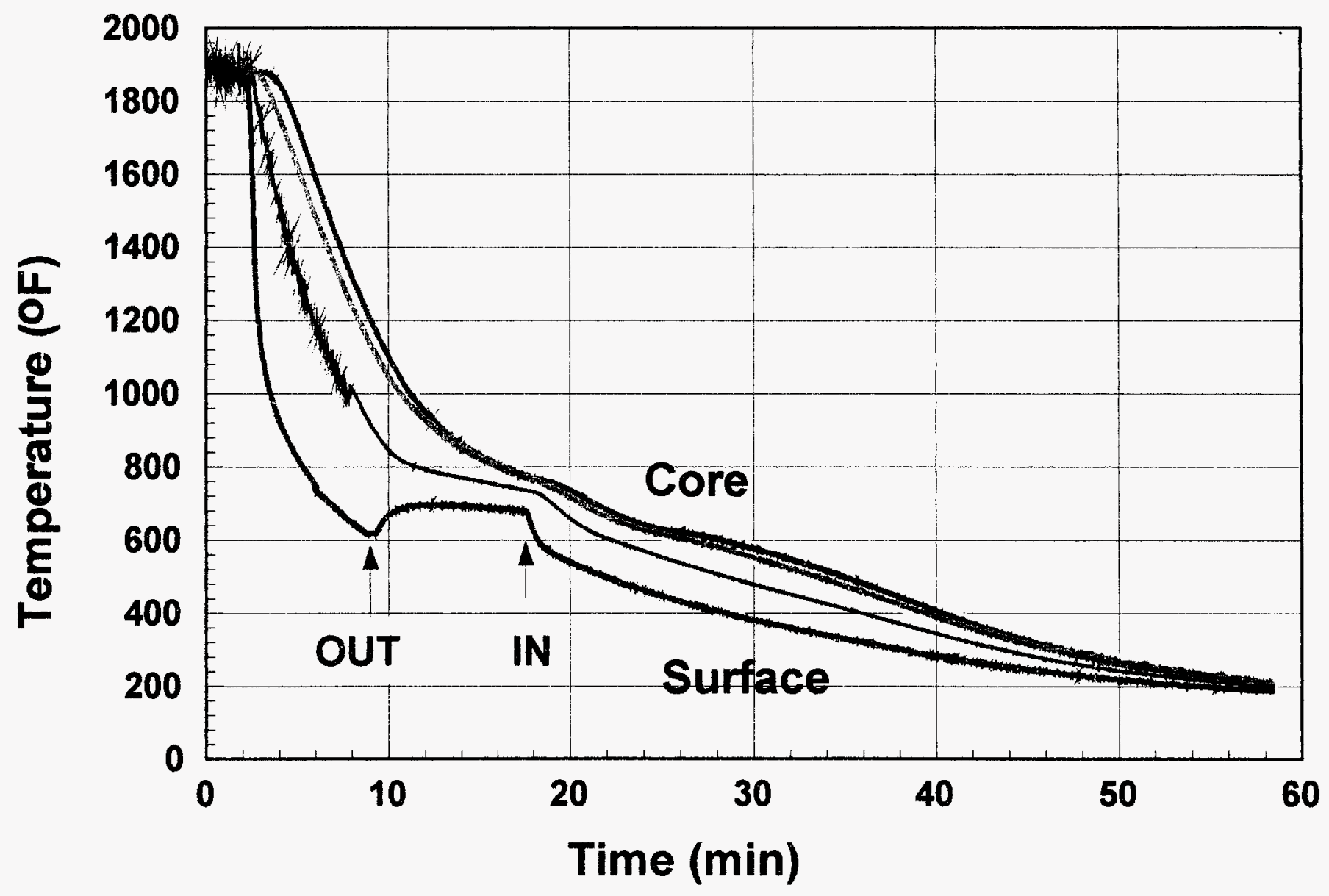

Cooling rate measured by the surface (1/8") thermocouple at the center of the largest face between $17500 \mathrm{~F}$ to $6150 \mathrm{~F}$ is $1770 \mathrm{~F} / \mathrm{min}$. 


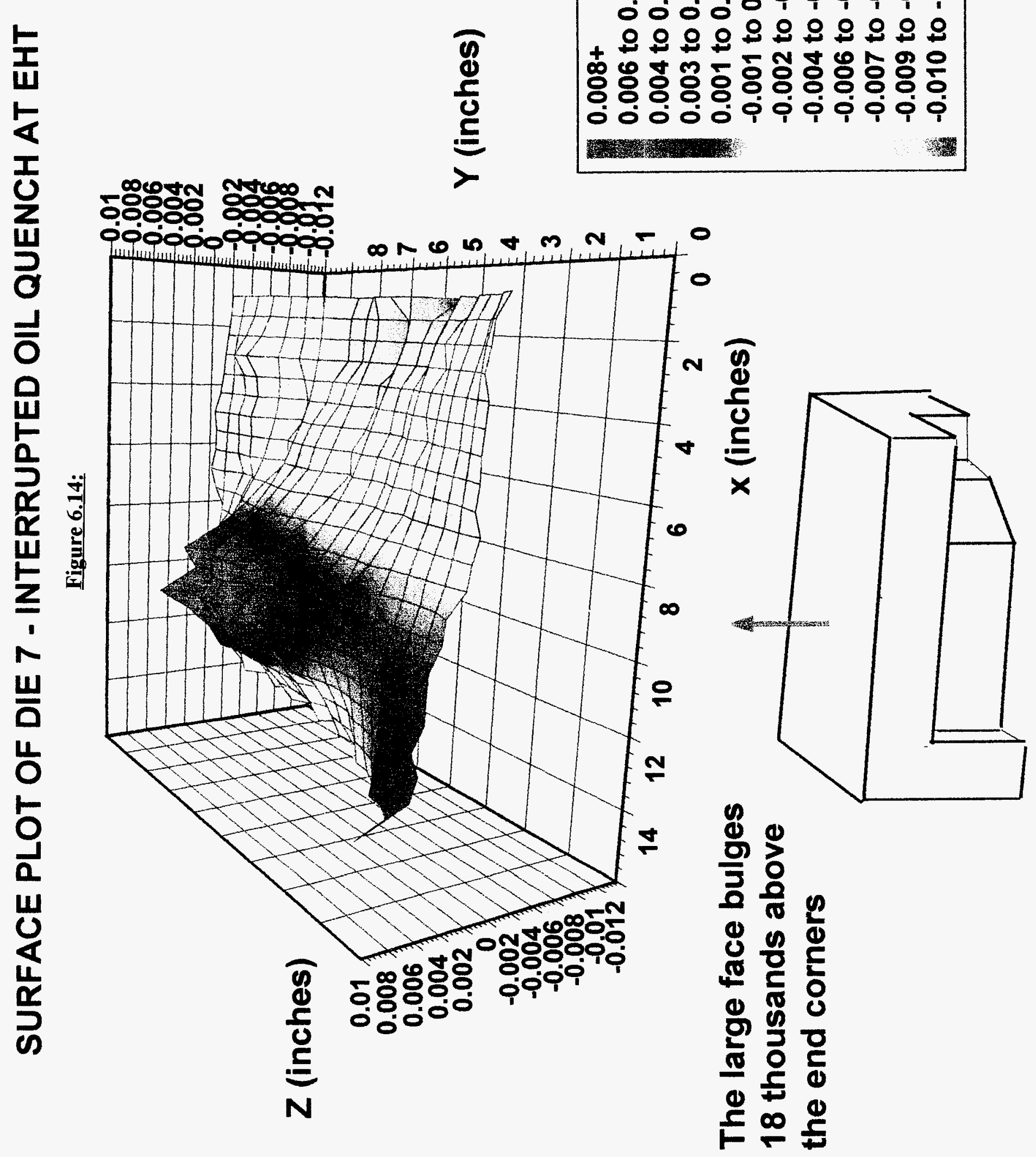


Figure 6.15: Vector Plot of Side 1 - Die 7 Interrupted Oil Quench at EHT

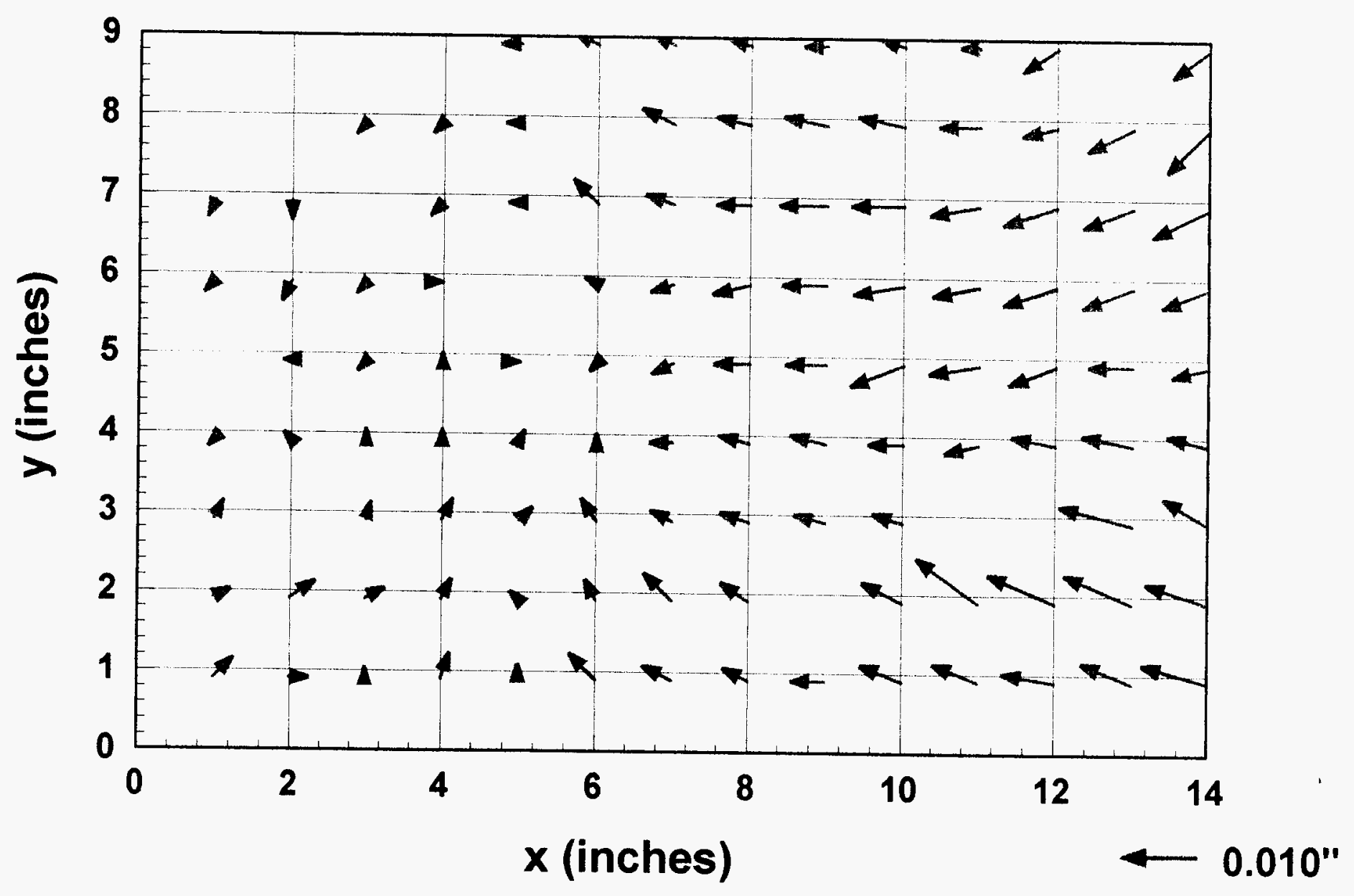

Shows the direction and magnitude of the $X-Y$ move for every point on side 1 of the die as a result of the quench. This face of the die became 0.013 " shorter $(0.1 \%)$ than before the quench. 


\section{Figure 6.16: Die Insert \#8}
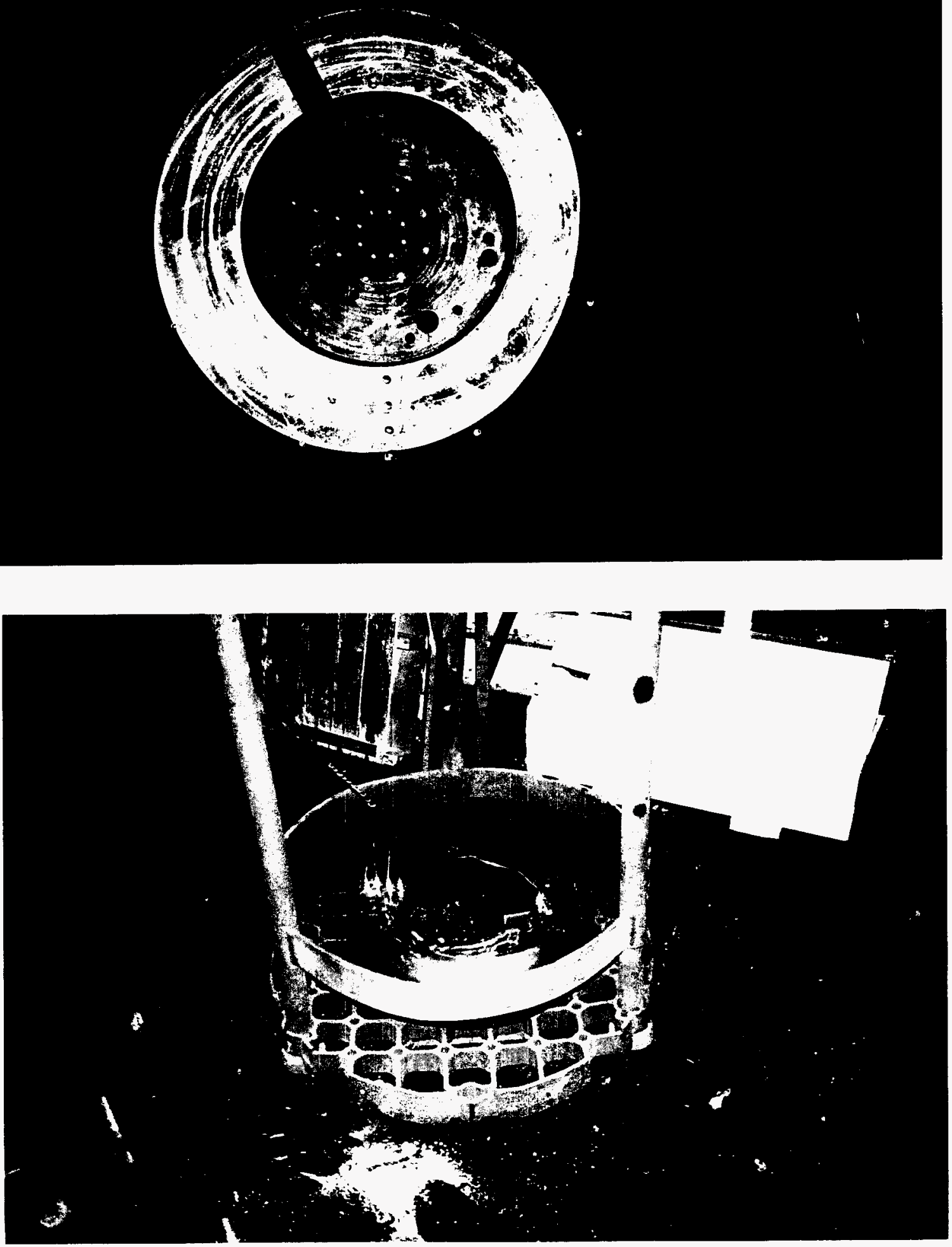


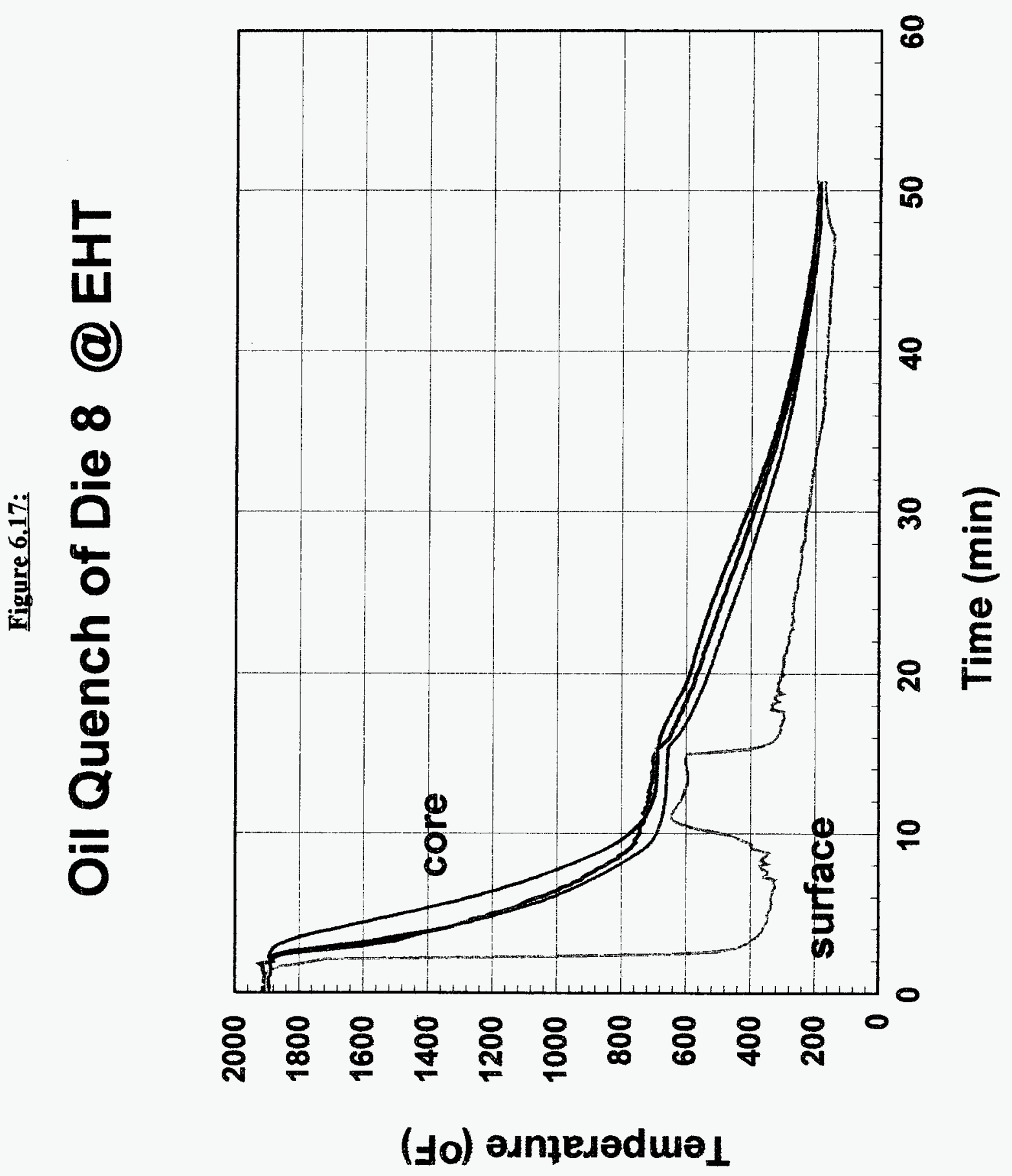




\section{Figure 6.18: Die Insert \#9}
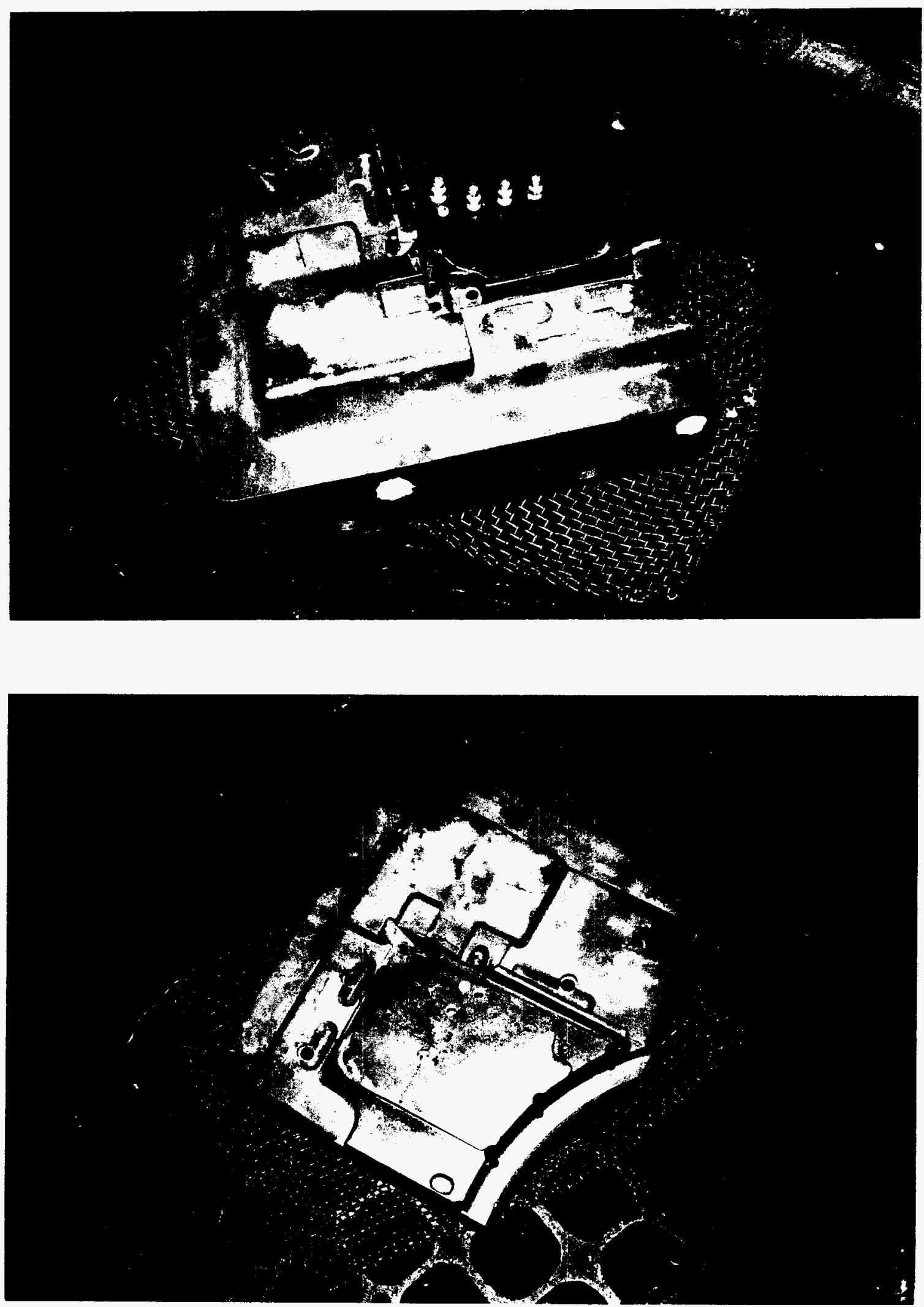

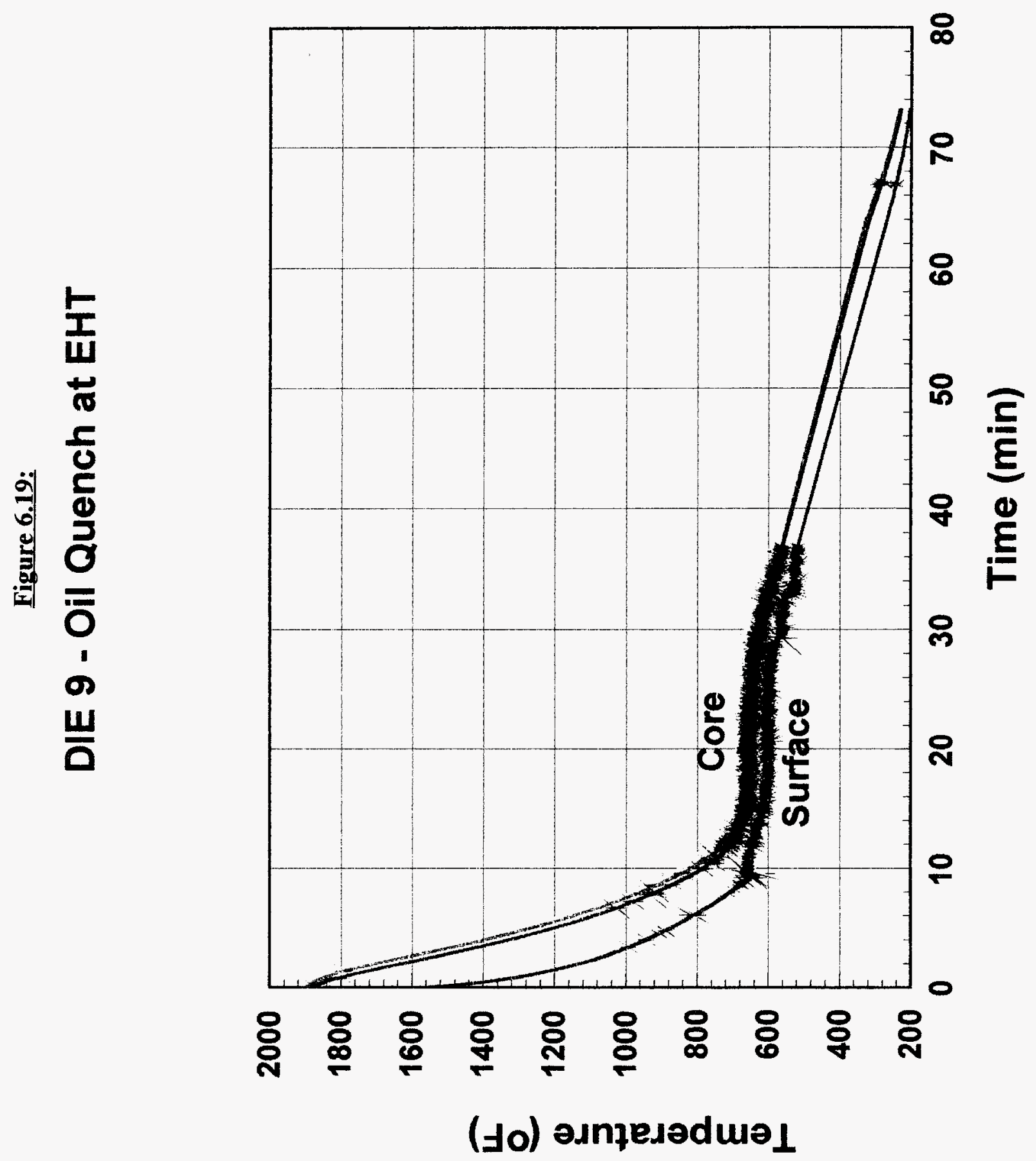


\section{Figure 6.20; Ford Insert \#1}
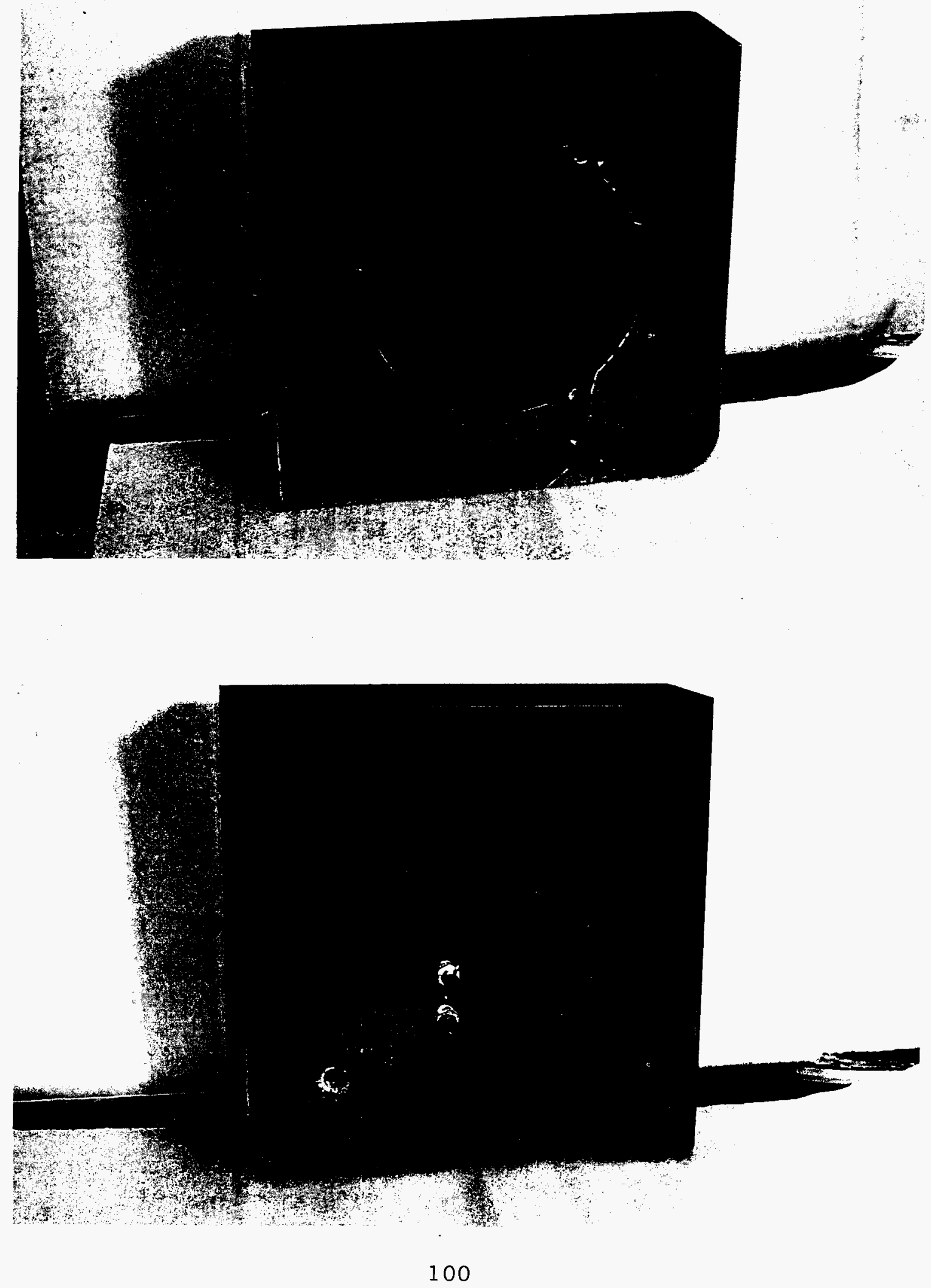


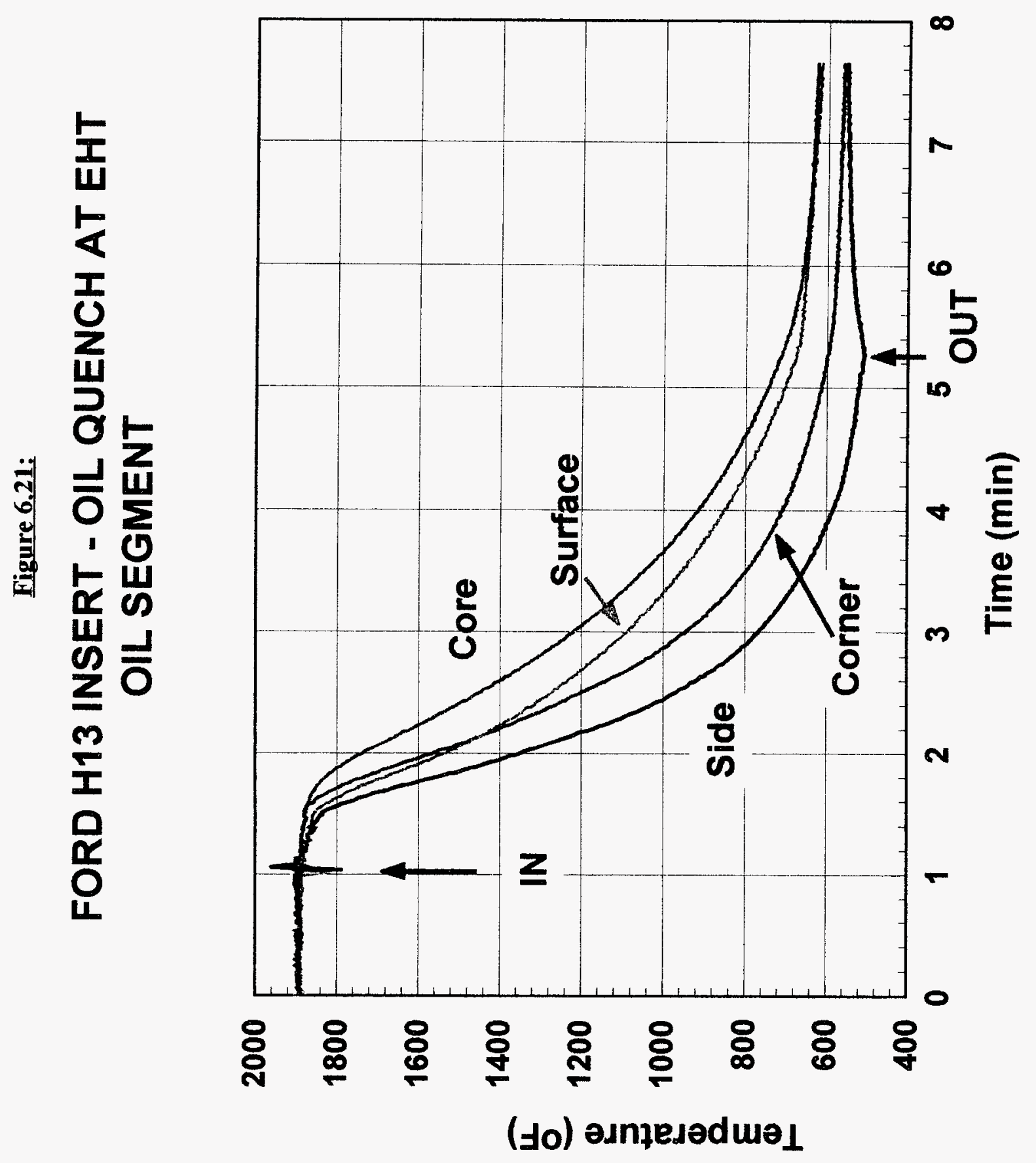




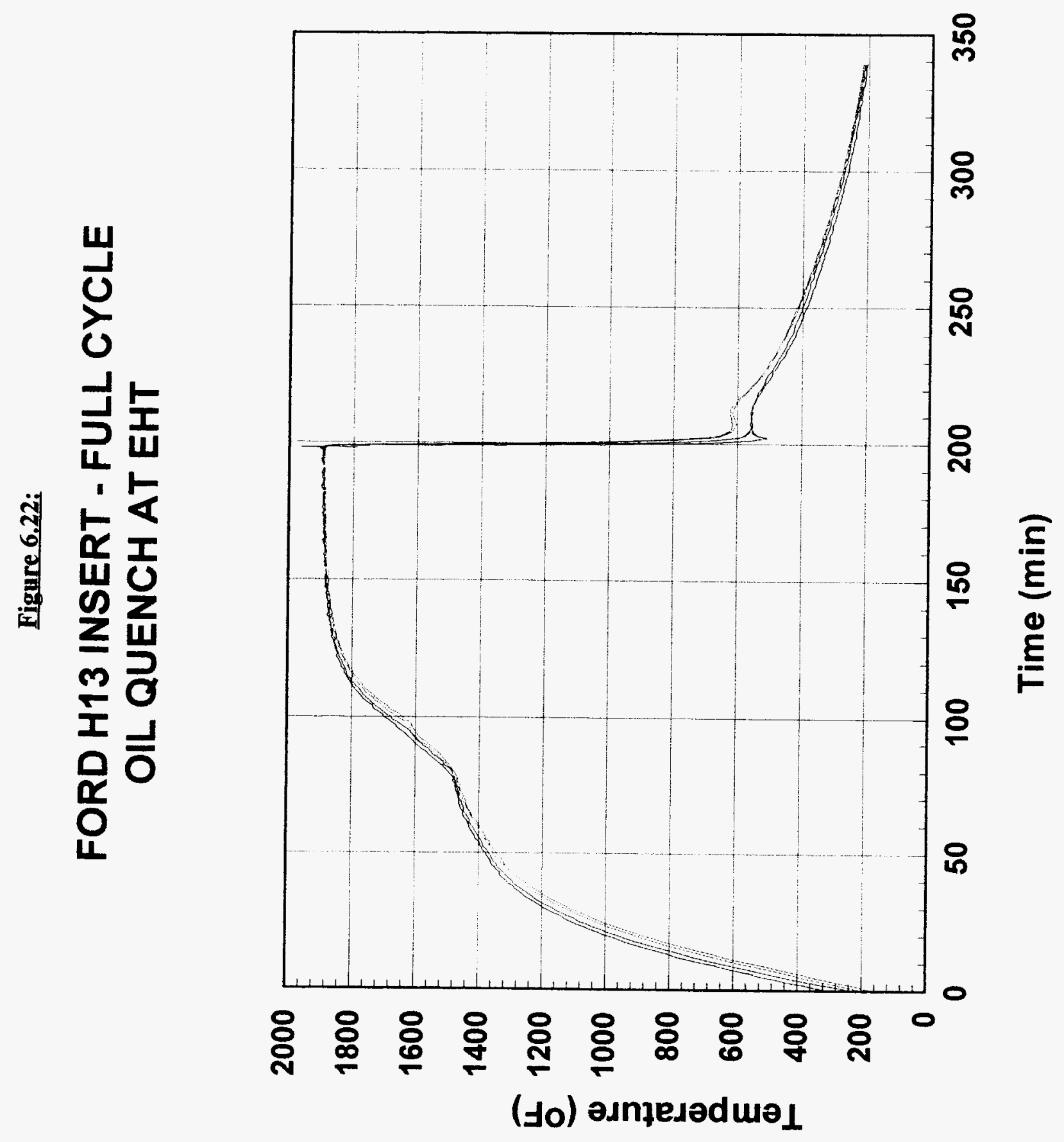


Figure 6.23:

\section{FORD H13 INSERT - OIL QUENCH AT EHT} OIL+AIR COOL SEGMENTS

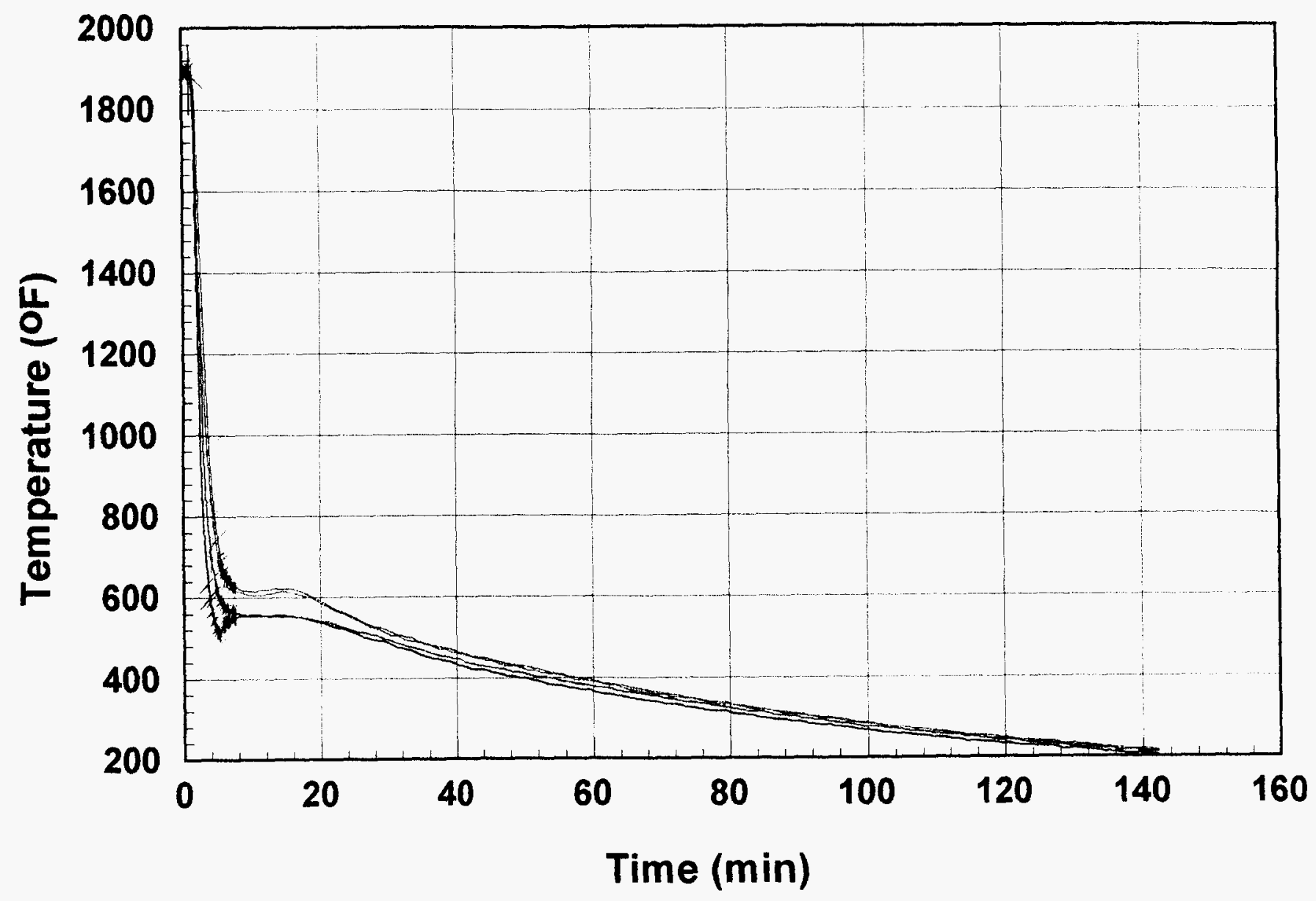




\section{Eigure 6.24: Ford Insert \#2}
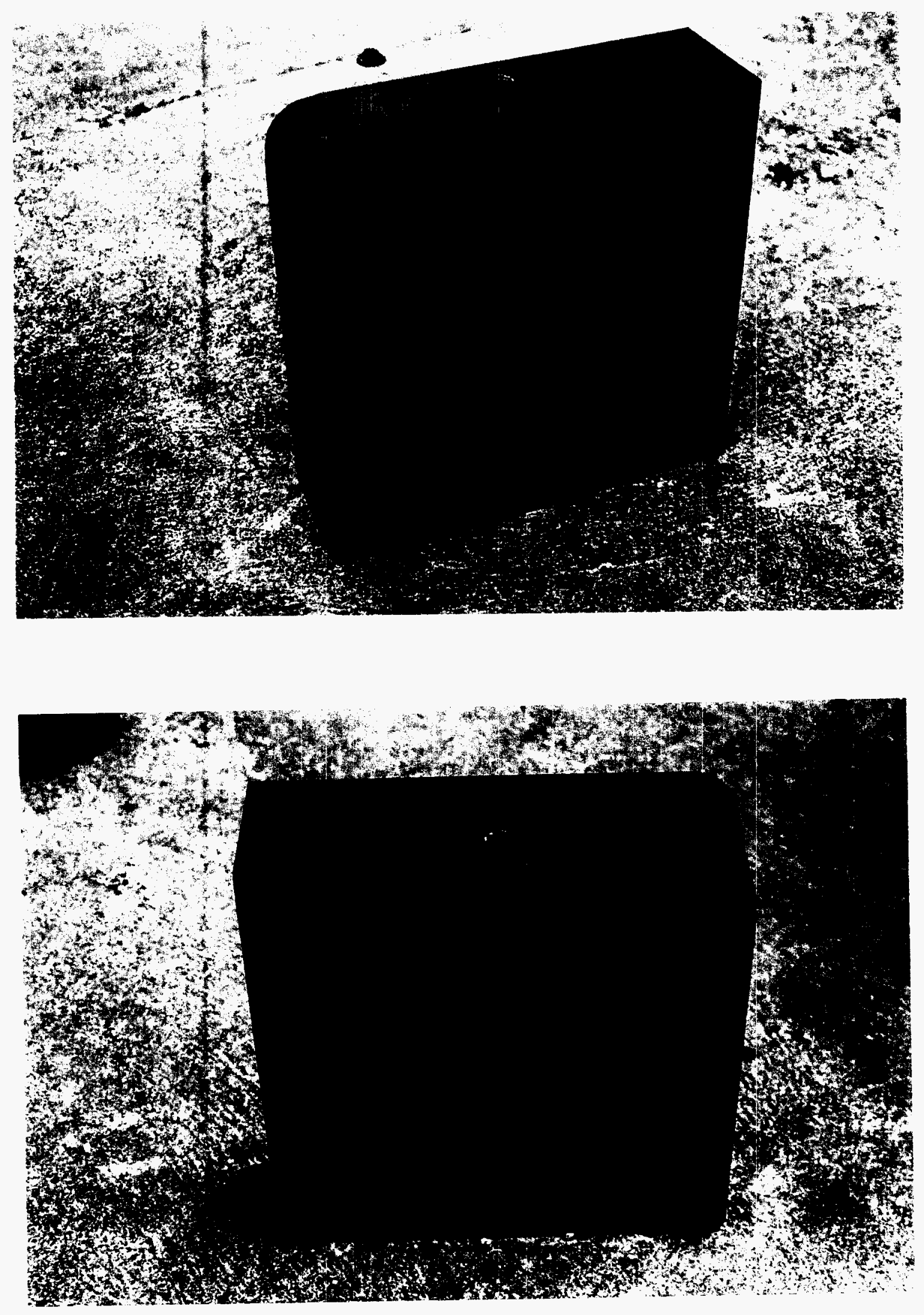


\section{Figure 6.25: Ford Insert \#3}
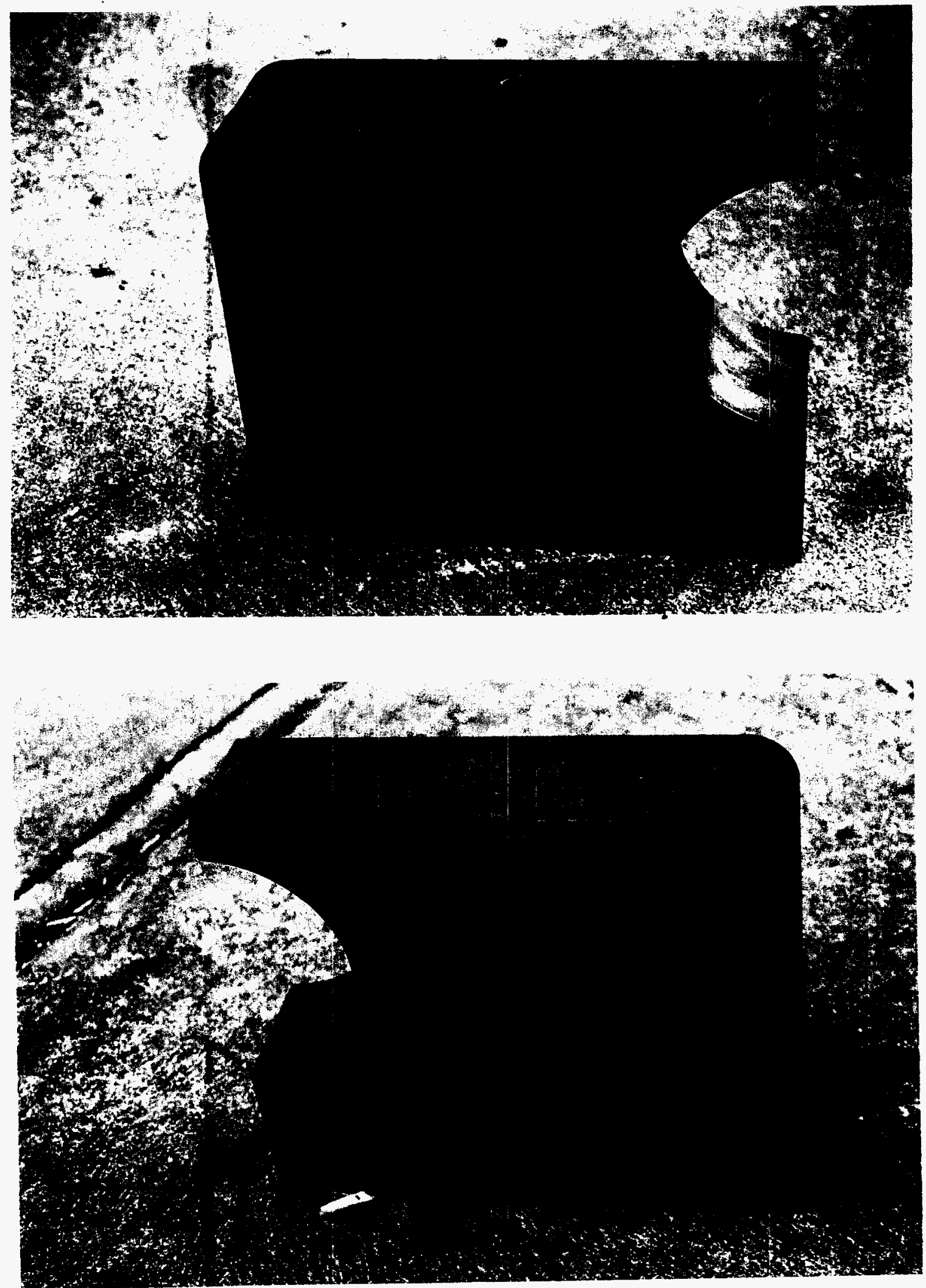
Figure 6.26:

\section{FORD KDA1 CAVITIES - OIL QUENCH SEGMENT} INTERRUPTED OIL QUENCH AT EHT

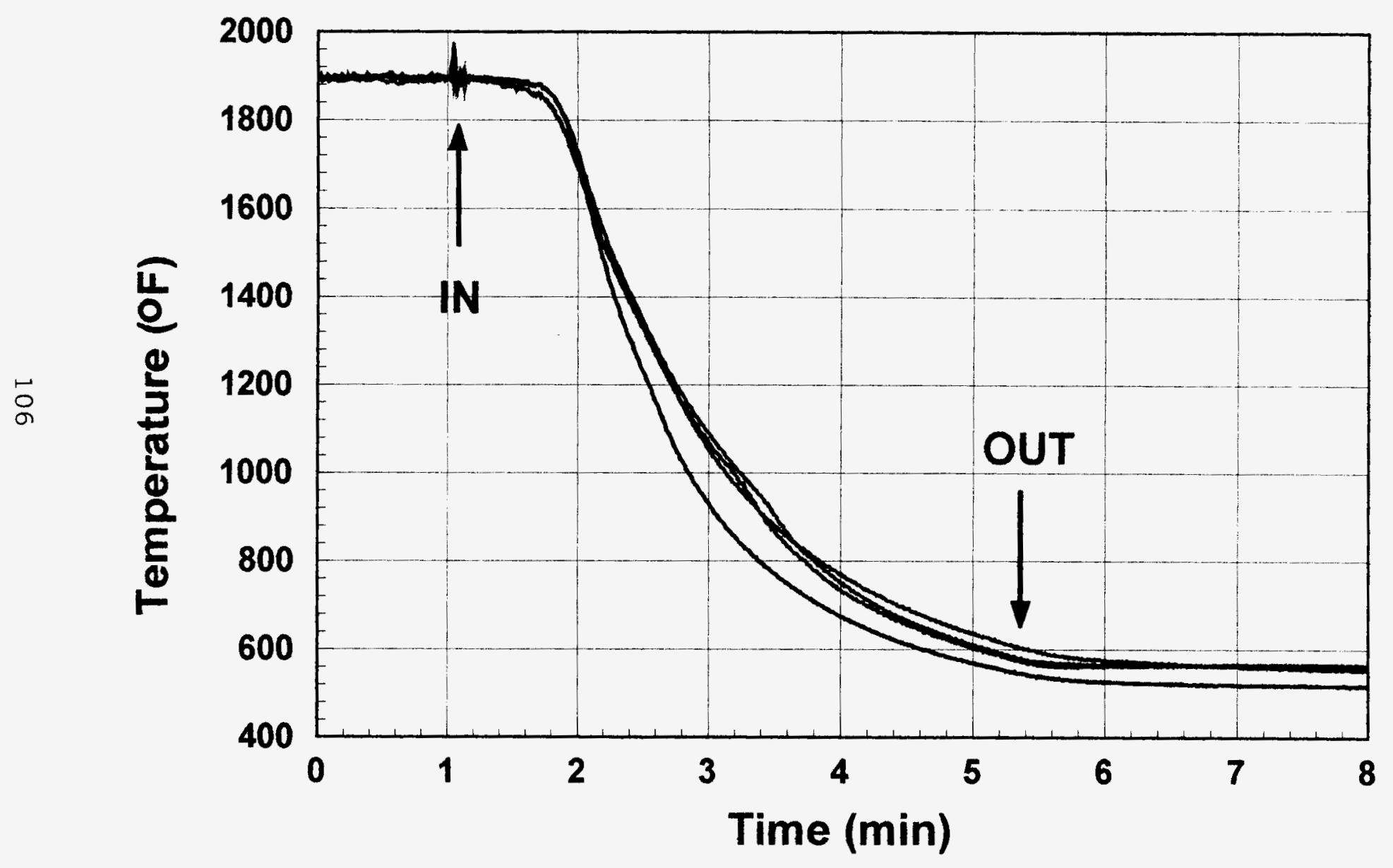

The four thermocouples are embedded at the corner and side ( 2 per cavity) using existing threaded holes. The quench conditions were determined in a previous run with an identical cavity that had the same thermocouples + two more at the core. 
Figure 6.27:

FORD KDA1 CAVITIES - OIL + AIR SEGMENTS

INTERRUPTED OIL QUENCH AT EHT

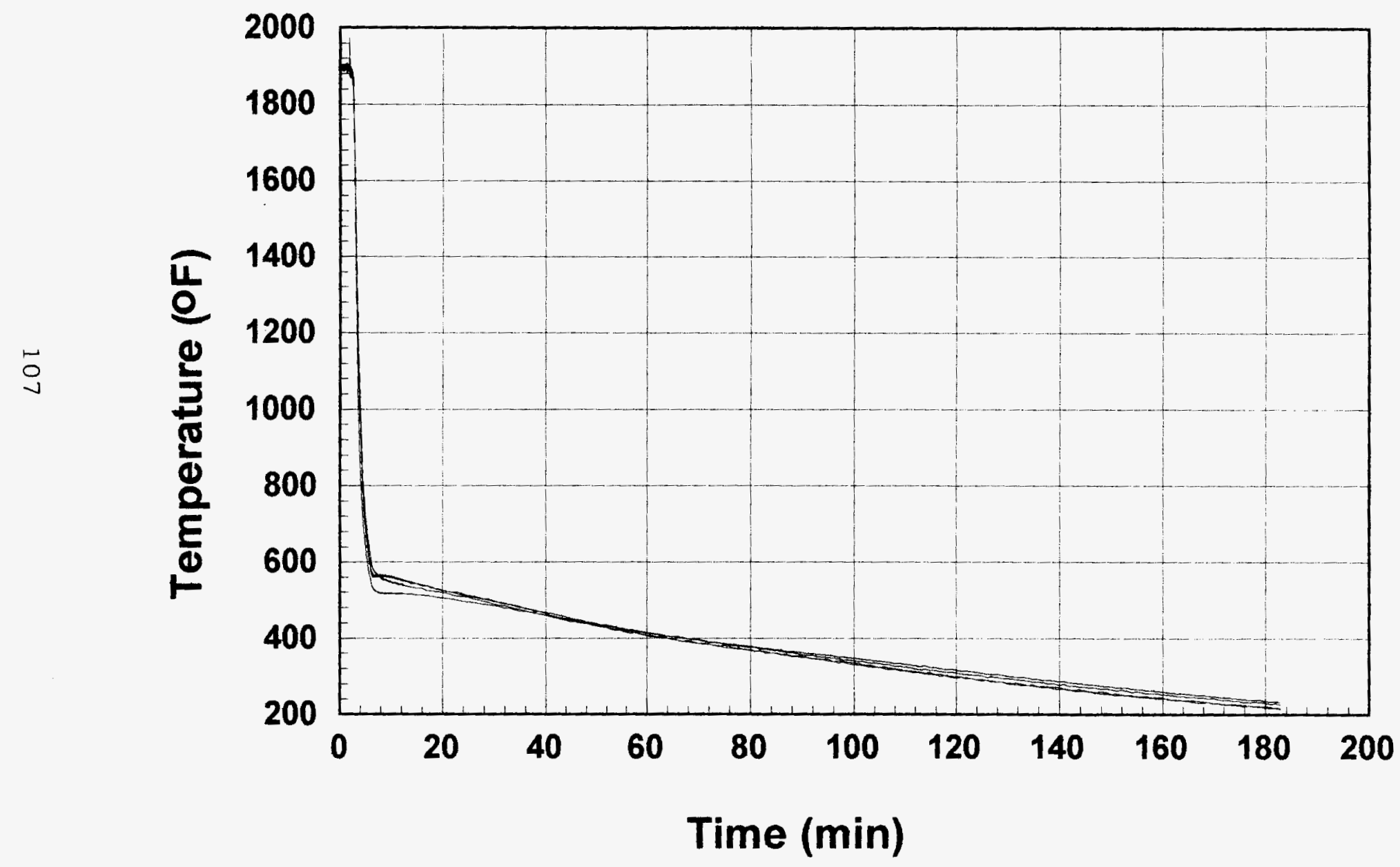


Figure 6.28:

FORD KDA1 CAVITIES - FULL CYCLE INTERRUPTED OIL QUENCH AT EHT

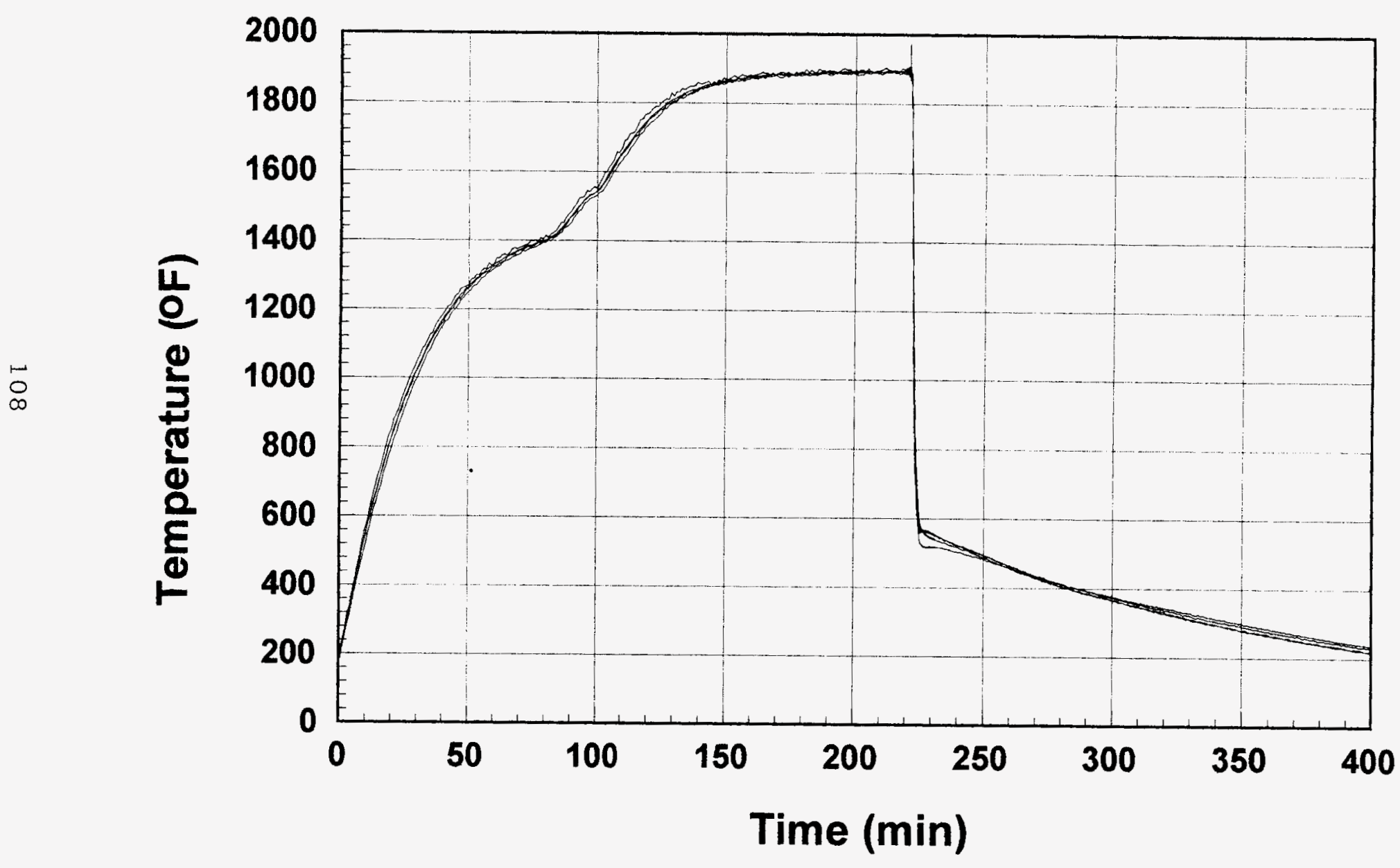


Table 6.1: SUMMARY OF THE OIL QUENCHING EXPERIMENTS

\begin{tabular}{|c|c|c|c|c|c|c|}
\hline Die \# & $\begin{array}{l}\text { Interrupt } \\
\text { Temp. }{ }^{(*)} \\
\left({ }^{\circ} \mathbf{F} / \mathbf{m i n}\right)\end{array}$ & $\begin{array}{l}\text { Position } \\
\text { in basket }\end{array}$ & $\begin{array}{l}\text { Surface cooling } \\
\operatorname{rate}(* *)\left({ }^{\circ} \mathrm{F} / \mathrm{min}\right)\end{array}$ & $\begin{array}{l}\text { Core cooling rate } \\
\left.\text { ( }{ }^{\circ} \mathrm{F} / \mathrm{min}\right)\end{array}$ & $\begin{array}{l}\text { Total Cooling } \\
\text { time to } 200^{\circ} \mathrm{F} \\
\text { (minutes) }\end{array}$ & Die integrity \\
\hline $\begin{array}{l}\text { Die \#4 } \\
\text { (used) }\end{array}$ & 750 & vertical & 250 & 83 & 45 (in oil) & Not cracked \\
\hline $\begin{array}{l}\text { Die \#6 } \\
\text { (used) }\end{array}$ & 600 & horizontal & 350 & 140 & 35 (in oil) & Cracked \\
\hline $\begin{array}{l}\text { Die \#7 } \\
\text { (used) }\end{array}$ & 700 & vertical & 250 & 63 & 60 (in oil) & Not Cracked \\
\hline $\begin{array}{l}\text { Die \#8 } \\
\text { (used) }\end{array}$ & 600 & horizontal & N/A & 100 & 60 (in oil) & Cracked \\
\hline $\begin{array}{l}\text { Die \#9 } \\
\text { (used) }\end{array}$ & 650 & horizontal & 160 & 125 & 75 (in oil) & Cracked \\
\hline $\begin{array}{l}\text { Ford \#1 } \\
\text { (new) }\end{array}$ & 550 & vertical & 450 & 350 & 140 (in air) & Not Cracked \\
\hline $\begin{array}{l}\text { Ford \#2,3 } \\
\text { (new) }\end{array}$ & 550 & vertical & 450 & 350 & 180 (in air) & Not cracked \\
\hline
\end{tabular}

measured by a thermocouple embedded at the center of the largest side, about $0.25^{\prime \prime}$ from the surface.

In irregular shapes, measured at the fastest cooling section.

** - in the range of $1750-750^{\circ} \mathrm{F}$

*** - inserts were more apt to crack when placed into oil horizontally; prefer vertical orientation. 


\section{POTENTIAL METHODS FOR OIL QUENCHING OF DIE STEELS}

CONVENTIONAL QUENCHING

(only for small cores and inserts)

$\stackrel{\rightleftarrows}{\bullet}$

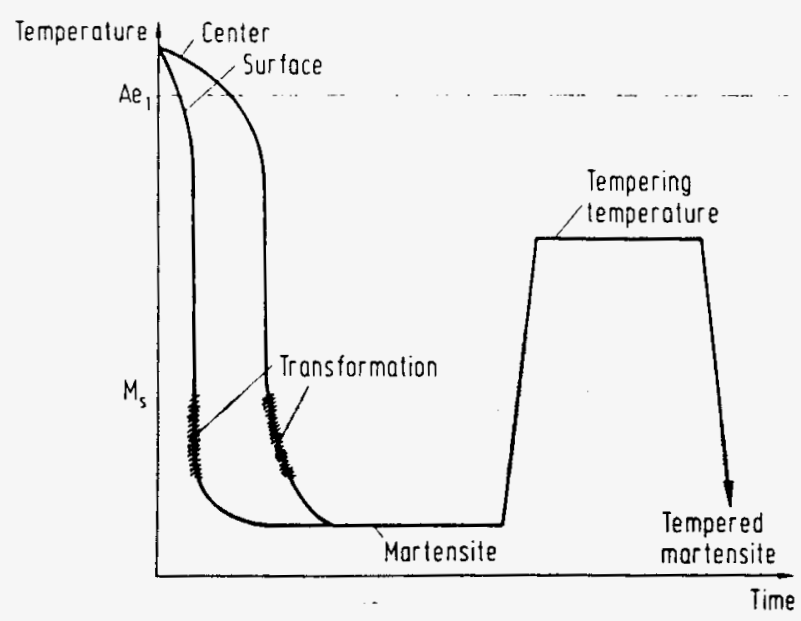

MARTEMPERING

( for small and medium size cores and inserts)

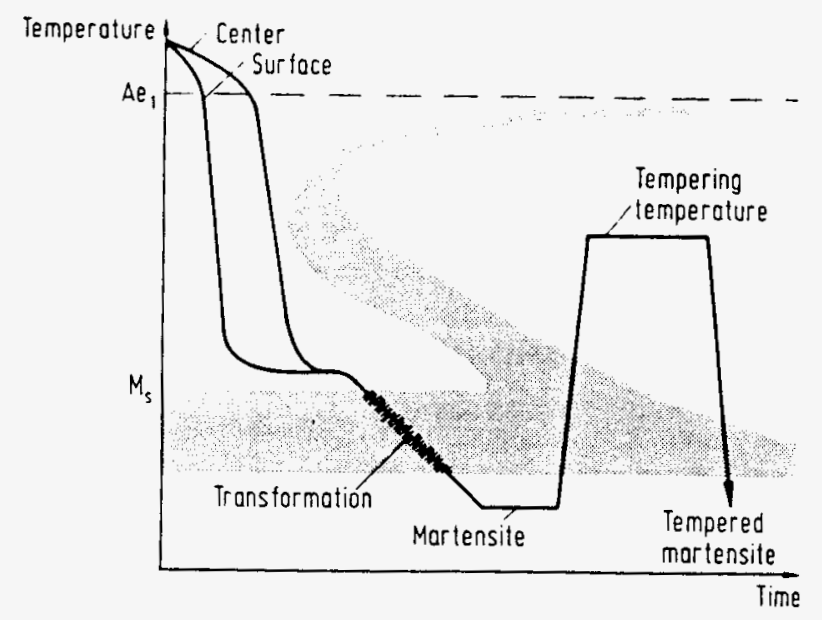

\section{MODIFIED MARTEMPERING}

( for medium size cores and inserts)

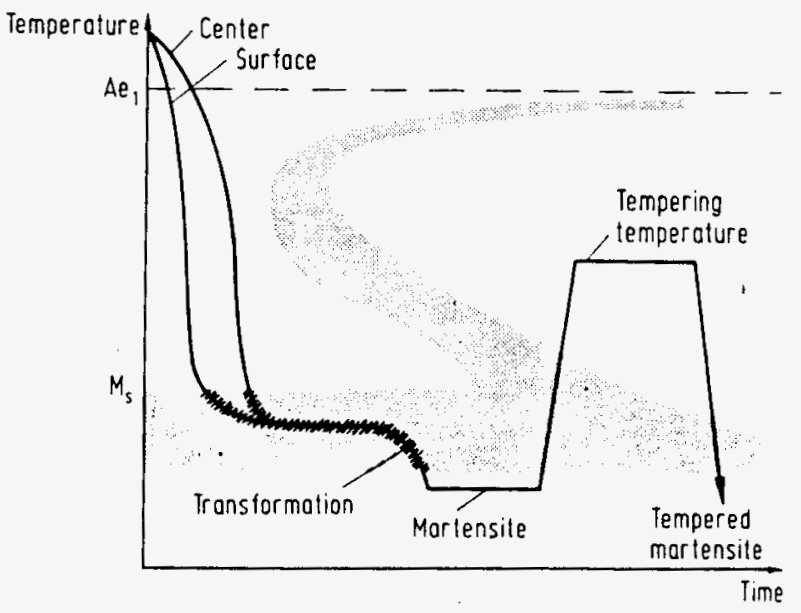

AUSTEMPERING

(for medium and large size cores and inserts)

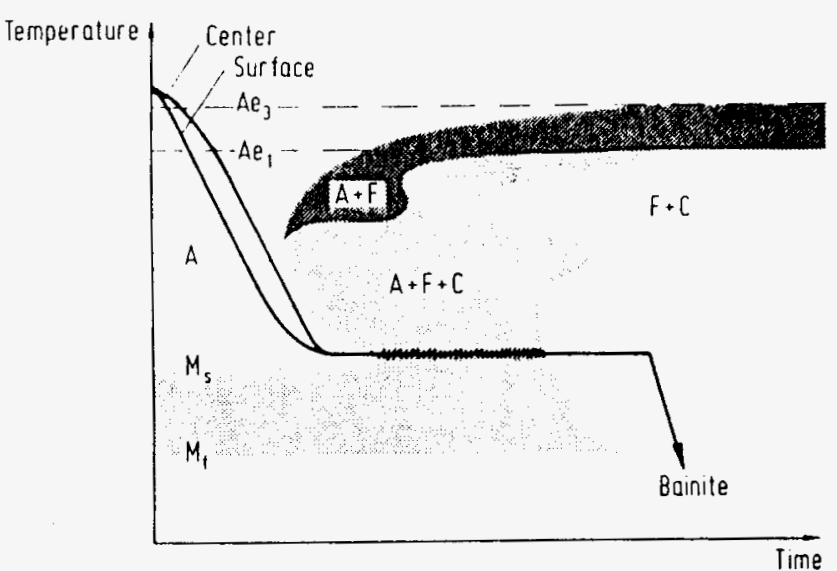



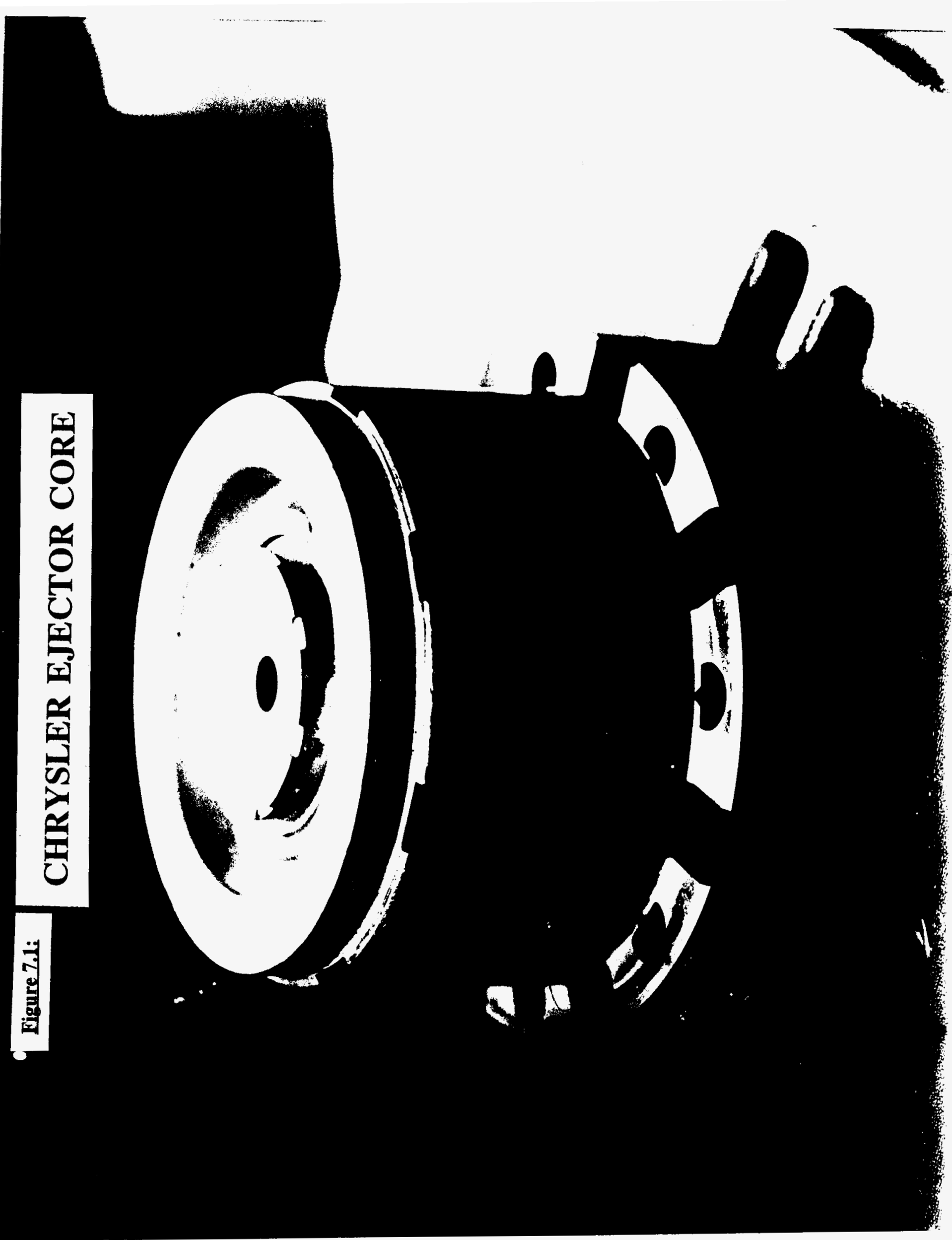



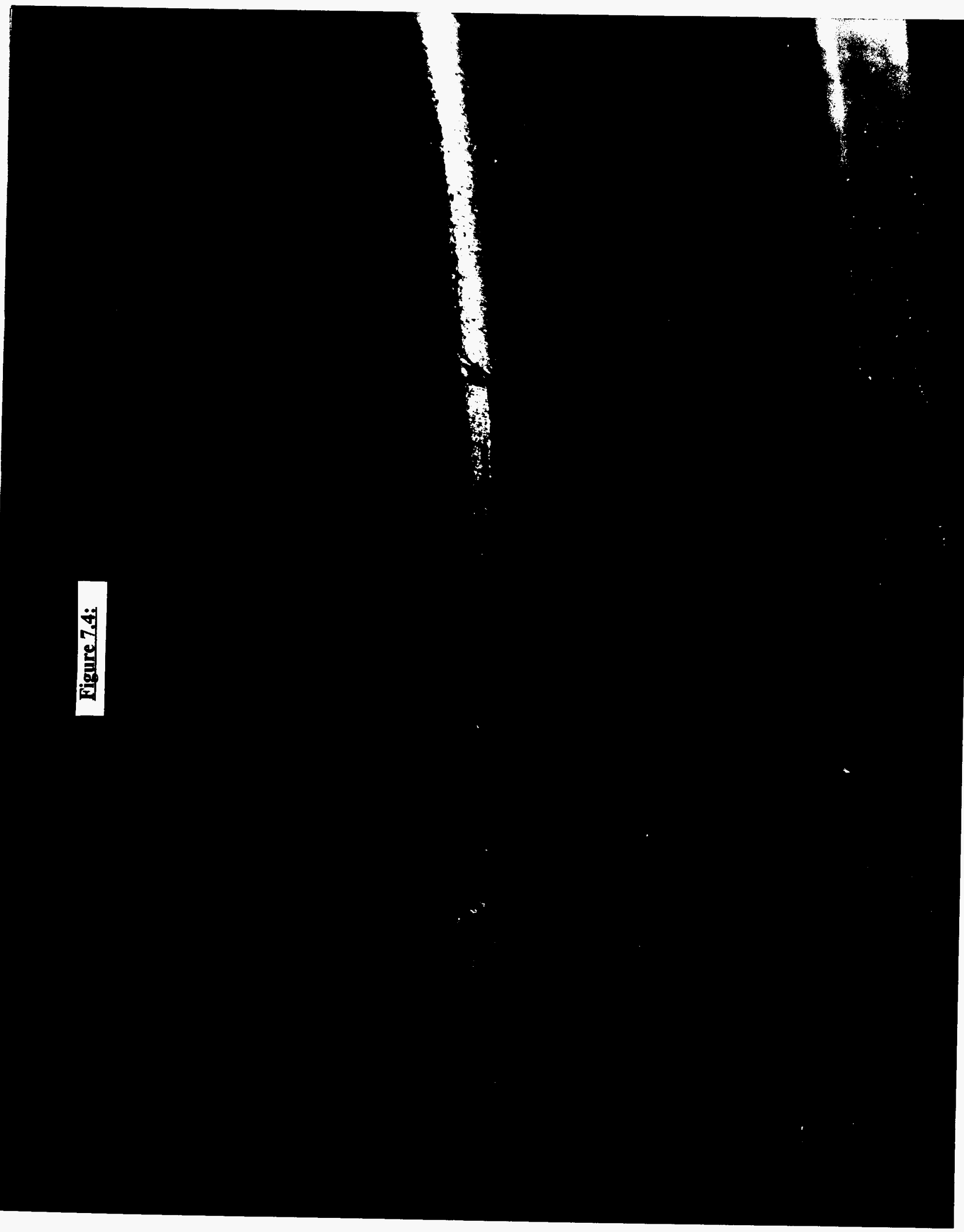




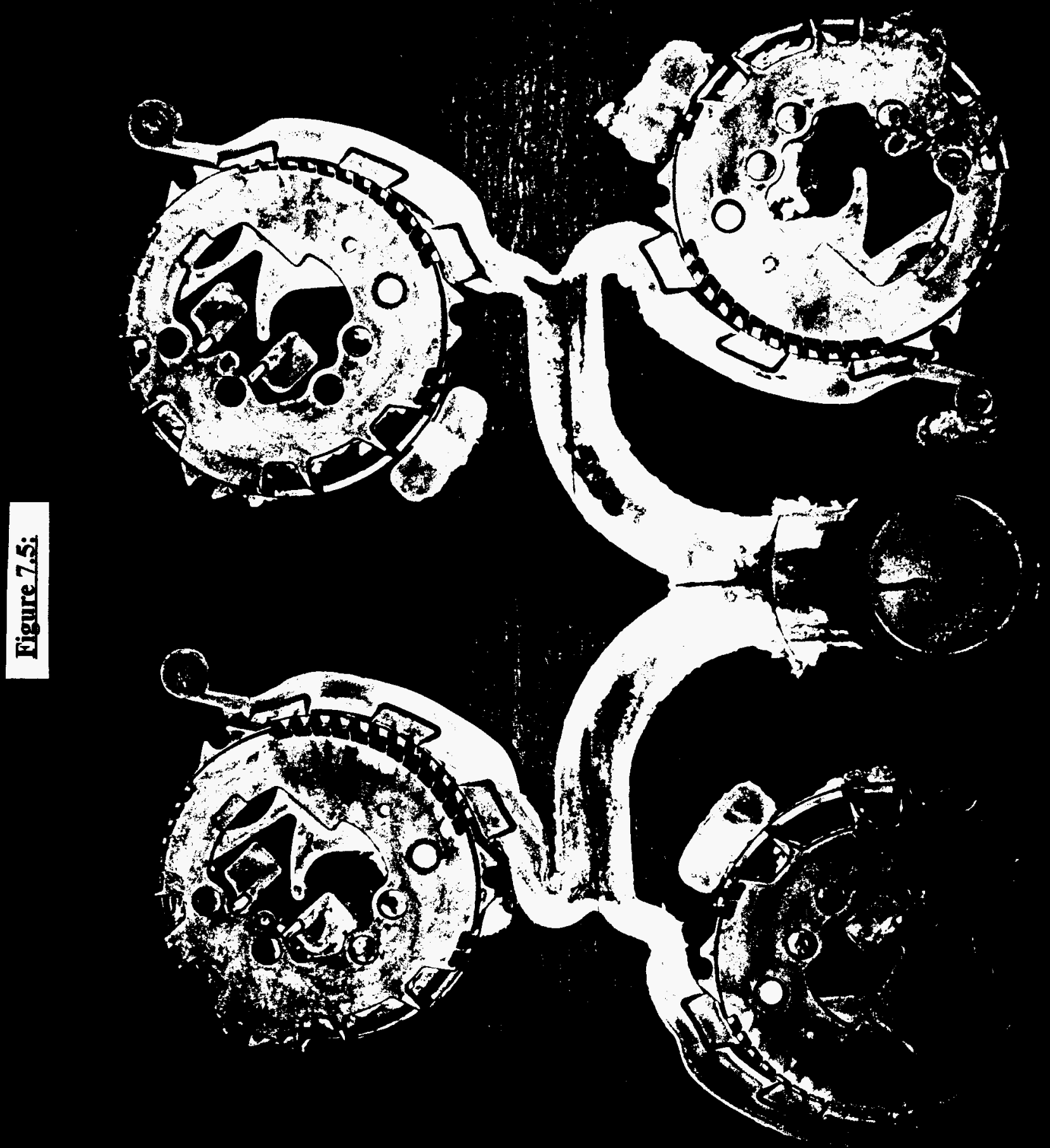




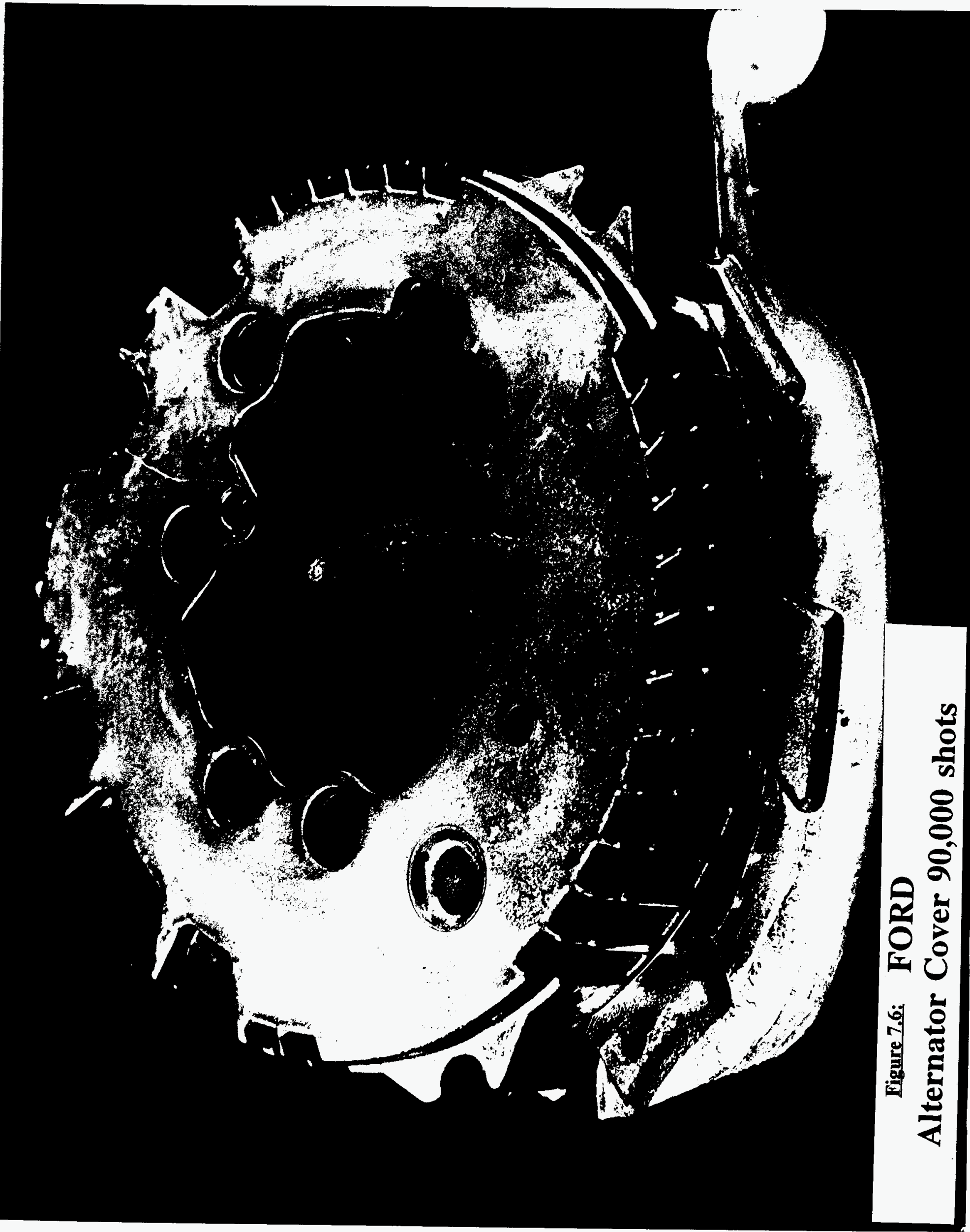




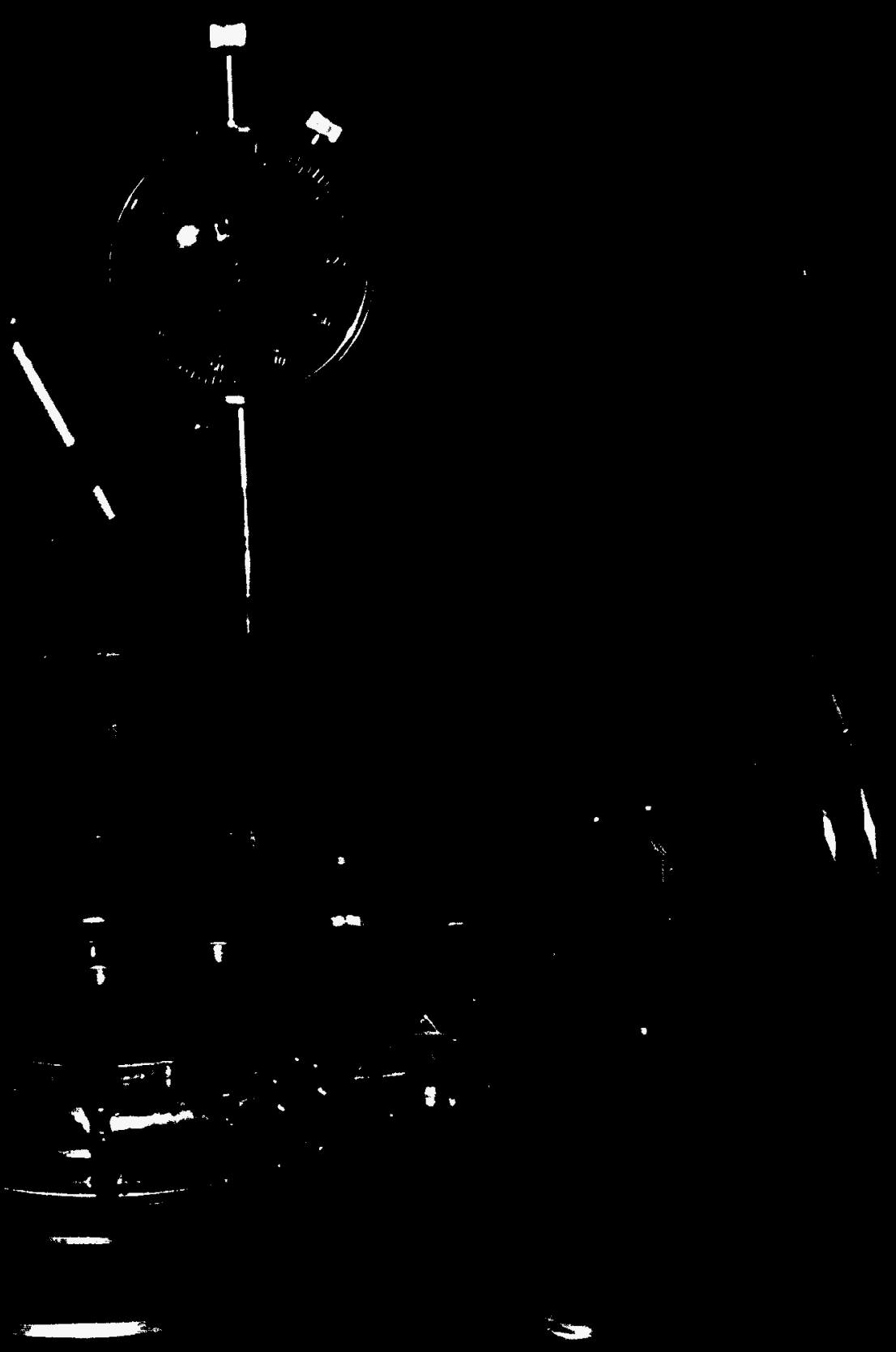




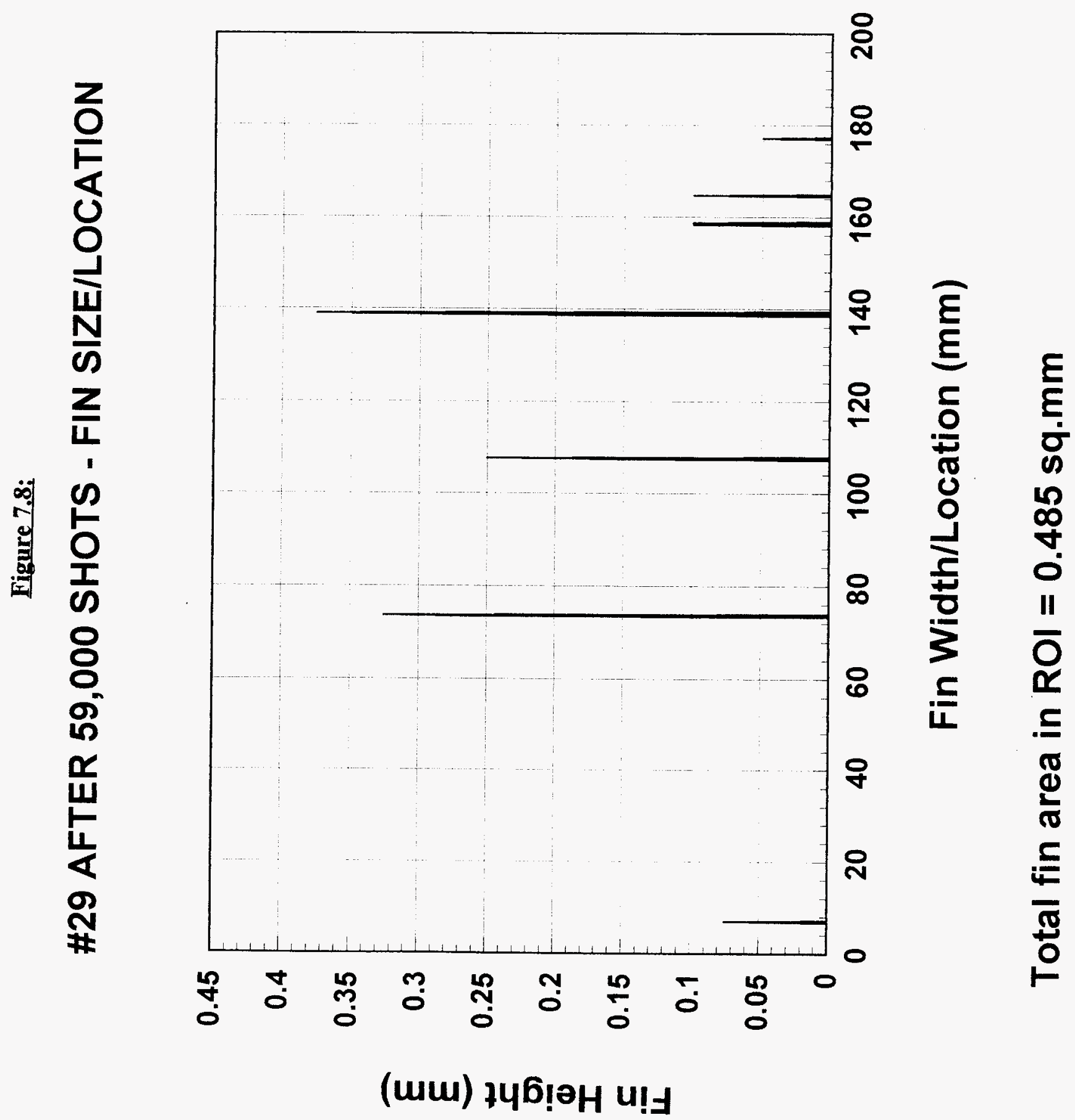


Crack Area in the Region of Interest of a Four Cavity Die: \#29, \#30, \#31, \#32

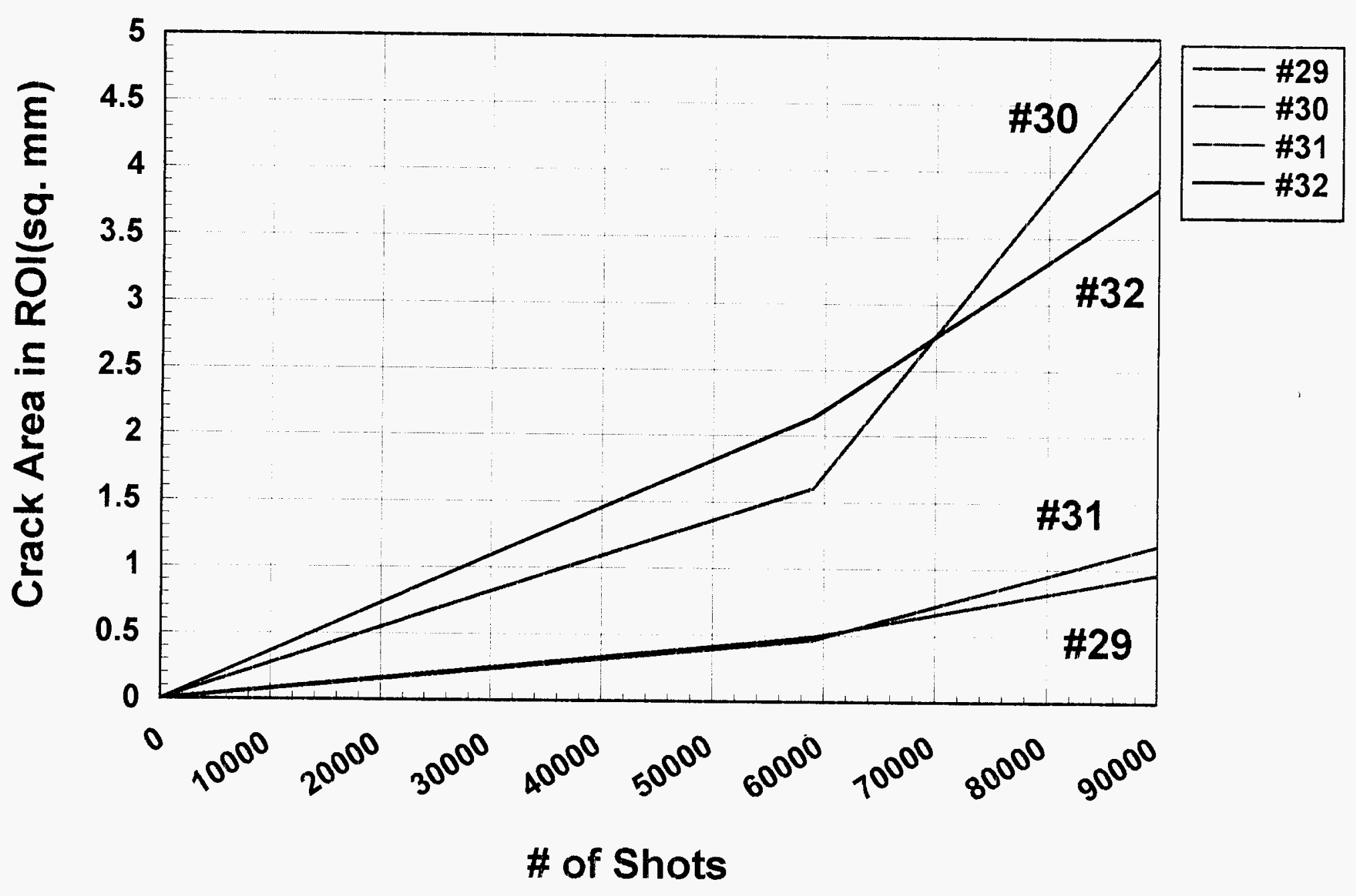

Note: Crack area was measured by profilometry on castings sampled randomly after 59,000 and 90,000 shots 